


\title{
Ingeniería Mecánica: Resultados de investigación
}

\author{
Juan Camilo Mejía \\ Juan David Ramírez \\ Juan Camilo Zapata \\ Héctor Fabio Quintero Riaza \\ Carlos Alberto Romero Piedrahita \\ Edison Henao Castañeda \\ Juan Manuel Manzano Martínez \\ José Luis Tristancho Reyes \\ Juan Carlos Castillo Herrera \\ David Andrés Serrato Tobón \\ Juan Esteban Tibaquirá \\ Álvaro Restrepo \\ Harold Salazar
}

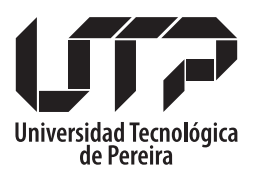

Vicerrectoría de Investigaciones, Innovación y Extensión

Facultad de Ingeniería Mecánica 
Vicerrectoría de Investigaciones, Innovación y Extensión

Ingeniería mecánica : Resultados de investigación /

Vicerrectoría de Investigaciones, Innovación y Extensión.

Pereira : Universidad Tecnológica de Pereira, 2020.

105 páginas. - (Colección Trabajos de investigación).

elSBN: 978-958-722-500-6

1. Ciencia e ingeniería de los materiales 2 . Motores de combustión interna - Mantenimiento 3. Biocombustible -

Análisis energético 4. Ensayos mecánicos 5. Resistencia -

Ciencia de materiales 6 . Carrocería de vehículos - Resistencia

mecánica 7. Fallo - Ciencia de materiales 8. Fuerza - Ciencia

de materiales.

CDD. 620.112

Ingeniería Mecánica: Resultados de investigación

(C) Vicerrectoría de Investigaciones, Innovación y Extensión

(C) Universidad Tecnológica de Pereira

Publicación financiada con recursos de la Vicerrectoría de Investigaciones, Innovación y

Extensión de la Universidad Tecnológica de Pereira

eISBN: 978-958-722-500-6

Trabajo de Investigación

Universidad Tecnológica de Pereira

Vicerrectoría de Investigaciones, Innovación y Extensión

Editorial Universidad Tecnológica de Pereira

Pereira, Colombia

Coordinador editorial:

Luis Miguel Vargas Valencia

luismvargas@utp.edu.co

Teléfono 3137381

Edificio 9, Biblioteca Central "Jorge Roa Martínez"

Cra. 27 No. 10-02 Los Álamos, Pereira, Colombia

www.utp.edu.co

Montaje y producción:

María Alejandra Henao Jiménez

Universidad Tecnológica de Pereira

Pereira 


\section{CONTENIDO}

\section{CAPÍTULO UNO.}

RESULTADOS DEL PROYECTO DESARROLLO DE UN SISTEMA DE MONITOREO PARA EL ANÁLISIS ENERGÉTICO Y DE CONDICIÓN DE EMISIONES EN MOTORES DE COMBUSTIÓN INTERNA DIÉSEL CON BASE EN TÉCNICAS NO INTRUSIVAS / RESULTS OF THE PROJECT DEVELOPMENT OF A MONITORING SYSTEM FOR ENERGY AND EMISSION CONDITION ANALYSIS IN DIESEL INTERNAL COMBUSTION ENGINES BASED ON NON- INTRUSIVE TECHNIQUES

Juan Camilo Mejía, Juan David Ramírez, Juan Camilo Zapata, Héctor Fabio Quintero Riaza, Carlos Alberto Romero Piedrahita, Edison Henao Castañeda

\section{CAPÍTULO DOS.}

CARACTERIZACIÓN DE MATERIAL COMPUESTO PARA LA CONSTRUCCIÓN DE LA CARROCERÍA DE UN VEHÍCULO SUPERMILAGE /

CHARACTERIZATION OF COMPOSITE MATERIAL FOR THE CONTRUCTION OF THE BODYWORK OF A SUPERMILAGE

VEHICLE .42

Juan Manuel Manzano Martínez, José Luis Tristancho Reyes.

\section{CAPÍTULO TRES.}

MÉTODO PARA EVALUAR LA INCORPORACIÓN DE FUENTES NO CONVENCIONALES DE ENERGÍA EN COLOMBIA / ASSESSMENT METHOD FOR THE INCLUSION OF NON-CONVENTIONAL ENERGY SOURCES IN COLOMBIA . .76 Juan Carlos Castillo Herrera, David Andrés Serrato Tobón, Juan Esteban Tibaquirá, Álvaro Restrepo, Harold Salazar 



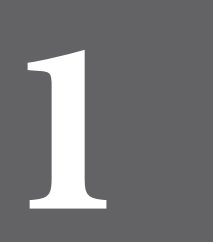

CAPÍTULO

UNO 



\title{
Resultados del proyecto desarrollo de un sistema de monitoreo para el análisis energético y de condición de emisiones en motores de combustión interna diésel con base en técnicas no intrusivas
}

\section{Results of the project development of a monitoring system for energy and emission condition analysis in diesel internal combustion engines based on non-intrusive techniques}

\author{
Autores \\ Juan Camilo Mejía - Universidad Tecnológica de Pereira \\ j.mejia1@utp.edu.co \\ Juan David Ramírez - Universidad Tecnológica de Pereira \\ juandaviramireza@utp.edu.co \\ Juan Camilo Zapata - Universidad Tecnológica de Pereira \\ juanchozapaata@utp.edu.co
}

Héctor Fabio Quintero Riaza - Universidad Tecnológica de Pereira hquinte@utp.edu.co

Carlos Alberto Romero Piedrahita - Universidad Tecnológica de Pereira cromero@utp.edu.co

Edison Henao Castañeda - Universidad Tecnológica de Pereira edisonhenao@utp.edu.co 


\section{Resumen}

El sector transporte, al ser reconocido mundialmente como uno de los mayores emisores de gases de efecto invernadero, es objeto clave de estudio a la hora de buscar reducir el impacto negativo sobre el medio ambiente generado por el alto consumo de recursos fósiles. Con la presente propuesta de investigación, se pretende establecer una metodología que permita el análisis energético y monitoreo de condición de emisiones en motores de combustión interna trabajando con combustible diésel y biodiésel, con base en técnicas no intrusivas. Mediante este proyecto, se pretende desarrollar una metodología de mantenimiento predictivo para el sector transporte colombiano, orientado al análisis energético y control de las emisiones de los vehículos de transporte por carretera.

Con el objetivo de sacar el mejor provecho de esta tecnología de monitoreo, se pretende analizar mediante técnicas especializadas basadas en procesos estocásticos y caracterización en tiempo y/o frecuencia señales no intrusivas adquiridas en los motores, de tal manera que permita al operador programar de una manera más eficiente un plan de mantenimiento de los vehículos de las empresas de transporte público, lo que se conoce como mantenimiento basado en el monitoreo de condición, y que permitirá tomar decisiones de intervención y operación por parte del personal de mantenimiento para realizar los requeridos ajustes y mantener los motores en el estado de disponibilidad deseado, tema que coadyuva a la innovación incremental de las organizaciones, y que permite mejorar la rentabilidad de las empresas al reducir el porcentaje del costo de mantenimiento y optimización en el uso de aceites y combustibles.

Como resultados del proyecto, se espera un nuevo sistema, basado en la integración de hardware y el desarrollo de software altamente especializado, que permita el monitoreo y análisis objetivo de la condición del motor, con aplicación directa al parque 
automotor bajo estudio. Igualmente, se espera la concepción, desarrollo y publicación de material científico que sustente con evidencias la nueva herramienta tecnológica.

Palabras claves: Motores de combustión interna, vibraciones mecánicas, gasolina, diésel.

\section{Abstract}

The transport sector, being recognized worldwide as one of the largest emitters of greenhouse gases, is a key object of study when seeking to reduce the negative impact on the environment generated by the high consumption of fossil resources. With this research proposal, it is intended to establish a methodology that allows energy analysis and monitoring of emissions condition in internal combustion engines working with diesel fuel and biodiesel, based on non-intrusive techniques. Through this project, it is intended to develop a predictive maintenance methodology for the Colombian transport sector, aimed at energy analysis and control of emissions from road transport vehicles.

In order to get the best out of this monitoring technology, it is intended to analyze through specialized techniques based on stochastic processes and characterization in time and / or frequency, non-intrusive signals acquired in the motors, in such a way that it allows the operator to program in a more efficiently a maintenance plan for the vehicles of public transport companies, which is known as maintenance based on condition monitoring, and which will allow intervention and operation decisions by maintenance personnel to make the required adjustments and keeping the engines in the desired state of availability, an issue that contributes to the incremental innovation of the organizations, and that allows to improve the profitability of the companies by reducing the percentage of the maintenance cost and optimization in the use of oils and fuels. 
As results of the project, a new system is expected, based on the integration of hardware and the development of highly specialized software, which allows the objective monitoring and analysis of the condition of the engine, with direct application to the vehicle fleet under study. The conception, development and publication of scientific material that supports the new technological tool with evidence is also expected.

Keywords: Internal combustion engines, mechanical vibrations, gasoline, diesel.

\section{Introducción}

Desde la invención, el Motor de Combustión Interna (MCI) se utiliza en una amplia gama de aplicaciones automovilísticas, aeronáuticas, ferroviarias entre otras. Debido a lo anterior, se han desarrollado diversas técnicas de monitoreo, diagnóstico y mantenimiento para los MCI, las cuales tienen como objetivo mantenerlos en buen estado para reducir costos de reparación, garantizar la disponibilidad y eficiencia. Generalmente, las técnicas de mantenimiento de los MCI se basan en el análisis de señales intrínsecas provenientes de los mismos (temperatura, vibraciones, gases, etc.) y la captura de estas conlleva un enorme trabajo de instrumentación. Para el diagnóstico, es importante estudiar la relación entre la combustión en el motor y las variables dinámicas, [1], así como la estimación de la presión en la cámara de combustión [2], [3]. De esta forma se puede implementar técnicas de diagnóstico en el motor como en [4], [5], [6]. El grupo de investigación ha desarrollado algoritmos para el diagnóstico de máquinas rotativas, tales como [7], [8], [9].

En este trabajo se presenta el análisis de un motor monocilíndrico Changfa 186 realizando análisis de exergía, emisiones, condición de operación, estimación de la presión en la cámara de combustión y análisis de gases. Las señales capturadas son: Presión en cámara de combustión, presión del aire de admisión (MAP), velocidad, golpeteo, señales de vibración en 
tres ejes $\mathrm{X}, \mathrm{Y}$ y Z, carga, flujo másico de aire (MAF), pulsos de inyección, flujo de combustible y sonido. Para la estimación de la presión a partir de las señales obtenidas, se implementa un modelo de regresión lineal y un modelo de regresión rígida nolineal con kernel gaussiano.

Para el procesamiento se utilizan metodologías tiempofrecuencia, Análisis de Componentes Principales (PCA), Entropías de Permutación Multiescalar (MPE), Regresiones Gaussianas y algoritmos de clasificación basados en aprendizaje de máquina. Dichas metodologías se usan para reconstruir la señal de presión en la cámara de combustión e identificar la carga, velocidad y relación de compresión del motor desde las vibraciones mecánicas.

Los biocombustibles, como el etanol, se han utilizado en motores de combustión interna para reducir las emisiones contaminantes. Sin embargo, algunos estudios demuestran que afectan el desempeño de los motores debido a que presentan diferencias en sus propiedades termo-físicas. En este trabajo, se realiza un estudio comparativo del desempeño de un motor mono-cilíndrico de relación de compresión variable, operando con gasolina, diésel, etanol y una mezcla de etanol-gasolina (E50). Las pruebas se realizaron con relaciones de compresión 9:1, 12:1, $14: 1$ y $17: 1$ y con frecuencia de giro cercanas a $1500,2100,2600$ y $3200 \mathrm{~min}^{-1}$.

En este trabajo, se presenta una metodología para el diagnóstico de MCI (motores de combustión interna) basada en parte de los datos no intrusivos obtenidos, espáticamente, señales de vibraciones. Estas señales se procesan con base en el método robusto de extracción de características MPE (Entropía de Permutación Multiescalar) y al algoritmo de selección de características VRA (Análisis de relevancia de varianza), para usar como información base para clasificar diferentes variables del estado actual de un ICE, con la ayuda del eficiente algoritmo de aprendizaje automático de clasificación supervisado de los $\mathrm{K}$ vecinos más cercanos. 


\section{Planteamiento del problema y justificación}

El mercado mundial de transporte está integrado por el sector de infraestructura y por los servicios de transporte. El servicio de transporte es uno de los principales pilares del desarrollo social y económico de una sociedad, [10], y se encuentra relacionado con la economía, a tal punto que se puede afirmar que el transporte, como cualquier otra actividad productiva, es parte de ella. El auge y la popularización del transporte han hecho de este el principal consumidor de recursos fósiles, en su mayoría de aquellos derivados del petróleo.

Según la Agencia Internacional de la Energía (IEA), el 64,5 \% del petróleo comercializado en el 2014 fue destinado a la operación del sector transporte, [11]. Según el último reporte del Inventario Nacional de Gases de Efecto Invernadero (GEI) [12], Colombia emite más de 178 toneladas anuales de dióxido de carbono de los cuales el $37 \%$ es quema de combustibles fósiles y de estos el 33 $\%$ es responsable el sector de transporte. Además, la UPME [13] presenta que, en el 2012, el $81 \%$ del diésel comercializado en el país fue empleado en el sector transporte por carretera, siendo los principales consumidores los camiones, tractocamiones y buses, cuya participación fue del $31 \%, 27 \%$ y $19 \%$, respectivamente; y destaca que, el $7 \%$ de la flota nacional es vehículos de transporte de carga y de transporte público de pasajeros. Estos estudios muestran la importancia que tiene el combustible diésel en la canasta energética del país. Además del $\mathrm{CO}_{2}$, las principales emisiones generadas durante la operación de los vehículos diésel, y que son de carácter contaminante, son: el monóxido de carbono (CO), los óxidos de nitrógeno (NOx), los hidrocarburos no quemados (HC) y el material particulado (PM) [14].

En general, la concentración de cada uno de los gases de escape depende tanto de la eficiencia de la combustión como de la calidad y propiedades de los combustibles [14]. La formación de NOx está directamente relacionada con la temperatura en la 
cámara de combustión, a mayor temperatura y mayor eficiencia de combustión, mayor es la formación de NOx [14], [15] mientras que las condiciones de combustión incompleta, causan una formación de HC, CO y PM [14], [15]. Esta relación inversa entre las emisiones de NOx y de PM es una de las principales barreras en la búsqueda de reducción de las emisiones en vehículos diésel. Otra de las emisiones que resultan ser de gran importancia, y que son causantes de grandes problemas de contaminación ambiental, son los gases sulfatados, originados principalmente por el contenido de azufre de los combustibles. El azufre es precursor de varios efectos negativos en la operación de los vehículos, entre ellos: desgaste del motor, formación de depósitos y emisiones sulfatadas, y reducción de la efectividad de los sistemas de control, afectando principalmente la eficiencia de los catalizadores; además de problemas respiratorios en los seres vivos y de la acidificación del ambiente [16]. Debido a esto, muchos países se han interesado en mejorar la calidad de sus combustibles, principalmente mediante la reducción del contenido de azufre, con el fin de mitigar la formación de contaminantes en los gases de escape de los vehículos.

Para reducir la cantidad de emisiones producidas por el sector transporte, es necesario principalmente garantizar que estos grandes sistemas trabajen de una manera eficiente, para lograr dicho fin, es importante mantener a cada una de sus partes operando de la mejor forma posible, es decir, es necesario implementar protocolos de mantenimiento efectivos. El mejoramiento de los programas de mantenimiento mediante el modelamiento y la optimización ha sido el tema fundamental de un gran número de estudios, [17]. El mantenimiento preventivo tradicional busca maximizar la operación adecuada de equipos mediante una serie de rutinas de inspección realizadas a unos intervalos de tiempo determinados, los cuales, en forma general, se incrementan en frecuencia a medida que transcurre tiempo sin presentarse un estado anormal. Sin embargo, a medida que el 
tiempo transcurre, el aumento en la frecuencia de ejecución del mantenimiento ocasiona un incremento en la probabilidad de falla, o estado anormal no deseado.

Los objetivos fundamentales del mantenimiento han ido evolucionando paralelamente con el mismo, llegando a nuestros días donde los ingenieros de mantenimiento, con avanzados equipos de medida y apoyados con sofisticadas herramientas informáticas, se encargan de establecer el estado de las máquinas, diagnosticar fallas y definir el mejor plan de actuación sobre ellas [18]. Este último enfoque, denominado mantenimiento predictivo, está basado en la condición que se efectúa realizando pronostico derivado del análisis y la evaluación de los parámetros significativos de la degradación de un ítem [19]. Para llevar a cabo este tipo de mantenimiento y analizar fallas en los componentes principales de los motores de combustión interna, muchas veces se requiere realizar pruebas intrusivas, lo que obliga a detener el funcionamiento del motor para efectuar un diagnóstico de dichas fallas, empleando una gran cantidad de tiempo e incrementando el costo final de reparación. Las técnicas intrusivas más utilizadas para el diagnóstico de motores son: boroscopios (endoscopios industriales), lectura de gráficos presión-volumen, análisis de aceite y ubicación de sensores en la culata para conocer la presión en cámara.

Con base en lo anterior, este proyecto busca darle respuesta a la necesidad de conocer si existe la posibilidad de desarrollar una metodología de mantenimiento predictivo que permita el análisis energético y de condición de emisiones en motores de combustión interna, funcionando con combustible diésel y biodiesel, con base en técnicas no intrusivas. Lo anterior con el fin de contribuir a las técnicas de monitoreo de condición, a la reducción del consumo de combustible y de los costos de mantenimiento del tipo de motores de combustión interna evaluados en el proyecto. 
La necesidad de conocer si un elemento está en estado de falla, cuando ha sido sometido a un entorno de evolución aleatoria, es una de las principales problemáticas a las que se han visto sometidos los ingenieros de mantenimiento durante los últimos años. Es por ello que el hecho de saber si un elemento al ser usado es confiable juega un rol importante en todos los sistemas de ingeniería. Una muestra de la importancia de esto lo da el Centro de Sistemas Inteligentes de Mantenimiento [20], el cual estima que alrededor de 35 billones de dólares podrían ahorrarse y miles de vidas podrían salvarse anualmente en los Estados Unidos, si se emplea tecnología para el Mantenimiento Basado en Condición $(\mathrm{CBM})$. El hecho que una de las principales problemáticas a las que se enfrenta el personal de mantenimiento sea conocer el estado de salud de una máquina ha generado avances en el desarrollo de diferentes alternativas para evaluar la condición de operación de las máquinas, profundizando de manera especial en el campo del mantenimiento predictivo o CBM [21].

En el CBM, la aplicación de técnicas que permiten predecir el momento en el cual fallará un sistema o uno de sus elementos se ha basado en estudios estadísticos tradicionales, lo cual resulta no aplicable en la mayoría de los casos por la dificultad presente en plantear un modelo efectivo. Motivo por el cual se han desarrollado nuevas técnicas estadísticas basadas en los procesos estocásticos y en el entrenamiento de máquina. Estas técnicas han tenido su gran polo de desarrollo en la extensión de vida útil y predicción de estado de falla en componentes de máquinas, hasta el punto de significar ahorros por hora de operación que permiten extender la disponibilidad de los elementos en comparación con los diseños originales [22].

En el caso especial de los motores de combustión interna, mejorar los niveles de seguridad y de eficiencia asociados a las acciones de mantenimiento es materia de estudio para diseñadores, constructores y operadores de estos. El aumento de su seguridad y eficiencia puede ser alcanzado mediante la optimización 
de las acciones y programas de mantenimiento; diseñando, desarrollando o aplicando nuevas técnicas. Considerando que, en los últimos años, debido a la importancia que han tomado el CBM y los análisis de señales capturadas mediante técnicas no intrusivas, como: análisis de señales de vibración, de señales acústicas, de gases, de golpeteo, entre otros, se han convertido en técnicas exitosas y eficaces para el diagnóstico de falla en motores [23]. Por ello, resulta conveniente y oportuna la implementación de metodologías que contribuyan al diagnóstico de fallas y al mantenimiento basado en la condición, utilizando técnicas no intrusivas, para la reducción de costos de mantenimiento, involucrando mejoras en la eficiencia y consumo de combustible. Esto demuestra el impacto positivo que se puede obtener al aplicar estas metodologías predictivas del mantenimiento, ya que se maximiza el tiempo operacional de los componentes del sistema al solo realizar prácticas de mantenimiento en el momento que es necesario sin invadir el funcionamiento de los motores.

El desarrollo de la presente propuesta brinda una herramienta de mantenimiento, basada en la condición de tal manera que se pronostique mediante un sistema basado en procesos estocásticos y caracterización en tiempo y/o frecuencia, los requerimientos de mantenimiento con respecto a la operación energética de los motores y la condición de las emisiones, que, además, recomiende de manera automática la generación de órdenes de trabajo y la planeación del mantenimiento mediante la programación de las tareas asignadas a la misma área. Todo lo anterior generará una metodología de diagnóstico para el mantenimiento basado en la condición aprovechando hardware y software, la cual podrá ser replicada fácilmente en empresas de transporte del orden nacional e internacional, dado que se tendrán también resultados de prueba en diferentes vehículos.

En los últimos años, la Federación Nacional de Biocombustibles ha contribuido al crecimiento sostenible de la industria de los biocombustibles en Colombia, mediante la 
representación de los intereses de sus agremiados, la gestión de la política sectorial, la producción de información y difusión de conocimientos, promoviendo la investigación y desarrollo de nuevas tecnologías y la generación de empleo, la protección del medio ambiente y la diversificación de la canasta energética. En alianza con la Federación Nacional de Biocombustibles de Colombia, se pretende aplicar la metodología de diagnóstico generada no solo evaluando motores funcionando con combustible diésel, sino también con biodiesel, ya que el uso del biodiesel en flotas vehiculares se ha tornado una práctica popular alrededor del mundo. Una de las principales diferencias entre el biodiesel y el diésel común es el ultra bajo contenido de azufre del biodiesel (menor a $15 \mathrm{ppm}$ ), satisfaciendo los requerimientos establecidos por la EPA; además, el uso del biodiesel favorece la reducción en las emisiones y favorece la combustión completa, ya que contiene un $11 \%$ de oxígeno en peso y un número de cetano ligeramente mayor que el diésel [23]. Es así como se desea observar la eficiencia energética de operación,

\section{Objetivos}

\section{Objetivo general}

Desarrollar un sistema de monitoreo de condición en motores de combustión interna diésel para el análisis energético y de condiciones de emisiones con base en técnicas no intrusivas.

\section{Objetivos específicos:}

1) Diseñar y desarrollar un protocolo para la adquisición de señales en motores de combustión interna diésel, a partir de técnicas no intrusivas.

2) Diseñar y desarrollar una metodología para preprocesar y procesar las señales adquiridas a partir de técnicas no intrusivas con base en métodos de optimización de características y diccionarios ampliados. 
3) Desarrollar una metodología para el análisis energético y de condición de emisiones de los motores de combustión interna, a partir de técnicas de procesamiento de señales y aprendizaje de máquina.

4) Desarrollar una metodología de validación que incluya el diagnóstico dado por un grupo de expertos en el área de motores de combustión interna diésel.

\section{Referente teórico}

\section{Mantenimiento predictivo}

La norma ISO 13372 [24] define el mantenimiento predictivo como "el mantenimiento enfocado en la predicción de la falla y en la toma de decisiones basadas en la condición del equipo para prevenir su degradación o falla". Adicionalmente, el EPRI - Electric Power Research Institute define al mantenimiento predictivo como: un proceso que requiere de tecnologías y personal capacitado que integra todos los indicadores disponibles de la condición de los equipos (datos de diagnóstico y rendimiento, registro de datos del operador), históricos de mantenimiento y el conocimiento de diseño para tomar decisiones oportunas sobre los requisitos de mantenimientos más importantes [25]. Esta técnica supone la medición de diversos parámetros que muestren una relación predecible con el ciclo de vida del componente. Algunos ejemplos de dichos parámetros son:

- Vibración de cojinetes

- Temperatura de las conexiones eléctricas

- Resistencia de aislamiento de la bobina de un motor

El uso del mantenimiento predictivo consiste en establecer, en primer lugar, una perspectiva histórica de la relación entre la variable seleccionada y la vida del componente. Esto se logra mediante la toma de lecturas; por ejemplo, la vibración de un cojinete, en intervalos periódicos hasta que el componente se rompa 
o se averíe. Las técnicas aplicadas al mantenimiento predictivo son [26]: Análisis de vibraciones, Análisis de lubricantes, Análisis por ultrasonidos, Termografía, Análisis por algoritmos estadísticos y Análisis eléctrico.

\section{Monitoreo de condición}

Comprende todas las técnicas necesarias para la detección de fallas, es importante porque [27]:

- Provee una señal temprana sobre potenciales fallas que afecten la confiabilidad del sistema.

- Permite una evaluación del costo de costo de vida para ser llevado a cabo.

- Permite establecer las componentes de menor confiabilidad.

- Cada vez se usa más en licitaciones, contratos y estándares de seguridad.

Las características de un sistema de detección de fallas deberían tener: rapidez de detección, aislamiento (habilidad del sistema para distinguir entre fallas), debe ser robusto, estimar el error, adaptable y con la capacidad de identificar fallas múltiples [28].

\section{Técnicas no intrusivas}

Vibraciones: el monitoreo y análisis de vibraciones es una de las técnicas más ampliamente utilizadas en el área del mantenimiento industrial con la cual puede establecerse la condición de equipos y máquinas a partir de la información de señales de vibración. La medición y análisis de estas señales brinda información relacionada con las condiciones de falla de los equipos y maquinaria, las cuales evolucionan con el tiempo. Estas condiciones, de no ser erradicadas, incrementan la probabilidad de ocurrencia de daños catastróficos. 
Emisión acústica: los ensayos mediante emisiones acústicas han llegado a ser reconocidos como métodos de ensayo no destructivos, comúnmente utilizados para detectar y localizar fallas en estructuras y componentes sometidos a cargas. Las emisiones acústicas proveen información sobre el origen de los defectos y de la evolución de estos mientras el componente está sometido a esfuerzos repetitivos. Las discontinuidades en los componentes liberan energía mientras el componente se encuentra sometido a cargas y esfuerzos. Esta energía viaja en forma de ondas de alta frecuencia. Estas oscilaciones se reciben mediante un sensor (transductor) que convierte la energía transportada por la onda en una señal de tensión la cual es amplificada y procesada. Análisis de gases de escape: la huella de carbono que el hombre está generando alrededor del mundo ha llegado a ser un tema de vital importancia en la última década. Nuevas regulaciones están siendo impuestas en un gran número de países con el fin de controlar las emisiones de gases de efecto invernadero, por lo que se hace necesario desarrollar e implementar mejores estrategias para cuantificarlas y controlarlas. Las pruebas que involucran la medición de las concentraciones de los compuestos contaminantes y los gases de efecto invernadero en el escape de los vehículos con motores de combustión interna, por ejemplo, permiten tener un diagnóstico no intrusivo del estado actual del motor, evaluado desde el punto de vista de su desempeño y la eficiencia de la combustión al interior de la cámara; el cual permite, mediante la identificación de las concentraciones de estos gases que se encuentran fuera de los rangos permitidos establecidos por las regulaciones actuales, desarrollar estrategias eficientes que promuevan el mejoramiento del desempeño del vehículo y la disminución de las emisiones por kilómetro recorrido, [29].

\section{Aprendizaje de máquina}

El aprendizaje, así como la inteligencia, cubre un amplio rango de procesos que son difíciles de definir con precisión. En particular, se define el aprendizaje de máquina como un conjunto 
de métodos que permiten detectar, automáticamente, patrones en grandes cantidades de datos y, así, predecir el comportamiento de datos futuros o llevar a cabo procesos de toma de decisiones con cierta incertidumbre. Ciertamente, muchas técnicas desarrolladas en el aprendizaje de máquina se derivan, inicialmente, de un esfuerzo de los psicólogos en un intento por hacer más precisas sus teorías en relación con los procesos de aprendizaje de los animales y los seres humanos mediante modelos computacionales. El aprendizaje de máquina, usualmente, refiere los cambios en los sistemas que refieren la ejecución de tareas asociadas con la inteligencia artificial tales como: reconocimiento, diagnóstico, planeación, control y predicción, [30].

\section{Gestión energética}

La gestión energética es un sistema de gestión basado en un esfuerzo sistemático y continuado en la búsqueda del mejoramiento de la eficiencia energética de los procesos llevados a cabo por una organización, a partir de estrategias que facilitan el uso racional, eficiente y ambientalmente amigable de la energía bajo los niveles de calidad requeridos para la prestación de servicios, elaboración de productos y funcionamiento de los sistemas de las cadenas productivas. En los últimos años, diferentes entidades alrededor del mundo han incursionado en la investigación del aprovechamiento de las fuentes renovables de energía, tales como la solar, la eólica y la biomasa, en la búsqueda de la reducción del uso de las fuentes convencionales de energía, cuya utilización trae consigo efectos nocivos para el medio ambiente. Sin embargo, la gestión energética no se limita al uso de fuentes y tecnologías renovables, sino que pretende intervenir en el mejoramiento de la eficiencia de los equipos y procesos ya existentes.

Mediante la implementación de este sistema es posible detectar oportunidades de mejora en la calidad de la energía, realizar la planificación eficiente del funcionamiento y uso de los equipos, apoyar la planificación de una política energética 
e identificar los puntos de mayor consumo de un determinado proceso. De esta forma, se pueden desarrollar e implementar estrategias que permitan la reducción directa o inmediata del consumo de energía y de la tasa de emisiones contaminantes y gases de efecto invernadero provenientes de los diferentes sectores productivos [31].

\section{Metodología}

\section{En la Tabla 1, se muestra la metodología implementada en el proyecto.}

Tabla 1. Metodología del proyecto

\begin{tabular}{|c|c|}
\hline \multicolumn{2}{|c|}{$\begin{array}{l}\text { Objetivo específico 1: Diseñar y desarrollar un protocolo para la adquisición de señales a } \\
\text { partir de técnicas no intrusivas. }\end{array}$} \\
\hline Fase 1 & $\begin{array}{l}\text { Planificación del protocolo de adquisición con base en técnicas de diseño de } \\
\text { experimentos. }\end{array}$ \\
\hline Fase 2 & Generación y anotación de la base de datos. \\
\hline \multicolumn{2}{|c|}{$\begin{array}{l}\text { Objetivo específico 2: Diseñar y desarrollar una metodología para preprocesar y procesar las } \\
\text { señales adquiridas a partir de técnicas no intrusivas con base en métodos de optimización de } \\
\text { características y diccionarios ampliados. }\end{array}$} \\
\hline Fase 3 & Selección del mínimo trozo de señal que contenga información relevante. \\
\hline Fase 4 & Segmentación, normalización y filtrado de las señales adquiridas. \\
\hline Fase 5 & Análisis de la dinámica intrínseca de las señales. \\
\hline Fase 6 & $\begin{array}{l}\text { Selección de la mejor técnica de caracterización, de acuerdo con la dinámica } \\
\text { intrínseca de las señales. }\end{array}$ \\
\hline Fase 7 & Selección de características utilizando métodos de optimización. \\
\hline \multicolumn{2}{|c|}{$\begin{array}{l}\text { Objetivo específico 3: Desarrollar una metodología para el análisis energético y de condición } \\
\text { de emisiones de los motores de combustión interna, a partir de técnicas de aprendizaje de } \\
\text { máquina. }\end{array}$} \\
\hline Fase 8 & $\begin{array}{l}\text { Desarrollar un algoritmo basado en procesos estocásticos para el análisis } \\
\text { energético de los motores a partir de las señales adquiridas. }\end{array}$ \\
\hline Fase 9: & $\begin{array}{l}\text { Desarrollar un algoritmo basado en procesos estocásticos para el análisis de } \\
\text { condición de emisiones de los motores a partir de las señales adquiridas. }\end{array}$ \\
\hline \multicolumn{2}{|c|}{$\begin{array}{l}\text { Objetivo específico 4: Desarrollar una metodología de validación que incluya el diagnóstico } \\
\text { dado por un grupo de expertos en el área de motores de combustión interna diésel. }\end{array}$} \\
\hline Fase 10 & $\begin{array}{l}\text { Realizar pruebas de operación de los motores de combustión interna para } \\
\text { evaluar la confiabilidad de la metodología implementada. }\end{array}$ \\
\hline Fase 11 & Diagnóstico por parte del grupo de expertos. \\
\hline
\end{tabular}


Resultados

Para dar cumplimiento al objetivo específico 1, "Diseñar y desarrollar un protocolo para la adquisición de señales en motores de combustión interna diésel a partir de técnicas no intrusivas", se procedió a la adaptación de un Banco de ensayo con motor de combustión adecuado para operar con diferentes combustibles, [32], [33], tal como se muestra en la Figura 1.

Figura 1. Banco de pruebas instrumentado. Izquierda - Esquema de instrumentación. Derecha - Motor instrumentado
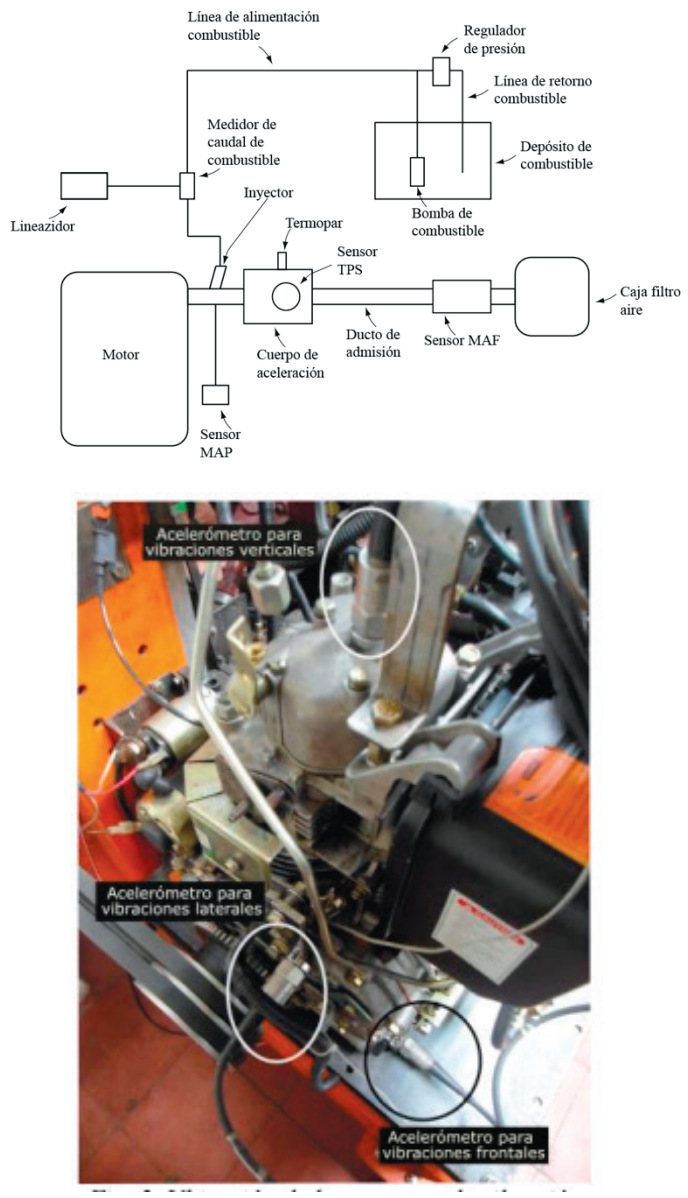
Después de la construcción del banco, se procede a elaborar el protocolo para la adquisición de señales en el banco a partir de técnicas no intrusivas, [34]. En el proyecto se realiza un estudio sobre la influencia de la presión de los inyectores sobre el funcionamiento del motor. En la Tabla 2 se presentan las características de los ensayos durante las pruebas. En las pruebas se realizaron mediciones de vibraciones y opacidad de los gases de combustión. En los ensayos se opera a 1800, 2400 y 3000 rpm.

Tabla 2. Características de los inyectores utilizados

\begin{tabular}{|lll|}
\hline & PRESIÓNDEINYECCIÓN \\
INYECTOR & {$[\mathrm{MPa}]$} & VOLUMEN $\left[\mathrm{cm}^{3}\right]$ \\
180 & 18,36 & 0,085 \\
200 & 20,00 & 0,090 \\
220 & 22,00 & 0,086 \\
\hline
\end{tabular}

La Tabla 3 muestra los diferentes tratamientos que requiere este ensayo, además de los diferentes niveles que posee cada variable. Es importante añadir que la matriz mostrada en la Tabla 3 será repetida en tres oportunidades por lo que se tendrá entonces, para cada tratamiento, un total de tres pruebas con su respectiva base de datos.

De los datos medidos con el opacímetro se realiza un análisis gráfico, verificando que esta opacidad aumentara directamente con los niveles de carga. La información media recolectada en cada prueba, es inicialmente ajustada restando a cada valor su respectivo "offset"; posteriormente se hace un promedio de las tres réplicas de cada tratamiento, diferenciando los niveles de carga, tal como se muestra en la Figura 2, Figura 3, Figura 4. Acorde con estos resultados, se advierte que los valores de opacidad dependen no solo de los niveles de carga sino también de la velocidad de giro; notándose un crecimiento no lineal cuando la velocidad supera las 2400 RPM, para carga media y alta; con carga baja se tiene un crecimiento casi lineal con respecto a la velocidad 
Tabla 3. Descripción del número y características de cada tratamiento.

\begin{tabular}{|c|c|c|c|c|}
\hline & Presión de inyección & Carga & Velocidad de giro & \\
\hline \multirow{27}{*}{ Niveles } & \multirow{9}{*}{$18 \mathrm{MPa}$} & \multirow{3}{*}{ BAJA } & 1800 RPM & 1 \\
\hline & & & 2400 RPM & 2 \\
\hline & & & $3000 \mathrm{RPM}$ & 3 \\
\hline & & \multirow{3}{*}{ MEDIA } & 1800 RPM & 4 \\
\hline & & & 2400 RPM & 5 \\
\hline & & & 3000 RPM & 6 \\
\hline & & \multirow{3}{*}{ ALTA } & $1800 \mathrm{RPM}$ & 7 \\
\hline & & & 2400 RPM & 8 \\
\hline & & & 3000 RPM & 9 \\
\hline & \multirow{9}{*}{$20 \mathrm{MPa}$} & \multirow{3}{*}{ BAJA } & $1800 \mathrm{RPM}$ & 10 \\
\hline & & & $2400 \mathrm{RPM}$ & 11 \\
\hline & & & 3000 RPM & 12 \\
\hline & & \multirow{3}{*}{ MEDIA } & 1800 RPM & 13 \\
\hline & & & $2400 \mathrm{RPM}$ & 14 \\
\hline & & & $3000 \mathrm{RPM}$ & 15 \\
\hline & & \multirow{3}{*}{ ALTA } & 1800 RPM & 16 \\
\hline & & & 2400 RPM & 17 \\
\hline & & & $3000 \mathrm{RPM}$ & 18 \\
\hline & \multirow{9}{*}{$22 \mathrm{MPa}$} & \multirow{3}{*}{ BAJA } & $1800 \mathrm{RPM}$ & 19 \\
\hline & & & $2400 \mathrm{RPM}$ & 20 \\
\hline & & & 3000 RPM & 21 \\
\hline & & \multirow{3}{*}{ MEDIA } & $1800 \mathrm{RPM}$ & 22 \\
\hline & & & $2400 \mathrm{RPM}$ & 23 \\
\hline & & & $3000 \mathrm{RPM}$ & 24 \\
\hline & & \multirow{3}{*}{ ALTA } & $1800 \mathrm{RPM}$ & 25 \\
\hline & & & $2400 \mathrm{RPM}$ & 26 \\
\hline & & & 3000 RPM & 27 \\
\hline
\end{tabular}


Figura 2. Opacidad Vs velocidad con presión de inyección $18 \mathrm{MPa}$

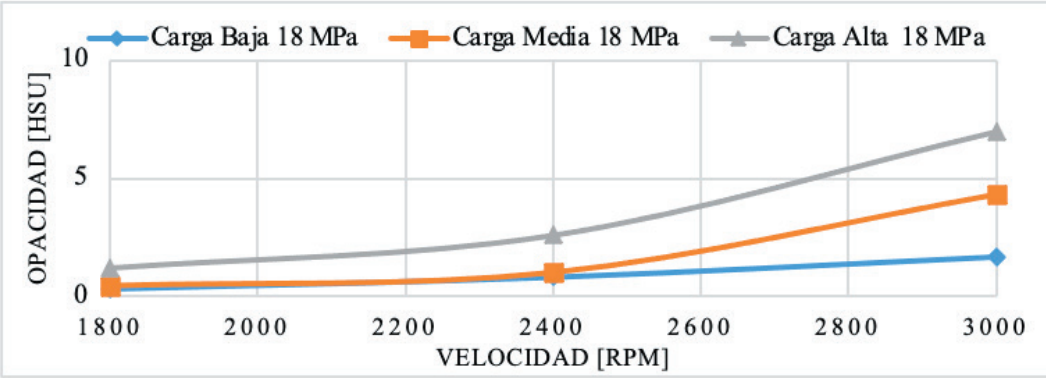

Figura 3. Opacidad Vs velocidad con presión de inyección $20 \mathrm{MPa}$

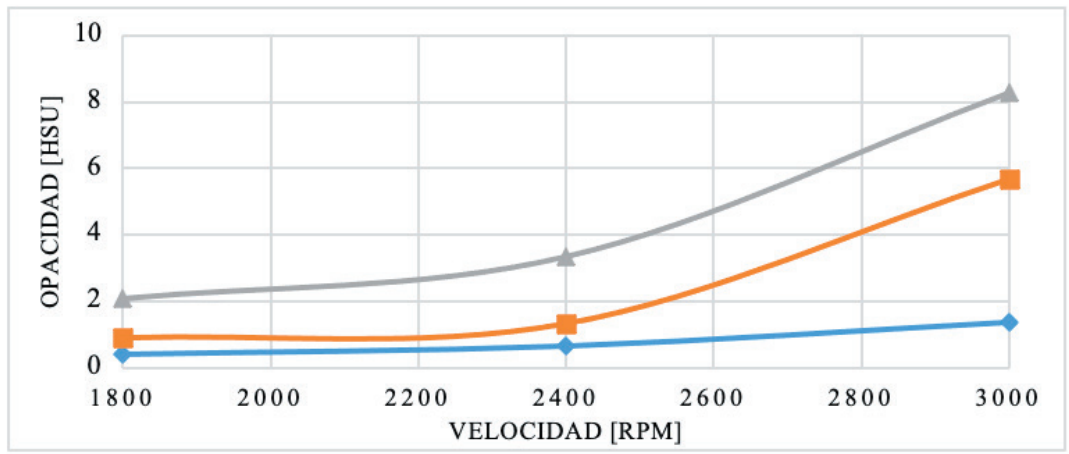

Figura 4. Opacidad Vs velocidad con presión de inyección $22 \mathrm{MPa}$

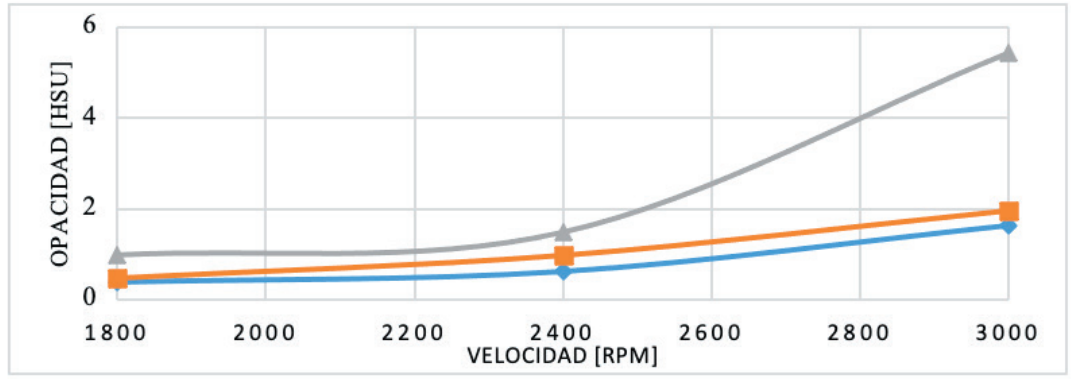

La base de datos está compuesta por 12 señales, cada una con una duración de 10 segundos a una frecuencia de muestreo de $512 \mathrm{kHz}$. Las señales capturadas son: Presión en cámara de combustión, presión del aire de admisión (MAP), velocidad, 
golpeteo, señales de vibración en tres ejes $\mathrm{X}, \mathrm{Y}$ y Z, carga, flujo másico de aire (MAF), pulsos de inyección, flujo de combustible y sonido. Las pruebas se realizaron con el motor a 1800 RPM con una carga del $90 \%$ (alta) del valor máximo. Dado que el sensor de presión requiere modificaciones en el motor, se desarrolla un modelo para estimar la presión analizando señales no intrusivas.

Inicialmente se entrena un modelo de regresión lineal con el fin de encontrar la relevancia de cada una de las señales cuando se pretende estimar la curva de presión. En la Figura 5 se muestra el modelo de estimación de presión con regresión lineal, y en la Figura 6 utilizando un modelo con regresión rígida con Kernel. Se observa que el modelo de regresión rígida es mejor.

Figura 5. Estimación de la presión con un modelo de regresión lineal

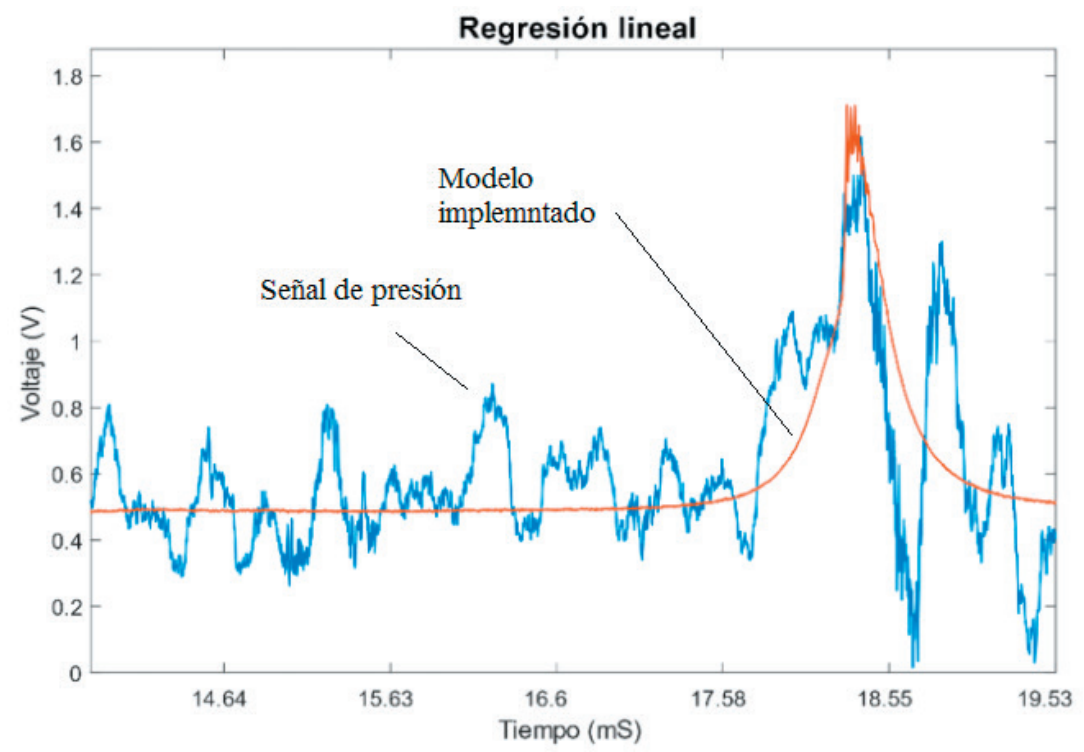


Figura 6. Estimación de la presión con un modelo de regresión rígida con kernel.

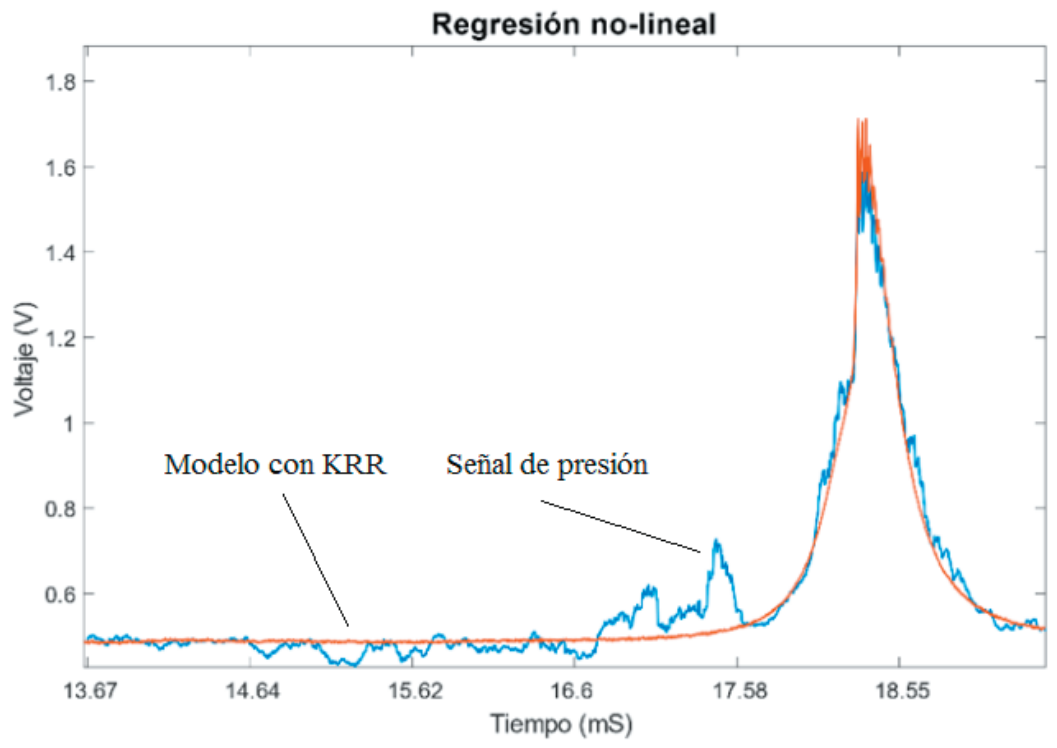

Las señales de vibración contienen mucha información del sistema que las genera, por lo cual son ampliamente utilizadas en para predecir fallos y realizar mantenimiento predictivo. En el anterior orden de ideas, se combinaron dichas señales con algoritmos de aprendizaje máquina para identificar diferentes estados del motor. Dichos algoritmos son representaciones de las metodologías de la Entropía De Permutación Multiescalar (MPE), Análisis de Componente Principales (PCA) y K Vecinos más Cercanos (KNN). Los resultados se pueden apreciar en la Figura 7. 
Figura 7. Resultados de clasificación del estado del motor mediante algoritmos de aprendizaje de máquina

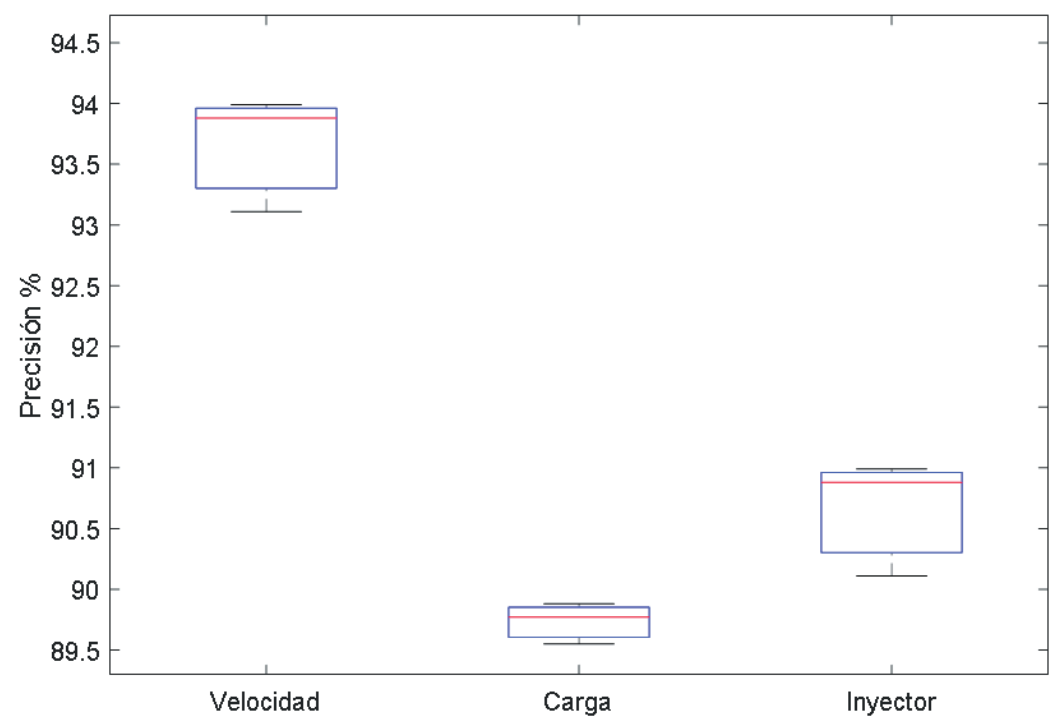

La MPE demuestra ser una metodología de caracterización altamente efectiva para encontrar información que permita separar clases. Los resultados confirman $93 \%$ para la identificación de la velocidad, $89 \%$ para la carga y $90 \%$ para el inyector.

Se realiza un análisis de exergía en el banco de pruebas, operando con diésel, etanol, y mezclas gasolina/etanol, y bajo diferentes condiciones de operación. Se realizaron pruebas operando el banco sin modificaciones con relación de compresión 17:1, y modificando para trabajar con mezclas gasolina/etanol, y etanol puro, con relación de compresión 9:1 y 12:1, operando a 1500, 2100, 2600 y $3200 \mathrm{~min}^{-1}$, [35], [36]. El análisis exergético permite identificar los puntos del proceso en el que se tienen mayores irreversibilidades. En la Figura 8 se muestra una recopilación de uno de los resultados obtenidos durante los ensayos. 
Figura 8. Tasa de destrucción de exergía en función de la velocidad de giro y de la relación de compresión

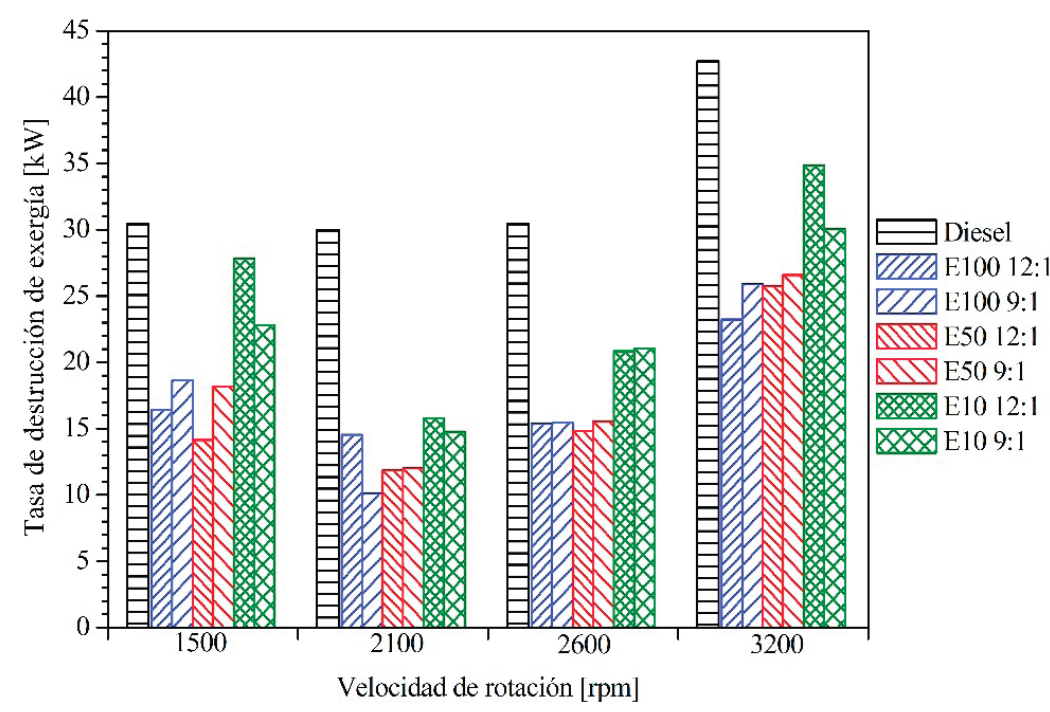

La Figura 8 muestra que el combustible diésel presenta mayores irreversibilidades en cada una de las velocidades de rotación, principalmente cuando se opera el motor a $3200 \mathrm{rpm}$, donde se obtiene un valor de 43,03 kW. Cuando se opera E50 en relación de compresión de 12:1, se muestran irreversibilidades más bajas en comparación con la relación de compresión 9:1, a diferencia de E100, que muestra irreversibilidades más bajas con una relación de 9:1. Claramente, la mayor parte del combustible suministrado a la cámara fue desaprovechado en la mayor velocidad de rotación del motor, debido a una transferencia de calor intensiva, mayor fricción mecánica y una reacción de combustión severa. Sin embargo, el efecto de la relación de compresión redujo los procesos irreversibles, como la tasa total de pérdida de exergía, la conversión termoquímica y las emisiones. 


\section{Productos del proyecto}

En el proyecto se obtuvieron productos de diferente índole. En la Tabla 4 se presentan la formación de personal científico en el proyecto, en la Tabla 5 se presentan los artículos obtenidos en el proyecto; se tienen pendiente de publicación varios de ellos. En la Tabla 6 se muestran la participación de trabajos para divulgación social de los resultados obtenidos. En la Tabla 7 se presentan los libros de capítulos y la vinculación de un joven investigador al proyecto.

Tabla 4. Productos del proyecto

\begin{tabular}{|c|c|c|}
\hline \multicolumn{3}{|c|}{ Estudiante de Maestría Vinculado } \\
\hline Estudiante & Programa & Titulo Trabajo de grado \\
\hline $\begin{array}{l}\text { Juan David Ramírez } \\
\text { Alzate }\end{array}$ & $\begin{array}{l}\text { Maestría en } \\
\text { Ingeniería } \\
\text { Mecánica }\end{array}$ & $\begin{array}{l}\text { Determinación experimental de las pérdidas } \\
\text { mecánicas en motores de combustión interna. }\end{array}$ \\
\hline $\begin{array}{l}\text { Juan Camilo Zapata } \\
\text { Mina }\end{array}$ & $\begin{array}{l}\text { Maestría en } \\
\text { Ingeniería } \\
\text { Mecánica }\end{array}$ & $\begin{array}{l}\text { Estudio comparativo del desempeño energético, } \\
\text { exergético y de emisiones en un motor monocilíndrico } \\
\text { operando con diésel y biodiesel de palma. }\end{array}$ \\
\hline $\begin{array}{l}\text { Andrés Felipe } \\
\text { Valencia }\end{array}$ & $\begin{array}{l}\text { Maestría en } \\
\text { Ingeniería } \\
\text { Eléctrica }\end{array}$ & $\begin{array}{l}\text { Desarrollo de una metodología para la estimación de } \\
\text { la composición de las emisiones producidas por un } \\
\text { motor diésel utilizando técnicas de regresión múltiple } \\
\text { basadas en aprendizaje automático. }\end{array}$ \\
\hline \multicolumn{3}{|c|}{ Trabajos de grado: Maestría } \\
\hline Estudiante & Programa & Titulo Trabajo de grado \\
\hline $\begin{array}{l}\text { Juan Camilo Mejía } \\
\text { Hernández }\end{array}$ & $\begin{array}{l}\text { Maestría en } \\
\text { Ingeniería } \\
\text { Eléctrica }\end{array}$ & $\begin{array}{l}\text { Desarrollo de una metodología para la caracterización } \\
\text { y clasificación de señales no estacionarias usando } \\
\text { mediciones de Entropía de Permutación Multiescalar }\end{array}$ \\
\hline \multicolumn{3}{|c|}{ Trabajos de grado: Pregrado } \\
\hline Estudiante & Programa & Titulo Trabajo de grado \\
\hline $\begin{array}{l}\text { Daniela Marín, Miguel } \\
\text { Toro Ladino }\end{array}$ & $\begin{array}{l}\text { Ingeniería } \\
\text { Mecánica }\end{array}$ & $\begin{array}{l}\text { Caracterización estadística de las curvas de presión, } \\
\text { potencia y par de un motor de combustión interna } \\
\text { monocilíndrico bajo diferentes regímenes de } \\
\text { operación. Junio de } 2018\end{array}$ \\
\hline $\begin{array}{l}\text { Camilo García } \\
\text { Jaramillo, }\end{array}$ & $\begin{array}{l}\text { Ingeniería } \\
\text { Mecánica }\end{array}$ & $\begin{array}{l}\text { Adquisición y preprocesamiento de señales de } \\
\text { vibración, acústicas y emisiones de gases en motores }\end{array}$ \\
\hline $\begin{array}{l}\text { Luis Miguel Sánchez } \\
\text { Ramírez }\end{array}$ & & $\begin{array}{l}\text { diésel. En ejecución: fecha tentativa de sustentación, } \\
\text { segundo semestre } 2018 \text {. }\end{array}$ \\
\hline
\end{tabular}


Tabla 5. Artículos publicados

\begin{tabular}{|l|}
\hline \multicolumn{1}{|c|}{ Artículos } \\
\hline - Juan David Ramírez, Juan Camilo Mejía Hernández, Héctor Fabio Quintero, Edison de Jesús \\
Henao Castañeda, Carlos Alberto Romero Piedrahita y Wilson Pérez Castro. Banco de \\
instrumentación para el acondicionamiento y adquisición de señales provenientes de un motor \\
de combustión interna. Revista Colombiana de Tecnologías de Avanzada. Volumen 3- \\
Número 32-1, pp 24-30 - 2018. ISSN: 1692-7257. \\
- Juan Camilo Zapata, Álvaro Hernán Restrepo, Carlos Alberto Romero, Héctor Fabio \\
Quintero. Exergy análisis of a diesel engine converted to spark ignition operating with diesel, \\
ethanol, and gasoline/diesel blends. Sustainable Energy Technologies and Assessments, 42, pp \\
100803, 9 páginas, 2020. \\
\hline
\end{tabular}

Tabla 6. Participación en Eventos Científicos o Jornadas de Comunicación Social del Conocimiento

\begin{tabular}{|c|}
\hline \\
\hline $\begin{array}{l}\text { Banco de instrumentación para la captura de señales provenientes de un motor de combustión } \\
\text { interna. IV Congreso AMDM 2018. Noviembre 7-9 de 2018, Manizales. }\end{array}$ \\
\hline $\begin{array}{l}\text { Banco de Instrumentación para el Acondicionamiento y Adquisición de Señales Provenientes de un } \\
\text { Motor de Combustión Interna. IX Congreso Latinoamericano de Ingeniería Mecánica. } 28 \text { al } 30 \text { de } \\
\text { noviembre, Pamplona. }\end{array}$ \\
\hline $\begin{array}{l}\text { XIV Congreso Iberoamericano De Ingeniería Mecánica, Cartagena, diciembre } 12 \text {-15 2019: i) } \\
\text { Detección de fallos en rodamientos a partir de vibraciones usando mediciones de entropía y algoritmos } \\
\text { de aprendizaje de máquina, ii) Análisis comparativo del desempeño de un motor mono-cilíndrico } \\
\text { operando con gasolina, etanol, diésel y mezclas etanol-gasolina, iii) Integración de un banco de } \\
\text { ensayos para la caracterización de pérdidas mecánicas en motores de combustión interna pequeños. }\end{array}$ \\
\hline $\begin{array}{l}\text { Análisis de las emisiones de mezclas etanol/gasolina en un motor mono-cilíndrico. VII Congreso } \\
\text { Colombiano y Conferencia Internacional Calidad de Aire y Salud Pública. Agosto 14-16 de 2019, } \\
\text { Barranquilla }\end{array}$ \\
\hline Comunicación social del conocimiento \\
\hline $\begin{array}{l}\text { III International Biofuels Conference In Colombia. } 28 \text { de febrero } 1 \text { de marzo 2019. Título de la } \\
\text { ponencia: Estudio comparativo sobre las emisiones de mezclas etanol y gasolina en un motor mono- } \\
\text { cilíndrico. Juan Camilo Zapata Mina. }\end{array}$ \\
\hline
\end{tabular}


Tabla 7. Otros resultados

Capítulos de libro de investigación

- Juan David Ramírez, Juan Camilo Mejía, Héctor Fabio Quintero, Edison Henao, Carlos Alberto Romero, Wilson Pérez. Banco de Instrumentación para el acondicionamiento. Publicado en Avances en Ingeniería Mecánica; Memorias de IX Congreso Latinoamericano de Ingeniería Mecánica, pp 487-494, ISBN 978-958-56670-8-2.

- Juan David Ramírez, Juan Camilo Mejía, Héctor Fabio Quintero, Edison Henao, Carlos Alberto Romero, Wilson Pérez. Desarrollo de un banco de instrumentación para la captura de señales provenientes de un motor de combustión interna diésel. Tecnologías Avanzadas de Mecatrónica, Diseño y Manufactura: IV Congreso Internacional AMDM 2018, pp 409-410. ISBN 978-9588730-94-3

- Juan Camilo Mejía Hernández, Federico Gutiérrez Madrid, Héctor Fabio Quintero, Julián David Echeverry, Edison de Jesús Henao Castañeda. Detección de fallos en rodamientos a partir vibraciones usando mediciones de entropía y algoritmos de aprendizaje de máquina. XIV CIBIM. ISBN: 978-958-52438-5-9. pp 83.

- Juan C. Zapata, Juan David Ramírez, Héctor Fabio Quintero, Edison Henao Castañeda y Carlos Alberto Romero. Análisis comparativo del desempeño de un motor mono-cilíndrico operando con gasolina, etanol, diésel y mezclas etanol-gasolina. XIV CIBIM. ISBN: 978-958-52438-5-9. pp 99 VINCULACIÓN DE JOVEN INVESTIGADOR COLCIENCIAS, CONVOCATORIA 2018 Federico Gutiérrez Madrid. Procesamiento de señales y aprendizaje de máquina aplicado al diseño y desarrollo de una metodología para el análisis de emisiones producidas por motores Diésel.

\section{Agradecimientos}

Los autores agradecen el apoyo de Colciencias mediante el proyecto Desarrollo de un sistema de monitoreo para el análisis energético y de condición de emisiones en motores de combustión interna diésel con base en técnicas no intrusivas, con código 1110776-57801, contrato FP44842-031-2018, con el cual fue posible la realización del trabajo. También agradecen a la Federación Nacional de Combustibles, por su apoyo durante la presentación y ejecución del proyecto

\section{Conclusiones}

Gracias al sistema de instrumentación implementado en el banco de pruebas, se crea una base de datos variando las condiciones de trabajo del MCI para ser utilizada como caso de estudio relacionando todas las características externas obtenidas. 
Por medio del análisis de las gráficas de PCA para opacidad, se evidenció como esta variable se encuentra fuertemente relacionada con la velocidad de giro y la carga, mientras que la presión de inyección no tiene un efecto importante en tanto que, independiente de esta presión, los efectos de la velocidad y la carga son predominantes.

Se determinó que a medida que se aumenta el porcentaje de etanol en la mezcla, las emisiones de $\mathrm{CO}$ y $\mathrm{NO}$ disminuyen hasta en $50 \%$ entre el E8 y E50 dependiendo de la carga.

Los resultados obtenidos permiten observar como la relación de compresión afecta el rendimiento de los motores, adicionalmente, se aprecia que el etanol no se aprovecha suficientemente al mantenerse la relación de compresión 9:1, dado que el consumo de combustible es elevado y las características de par y potencia son bajas comparadas con los otros combustibles.

\section{Bibliografía}

[1] C. A. Romero-Piedrahita y H. F. Quintero-Riaza, «Prediction of in-cylinder pressure, temperature and loads related to the crank slider mechanism of I.C. engines: A computational model,» SAE Technical Paper, pp. 2003-01-0728, 2003.

[2] D. Torres-Morimitsu, J. F. López-Lópezy H. F. Quintero-Riaza, «Caracterización de la presión en la cámara de combustión de un motor diésel monocilíndrico mediante el análisis de vibraciones mecánicas,» de El servicio a la sociedad a través de la investigación de la Universidad Tecnológica de Pereira, Pereira, Editorial Universidad Tecnológica de Pereira, 2019, pp. 128-150. 
[3] J. A. Grajales, H. F. Quintero, C. A. Romero, E. Henao, J. F. Lopez y D. Torres, «Combustion pressure estimation method of a spark ignited combustion engine based on vibration signal processing,» Journal of Vibroengineering, vol. 18, $\mathrm{n}^{\circ} 7$, pp. 4237-4247, 2016.

[4] J. A. Grajales y H. F. Quintero Riaza, «Análisis de falla y estimación de la curva de presión en un motor de combustión interna a gasólina a partir de señales no intrusivas,» de El servicio a la sociedad a través de la investigación de la Universidad Tecnológica de Pereira, Pereira, Editorial Universidad Tecnológica de Pereira, 2019, pp. 201-219.

[5] J. A. Grajales, H. F. Quintero, C. A. Romero y E. Henao, «Engine diagnosis based on vibration analysis using different fuel blends,» de Advances in Condition Monitoring of Machinery in Non-Stationary Operations. Applied Condition Monitoriong, Springer, 2018, pp. 267-274.

[6] J. A. Grajales, H. F. Quintero, C. A. Romero, E. Henao, J. F. López y O. Cardona, «Engine diagnosis based on vibration using different fuel blends,» Doagnostyka, vol. 18, $\mathrm{n}^{\circ} 4$, pp. 27-36, 2017.

[7] J. F. López-López y H. F. Quintero-Riaza, «Pronóstico de fallas en rodamientos de bolas con base en modelos matemáticos,» de El servicio a la sociedad a través de la investigación de la Universidad Tecnológica de Pereira, Pereira, Editorial Universidad Tecnológica de Pereira, 2019, pp. 220-238.

[8] J. Fernandez, A. Alvarez, H. Quintero, J. Echeverry y Á. Orozco, «Multilayer-Based HMM Training to Support Bearing Fault Diagnosis,» de Progress in Artificial Intelligence and Pattern Recognition. IWAIPR 2018, La Habana, Cuba, Springer, 2018, pp. 43-50. 
[9] J. F. López-López, J. J. Cuesta-Ramírez y H. F. Quintero-Riaza, "Gaussian processes in ball bearing prognostics,» Dyna, vol. 84, no 203, pp. 214-219, 2017.

[10] Z. Acossta, «Regulación de los servicios de transporte en Colombia y Comercio Internacional,» Archivos de Economía, vol. 265, pp. 33-43, 2004.

[11] Agency International Energy. Key World Energy Statistics 2016, «https://www.iea.org/publications/freepublications/ publication/KeyWorld2016.pdf,» 2016. [En línea].

[12] J. E. Mendoza, J. E. Gutiérrez y A. D. Pulido, «Tercera comunicación nacional del cambio climático,» Unidad de Planeación Minero Energética, vol. 3, pp. 1-33, 2016.

[13] UPME, «Consumo de ACPM en Colombia,» 2014.

[14] J. Yanowitz, R. McCormick y M. Graboski, «In use emissions from heavy duty diesel vehicles,» Environmental Science and Technology, vol. 34, pp. 23-44, 2000.

[15] A. Lloyd y T. Cackette, «Diesel engines environmental impact and control,» Journal of the Air and Waste Management Association, vol. 51, pp. 9-47, 2001.

[16] Programa de Naciones Unidas para el Medio Ambiente (UNEP), «Abriendo la puerta a los Vehículos limpios en países en desarrollo y en transición: El papel de los combustibles de bajo azufre,» Nairobi, Kenia, 2007.

[17] A. Alrabghi y A. Tiwari, «A novel approach for modelling complex maintenance systems using discrete event simulation,» Reliability Engineering \& System Safety, vol. 154, pp. 160-170, 2016. 
[18] C. Olmedo, «Diagnóstico de fallos de motores diesel mediante el análisis de la oscilación del bloque,» Universidad Politécnica de Valencia, Departamento de Máquinas y Motores Térmicos, Tésis Doctoral, pp 211, 2003.

[19] Estandar UNE, EN 13306:2011. Mantenimiento. Terminología del mantenimiento.

[20] Harbor Research Pervasive Internet Report, «Approaching zero downtime: The center for intelligent maintenance systems,» 2003.

[21] L. Deng y R. Zhao, "A vibration analysis method based on hybrid techniques and its application to rotating machinery,» Measurement, vol. 46, nº 9, pp. 3671-3682, 2013.

[22] D. White, «Helicopter usage monitoring using the MaxLife System,» de DSTO Workshop on Helicopter Health and Usage Monitoring System, Melbourne, Australia, 1999.

[23] S. Vulli, J. F. Dunne, R. Potenza, D. Richardson y P. King, «Time-frequency analysis of single-point engine-block vibration measurements for multiple excitation event identification,» Journal of Sound and Vibration, vol. 321, $\mathrm{n}^{\circ}$ 3, pp. 1129-1143, 2009.

[24] ISO 13372, «Condition monitoring and diagnostics of machines - Vocabulary,» 2012.

[25] A. Ruiz, «"Modelo para la implementación de mantenimiento predictivo en las facilidades de producción de petróleo,» Universidad Industrial de Santander. Facultad de Ingenierías Físico-Mecánicas. Monografía de grado. pp 130, 2012. 
[26] E. Labalen y G. Carrasco, Mantenimiento Predictivo: Curso sobre mantenimiento predictivo y sus distintas técnicas de aplicación, PREDICTIVE Ingenieros S.L. 2009, 2009, p. 14.

[27] D. Smith, Reliability, maintainability and risk: Practical methods for engineers, Sexta Edición ed., ButterworthHeinemann Ltd, 2001, p. 335.

[28] J. Porteiro, J. Collazo, D. Patiño y J. L. Miguez, «Diesel engine condition monitoring using a multi-net neural network system with nonintrusive sensors,» Applied Thermal Engineering, vol. 31, no 17-18, pp. 4097-4105, 2011.

[29] A. Faiz, C. S. Weaver y M. P. Walsh,, "Air pollution from motor vehicles: Standards and technologies for controlling emissions,» The World Bank, Washington D.C:, 1996.

[30] K. P. Murphy, Machine Learning: A probabilistic perspective, Londres: The MIT Press, 2012.

[31] Energy Institute, «Energy Essentials: A guide to energy management,» Londres, 2016.

[32] J. D. Ramirez, J. C. Mejía-Hernandez, H. F. QuinteroRiaza, E. Henao-Castañeda, C. A. Romero-Piedrahita y W. Pérez-Castro, «Banco de instrumentación para el acondicionamiento y adquisición de señales provenientes de un motor de combustión interna,» Revista Colombiana de Tecnología de Avanzada, vol. 3, n 32, pp. 24-30, 2018.

[33] J. D. Ramirez, J. C. Mejía-Hernández, H. F. Quintero-Riaza, E. Henao-Castañeda, C. A. Romero-Piedrahita y W. PérezCastro, «Banco de instrumentación para el acondicionamiento y adquisición de un motor de combustión interna,» de Avances en Ingeniería Mecánica: Memorias del IX Congreso LAtinoamericano de Ingeniería Mecánica, Pamplona, Editorial Universidad de Pamplona, 2018, pp. 487-494. 
[34] C. García-Jaramillo y L. M. Sánchez-Ramírez, «Adquisición y pre-procesamiento de señales de vibración, acústicas y emisiones de gases en un motor diésel monocilíndrico, Trabajo de grado, Ingeniería Mecánica, Unviersidad Tecnológica de Pereira,» Pereira, 2018.

[35] J. Zapata-Mina, A. Restrepo, C. Romero y H. Quintero, «Exergy analysis of a diesel engine converted to spark ignition operating with diesel, ethanol, and gasoline/ethanol blends,» Sustainable Energy Technologies and Assessments, vol. 42, p. 100803, 2020.

[36] J. C. Zapata-Mina, J. D. Ramírez, H. F. Quintero-Riaza, E. Henao-Castañeda y C. A. Romero, "Análisis comparativo del desempeño de un motor mono-cilíndrico operando con gasolina, etanol, diésel y mezclas etanol-gasolina,» de Memorias del XIV Congreso Iberoamericano de Ingeniería Mecánica, Cartagena, División de Publicaciones UIS, 2019, pp. 99-1,99-9.

[37] D. Batista, «Retificação térmica, termorretificação, tratamento térmico, tratamento com calor ou modificação térmica?,» Ciência florestal, vol. 29, n 1, p. 463, 2019.

[38] J. García, J. Romero y A. Pulido, «Determinación de la demanda real de gasolina corriente, gasolina extra, diésel oil y gnv en el territorio nacional, informe final,» Unidad de Planeación Minero Energética, vol. 20, pp. 50-83, 2014.

[39] A. Regalado, E. Paccha, O. Álvarez y T. Montaño, «Comportamiento de las concentraciones de pm10 en la ciudad de Loja - Ecuador y su relación con variables meteológicas,» Revista Ciencia e Investigación, vol. 5, n 1 , pp. 90-107, 2020. 


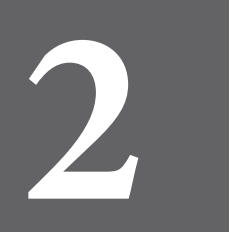

CAPÍTULO

DOS 



\title{
CARACTERIZACIÓN DE MATERIAL COMPUESTO PARA LA CONSTRUCCIÓN DE LA CARROCERÍA DE UN VEHÍCULO SUPERMILAGE
}

\section{CHARACTERIZATION OF COMPOSITE MATERIAL FOR THE CONTRUCTION OF THE BODYWORK OF A SUPERMILAGE VEHICLE}

\author{
Juan Manuel Manzano Martínez, \\ José Luis Tristancho Reyes. \\ Grupo de Investigación en Materiales Avanzados - GIMAV, \\ Facultad de Ingeniería Mecánica, \\ Universidad Tecnológica de Pereira. \\ josetris@utp.edu.co
}




\section{Resumen}

Durante el desarrollo de la presente investigación fueron caracterizados mediante ensayos mecánicos de resistencia a la tracción, dureza shore, resistencia al impacto, flexión y determinación de la densidad especifica los materiales compuestos de fibra de vidrio + resina poliéster + material rigidizantes "CORES"(estructura tipo sándwich) y de fibra de vidrio + resina poliéster que serán utilizados en la fabricación del molde y de la carrocería de un vehículo supermilage, para las categorías prototipo y etanol de la competencia Shell eco-marathon, respectivamente. De los resultados obtenidos se pudo evidenciar que el material compuesto "CORES", a usarse para la fabricación del molde, presentó valores de resistencia promedio al impacto de $97,13 \mathrm{~kJ} / \mathrm{m} 2$, dureza shore de 95 en escala A, esfuerzo máximo a tracción de 64,1 MPa, un esfuerzo máximo a flexión de 152,96 MPa y una densidad especifica de 9,9x10-4 g/cm3; mientras que para el material compuesto a ser usado para la fabricación de la carrocería se obtuvieron valores de resistencia promedio al impacto de $136,46 \mathrm{~kJ} / \mathrm{m} 2$, dureza shore de 90 en escala A, esfuerzo máximo a tracción de $86,6 \mathrm{MPa}$, un esfuerzo máximo a flexión de $205,76 \mathrm{MPa}$ y una densidad especifica de $1,2 \times 10-3 \mathrm{~g} / \mathrm{cm} 3$. Se pudo concluir que los dos materiales compuestos presentan buenas propiedades mecánicas para ser usados tanto en la fabricación del molde como en la carrocería del vehículo supermilage.

Palabras claves: Materiales Compuestos, Resina Poliéster, Fibra de Vidrio, Material Ridigizante, Ensayos Mecánicos.

\section{Abstract}

During the development of this research, the composite materials of fiberglass + polyester resin + ridigizer material "CORES" (sandwich structure) and fiberglass + polyester resin were characterized by mechanical tests of tensile strength, shore hardness, impact resistance, flexure and determination of specific 
density that will be used in the manufacture of the mold and the bodywork of a supermilage vehicle for the prototype and ethanol categories of the shell eco-marathon competition, respectively. From the results obtained, it was possible to show that the composite material "CORES", to be used for the manufacture of the mold, presented values of average resistance impact of 97,13 $\mathrm{kJ} / \mathrm{m} 2$, shore hardness of 95 on A scale, maximum tensile stress of $64,1 \mathrm{MPa}$, maximum bending stress of $152,96 \mathrm{MPa}$ and specific density of $9,9 \times 10-4 \mathrm{~g} / \mathrm{cm} 3$; while for the composite material to be used for the manufacture of the bodywork, average impact resistance values of $136,46 \mathrm{~kJ} / \mathrm{m} 2$, shore hardness of 90 on A scale, maximum tensile stress of $86,6 \mathrm{MPa}$, maximum bending stress of $205,76 \mathrm{MPa}$ and specific density of $1,2 \times 10-3 \mathrm{~g} / \mathrm{cm} 3$. It was concluded that the two composite materials have good mechanical properties tobe used both in the manufacture of the mold and in the bodywork of the supermilage vehicle.

Keywords: Composite Materials, Polyester Resin, Fiberglass, Ridigizer Materials, Mechanical Test.

\section{Introducción.}

La competencia Shell Eco Marathon Americas, es una de las competencias que impulsa a equipos conformados por estudiantes y docentes, de diferentes especialidades de todo el mundo, a diseñar, construir, ensayar y conducir vehículos energéticamente eficientes. Para logar esto deberá el equipo recorrer, en su monoplaza, la mayor distancia posible con la menor cantidad de combustible. Es así como el uso de materiales de que presenten alta resistencia mecánica y bajo peso que han de ser usados para la construcción del chasis y la carrocería del vehículo se hace necesario. En la búsqueda e innovación de nuevos materiales se involucra el uso de nuevas tecnologías que generen materiales compuestos que ofrezcan características como alta resistencia mecánica que permitan su uso como materiales estructurales y que, además comparados con otro tipo de material, presenten una reducción significativa en su peso. 
Durante el desarrollo de este proyecto de investigación se afianzaron conocimientos de ingeniería enfocados a la caracterización mecánica, mediante ensayos de resistencia a la tracción, dureza shore, resistencia al impacto, flexión y determinación de la densidad especifica los materiales compuestos de fibra de vidrio + resina poliéster + material ridigizante "CORES"(estructura tipo sándwich) y de fibra de vidrio + resina poliéster que serán utilizados en la fabricación del molde y de la carrocería de un vehículo supermilage, para las categorías prototipo y etanol de la competencia Shell eco-marathon, respectivamente.

\section{Planteamiento del problema y justificación.}

Para la competencia Shell Eco Marathon Americas es indispensable la construcción de un vehículo (monoplaza) tipo supermilage y esté deberá contar con sus respectivos parámetros de diseño y su análisis para lo cual se hace fundamental el conocimiento de los materiales con los que se han de fabricar, en este caso, la carrocería y su respectivo molde ya que en base a estos se obtendrán valores necesarios para complementar los respectivos cálculos para su fabricación. Debido a la naturaleza de la competencia, se ve factible el uso de materiales compuestos de fibra de vidrio + resina poliéster + material ridigizante "CORES" (estructura tipo sándwich) y de fibra de vidrio + resina poliéster para la fabricación del molde y de la carrocería del monoplaza respectivamente, siendo estos muy livianos permitiendo obtener la ligereza que el vehículo necesita, además, de presentar propiedades mecánicas que pueden llegar a favorecer el monoplaza en temas de seguridad.

Aunque los materiales compuestos, por lo general, presentan buena resistencia mecánica y bajo peso se hace necesaria la caracterización mecánica mediante ensayos de resistencia a la tracción, dureza shore, resistencia al impacto, flexión y determinación de la densidad especifica de los materiales 
seleccionados: fibra de vidrio + resina poliéster + material ridigizante "CORES" (estructura tipo sándwich) y de fibra de vidrio + resina poliéster, ya que al estar expuestos a ambientes agresivos pueden generarse en ellos degradaciones o rupturas irreparables.

\section{Objetivos.}

\subsection{Objetivo General.}

Caracterizar mediante ensayos mecánicos los materiales compuestos que serán utilizados en la fabricación del molde (fibra de vidrio + resina poliéster + material ridigizante "CORES") y la carrocería (fibra de vidrio + resina poliéster) de un vehículo supermilage.

\subsection{Objetivos Específicos.}

Evaluar el esfuerzo máximo a tracción al que pueden ser sometidos los materiales compuestos, fibra de vidrio + resina poliéster + material ridigizante "CORES" y fibra de vidrio + resina poliéster, utilizados en la fabricación del molde y la carrocería del vehículo supermilage en base a la norma técnica ASTM D3039.

Determinar la dureza Shore de los materiales compuestos, fibra de vidrio + resina poliéster + material ridigizante "CORES" y fibra de vidrio + resina poliéster, del molde y la carrocería de un vehículo supermilage bajo procedimientos establecidos en la norma técnica ASTM D2240.

Determinar la densidad específica de los materiales compuestos, fibra de vidrio + resina poliéster + material ridigizante "CORES" y fibra de vidrio + resina poliéster, utilizados para la fabricación del molde y la carrocería del vehículo supermilage en base a norma técnica ASTM D792. 
Evaluar la resistencia al impacto de los materiales compuestos del molde (fibra de vidrio + resina poliéster + material ridigizante "CORES") y la carrocería (fibra de vidrio + resina poliéster) bajo procedimiento establecido en la norma técnica ASTM D256.

Determinar los esfuerzos máximos a flexión de los materiales compuestos, fibra de vidrio + resina poliéster + material ridigizante "CORES" y fibra de vidrio + resina poliéster, que serán utilizados para la fabricación del molde y de la carrocería de un vehículo supermilage bajo parámetros de la norma técnica ASTM D790.

\section{Referente teórico.}

\subsection{Materiales Compuestos.}

Los materiales compuestos representan un paso gigante en el esfuerzo constante de la optimización de los materiales. La idea de obtención de un material compuesto no es nueva ni reciente, la naturaleza está llena de ejemplos en los que se evidencia la concepción de un material compuesto: la hoja de la palma de coco, por ejemplo, es esencialmente un voladizo que utiliza el concepto de refuerzo con fibras; la madera es un compuesto fibroso de fibras de celulosa en una matriz de lignina, en donde las fibras de celulosa presentan una alta resistencia a la tracción pero son muy flexibles (baja rigidez) mientras que la matriz de lignina se une a las fibras proporcionándole rigidez al compuesto; el sistema óseo, es otro ejemplo de un material compuesto natural, que soporta el peso de un ser vivo y consiste en el agrupamiento de fibras suaves y cortas de colágeno incrustadas en una matriz mineral denominada apatita. Existen muchos otros tipos de materiales compuestos que han sido usados en ingeniería durante mucho tiempo: el negó de carbón en caucho, el cemento portland o el asfalto mezclados con arena y fibras de vidrio mezcladas con resinas son algunos ejemplos de ellos. Se puede asegurar que a partir de 1960 se profundizó en el desarrollo y la investigación de los materiales compuestos debido a la creciente demanda de 
nuevos materiales más rígidos, más resistentes, pero más ligeros a ser usados en diferentes campos como el aeroespacial, el automotriz, la construcción, entre otros (Chawla, 2012).

La definición de material compuesto, a través del tiempo, ha sido sometida a diversas revisiones a fin de poder incorporar en ella nuevos productos y lograr mantener las diferencias con los ya existentes. En general se puede definir un material compuesto como la combinación o unión de dos o más materiales con interfaces de separación entre ellos para lograr la obtención de un nuevo material que presentará nuevas propiedades que no pueden ser alcanzadas por ninguno de los constituyentes actuando aisladamente (Paris, 2008).

\subsubsection{Clasificación de los materiales compuestos.}

La clasificación de los materiales compuestos puede estar basada en función de la matriz o en función de las fibras que lo componen.

4.1.1.1. Según el tipo de matriz: una adecuada selección de la matriz, del material compuesto, se hace en base a requerimientos químicos, térmicos, ambientales, costo, desempeño y manufactura. Es la matriz quien determina la temperatura de desempeño del material compuesto, así como los parámetros de manufactura a utilizar durante su procesamiento (Mazumdar, 2002).

Material Compuesto de Matriz Metálica (CMM): para este tipo de materiales, las matrices más utilizadas son los metales de baja densidad como el aluminio, el magnesio y el titanio que pueden ser reforzados con fibras o con partículas. Las matices metálicas presentan excelentes propiedades como: elevada resistencia, excelente conductividad térmica y eléctrica y alta resistencia a la elevada temperatura. Además, la matriz metálica cumple con las siguientes funciones: Proteger a las fibras o a las partículas del ambiente exterior, propiciar una adecuada unión de los elementos 
que constituyen el refuerzo evitando la transmisión de grietas a través del compuesto, repartir y transmitir las cargas de los elementos de refuerzo y deben presentar un buen comportamiento ante el ataque corrosivo. Los materiales compuestos de matriz metálica son usados principalmente en la industria aeronáutica y aeroespacial debido a que en estas áreas los materiales estarán sometidos a elevadas temperaturas y a desgaste abrasivo (da Costa, Velasco López , \& Torralba Castello, 2000)

Materiales compuestos de matriz cerámica (CMC): los materiales compuestos de matriz cerámica están formados por sólidos inorgánicos diferentes a los metales, pudiéndose encontrar los siguientes: vidrios o silicatos amorfos; cerámicas tradicionales como arcillas, cementos y vidrios de silicatos; nuevas cerámicas que son los más usados en la formación de materiales compuestos y están basados en compuestos de óxidos y carburos como la alúmina $(\mathrm{Al} 2 \mathrm{O} 3)$ y carburo de silicio $(\mathrm{SiC})$. Estos materiales compuestos presentan notables propiedades como alta resistencia a elevadas temperaturas, baja densidad y excelentes propiedades mecánicas. Su mayor desventaja es la fragilidad por lo que al combinarse con otros materiales para obtener un material compuesto es incrementar su tenacidad (Barry Carter \& Grant Norton, 2013)

Materiales compuestos de matriz polimérica (CMP): los materiales compuestos de matriz polimérica son materiales conformados por un polímero incorporado a una base de refuerzo que puede ser una fibra o un polvo. Son materiales que presentan buenas propiedades mecánicas como baja densidad, alta tenacidad y resistencia a la corrosión y a los agentes químicos convirtiéndose en un material apropiado para un extenso número de aplicaciones y que debido a sus propiedades física puede ser moldeado con absoluta libertad de forma mediante la aplicación de temperatura. Los materiales compuestos de matriz polimérica pueden clasificarse de la siguiente manera: a) Termoplásticos, materiales formados por moléculas unidas por enlaces débiles 
que al ser expuestos a ciertas temperaturas pueden ser fundidos y tomar diferentes formas, su composición se basa en derivados del petróleo, el carbono, el oxígeno y el hidrogeno, pueden ser usados en la fabricación de vidrios de seguridad, faros para automóviles, tuberías, pisos de vinilo, entre otros. b) Termoestables, aquellos materiales que poseen una estructura entrecruzada por lo que se convierten en resinas muy rígidas con baja elasticidad y alta fragilidad. Pueden ser usados en la fabricación de aislantes, empuñaduras para herramientas, bolas de billar, ruedas dentadas y algunos plásticos reforzados con fibra de vidrio. c) Elastómeros, son materiales que poseen cadenas con mucha libertad de movimiento molecular presentando alta elongación y gran flexibilidad ante cargas antes de fracturarse, pueden ser utilizados en la fabricación de suela de zapatos, prendas elásticas, neumáticos y llantas entre otros (Ravve, 2013).

4.1.1.2. Según el tipo de refuerzo: al diseñarse un material compuesto reforzado con fibras, deben tomarse en consideración muchos factores, incluyendo la longitud, el diámetro, la orientación, la cantidad y las propiedades de las mismas, así como las propiedades de la matriz y las propiedades de la unión entre ambas. Las fibras pueden ser cortas, largas e incluso continuas. Por lo general, sus dimensiones se caracterizan en función de la relación de forma $1 / \mathrm{d}$, donde 1 es la longitud de la fibra y d su diámetro. Las fibras más comunes presentan diámetros que varían desde $10 \mu \mathrm{m}$ hasta $150 \mu \mathrm{m}$. La resistencia del material compuesto mejora cuando la relación de forma es grande y se presenta un incremento en la resistencia y la rigidez del material compuesto al aumentar el contenido de fibras, se permite una fracción volumétrica máxima del 80\% (Askeland, 2016).

Las fibras se sitúan en capas o láminas superpuestas generando estructuras denominadas laminados, estas laminas nunca se superponen con la misma orientación de la fibra y es por esto que se debe analizar con detenimiento su secuencia de apilación y su orientación más adecuada ya que estos dos aspectos 
tienen más importancia que las características físicas de las fibras y de la matriz, pues son quienes dan las propiedades finales al laminado. Es así como al hacer uso de unas mismas fibras y matriz al variar la secuencia de apilado y orientación se pueden obtener comportamientos muy diferentes en resistencia, rigidez, tolerancia al daño, estabilidad dimensional o estabilidad de laminación (Islas Mascareñas, 2013).

Figura 1. Morfología de los compuestos reforzados con fibras: a) fibras continua unidireccionales b) fibras discontinuas orientadas al azar c) fibras ortogonales o tejidas d) fibras en capas múltiples.

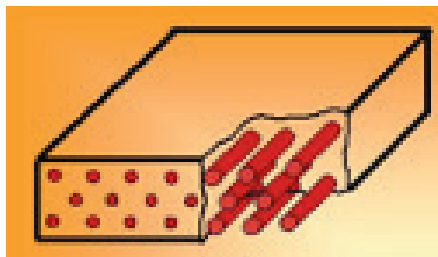

(a)

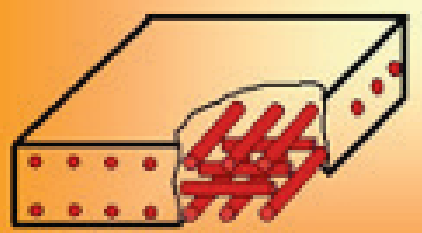

(c)

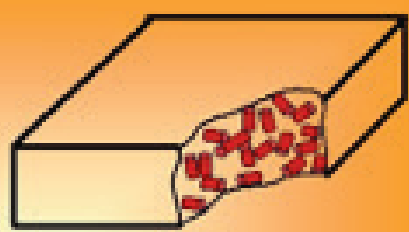

(b)

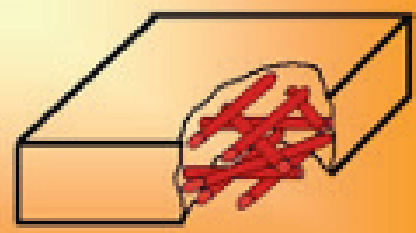

(d)

Fuente: (Universidad Politécnica de Valencia, 2020)

Fibras de carbono: el carbono es un material que genera fibras de alto desempeño utilizadas como refuerzo en los materiales de matriz polimérica. Las principales razones para utilizar las fibras de carbono como material de refuerzo son las siguientes: a) las fibras de carbono presentan el más alto módulo de tensión y resistencia específica de todos los materiales de refuerzo utilizados en la actualidad, b) mantienen su alto módulo de tensión y su alta resistencia aun cuando son expuestas a alta temperaturas, c) a temperatura ambiente, las fibras de carbono no se ven afectadas 
por la humedad y son capaces de resistir una gran variedad de solventes ácidos y bases. Las fibras de carbono son frágiles y muestran una recuperación elástica del $100 \%$ cuando se someten a esfuerzos inferiores a los de rotura. Lógicamente las propiedades transversales de las fibras son muy inferiores a las longitudinales. Uno de los mayores problemas de las fibras de carbono es la variabilidad de sus propiedades, condicionadas en gran medida por su efecto longitud ya que al aumentar ésta aumenta también la posibilidad de existencia de un defecto (Callister, Jr., 2009).

Fibras de vidrio: las fibras de vidrio o "fiberglass" son fibras de carácter isotrópico (su comportamiento depende de la dirección en que se les aplique el esfuerzo) a base de $\mathrm{SiO} 2$ y pueden tener algunas adiciones de +óxidos de calcio, boro, sodio, hierro y aluminio. Presentan diámetros entre 8 y $15 \mu \mathrm{m}$ y son usadas como material de refuerzo debido a: a) se obtienen fibras de alta resistencia desde su proceso de fundición, b) pueden ser fabricadas de manera económica mediante una amplia variedad de técnicas de manufactura, c) al ser una fibra relativamente fuerte y resistente al unirse con la matriz polimérica generan un compuesto de alta resistencia específica, d) al ser químicamente inertes permiten que el material compuesto sea usado en ambientes altamente corrosivos (Callister, Jr., 2009).

Fibras de aramida: las fibras de aramida son materiales de alta resistencia y alto modulo que son convenientes por su excelente relación resistencia - peso, que es superior a la de los metales. Desde el punto de vista de la composición química, este grupo de materiales son conocidos como tereftalamida de poliparafelino. Existen varios tipos de materiales de aramida entre ellos el kevlar y el Nomex. Mecánicamente estas fibras tienen resistencia a la tracción y módulo a la tracción longitudinal mucho más elevados que los de otros materiales fibrosos poliméricos; sin embargo, son relativamente débiles a compresión. Además, este material es conocido por su tenacidad, alta resistencia al impacto y su resistencia a la fluencia y a la rotura por fatiga. Algunas 
aplicaciones típicas de los materiales compuestos reforzados con fibras de aramida son los artículos de balística (chalecos a prueba de balas y blindajes), artículos deportivos, cuerdas, pastillas de frenos, entre otros (Callister, Jr., 2009).

\subsubsection{Materiales compuestos estructurales.}

Un material compuesto estructural está conformado por materiales homogéneos como compuestos, cuyas propiedades dependen no solamente de las propiedades de los materiales constituyentes sino también del diseño geométrico de los diferentes elementos estructurales. Los materiales compuestos estructurales más comunes son los compuestos laminares y los paneles tipo sándwich (Callister, Jr., 2009).

4.1.2.1. Materiales compuestos laminares: un material compuesto laminar está compuesto de hojas bidimensionales o paneles que tienen una dirección dominante de elevada resistencia. Las capas se apilan y luego se pegan entre sí de modo que la orientación de la dirección de elevada resistencia varía en cada una de las capas sucesivas (figura 2). De este modo un material compuesto laminar tiene una resistencia relativamente alta en varias direcciones en el plano bidimensional; sin embargo, la resistencia en cualquier dirección dada es, por supuesto, menor de lo que sería si todas las fibras estuvieran orientadas en esa misma dirección.

Figura 2. Esquema de un material compuesto laminado hibrido que contiene carbono y fibras de vidrio.

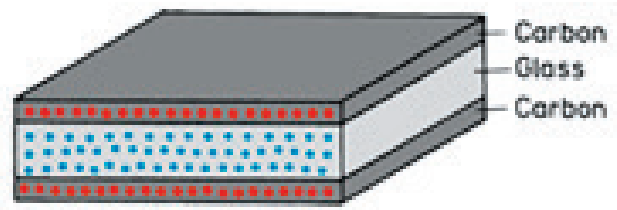

Fuente: (Chawla, 2012) 
4.1.2.2. Paneles Sándwich: los paneles tipo sándwich, se diseñan como vigas o paneles ligeros que tiene una rigidez y una resistencia relativamente altas. Un panel tipo sándwich consta de dos hojas exteriores resistentes separadas por un adhesivo adherido a un núcleo más grueso (figura 3). Las hojas exteriores están fabricadas de un material relativamente fuerte y rígido que imparte resistencia y rigidez a la estructura y deben ser suficientemente gruesas para resistir los esfuerzos de tracción y compresión que resultan de la carga. El material del núcleo es ligero y normalmente presentan módulos de elasticidad bajos, pueden estar ubicados en tres categorías: espumas poliméricas rígidas, maderas y panales estructuralmente el núcleo tiene varias funciones como proporcionar un soporte continúo para las caras, debe poseer suficiente resistencia a la cizalladura para resistir esfuerzos transversales y también debe ser suficientemente grueso para proporcionar una alta rigidez a la cizalladura (para resistir la deformación del panel). Cabe anotar que los esfuerzos de tracción y de compresión en el núcleo son muchos más bajos que en las caras.

Figura 3. Diagrama esquemático de la fabricación de panel tipo sándwich con núcleo en panal.
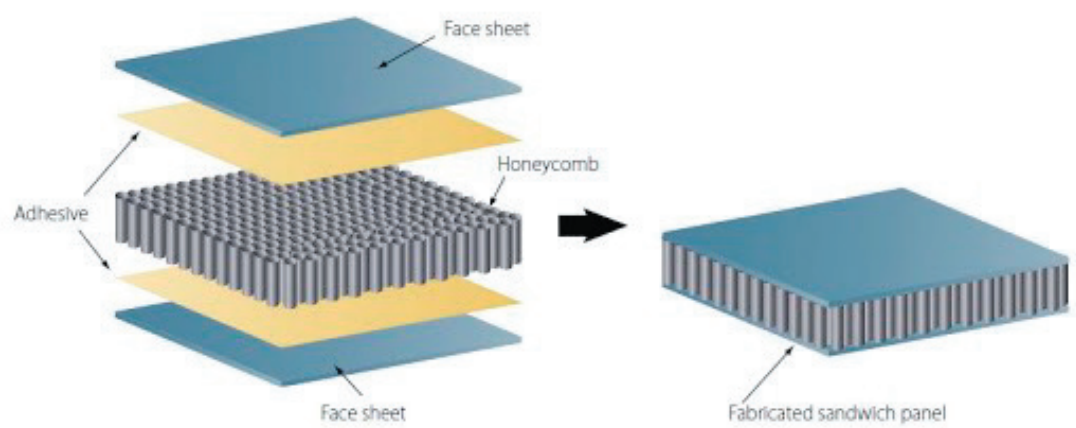

Fuente: (Callister, Jr., 2009) 
Las estructuras tipo sándwich pueden ser formadas a partir del uso de materiales ridigizante conocidos como "CORES" logrando obtenerse excelentes propiedades cumpliendo con estos requisitos:

Siempre deben llevar laminados de fibra de vidrio o fibras de carbono con resina, ubicados en cada uno de los lados del rigidizante, para obtener alta resistencia mecánica a tracción y a compresión.

El material del cual este fabricado el rigidizante debe tener baja densidad y alto volumen que permita incrementar fácilmente el espesor sin aumentar significativamente el peso y que permita transmitir los esfuerzos mecánicos a los laminados de fibra exteriores.

Debe existir una perfecta compatibilidad entre el material del rigidizante ya las resinas de uso común, poliéster, vinilester o epóxica. Esto garantizará la completa adhesión entre los laminados y el rigidizante lo que permitirá un buen acople mecánico que producirá propiedades homogéneas consistentes y predecibles.

Figura 4. Materiales rigidizantes de mayor uso

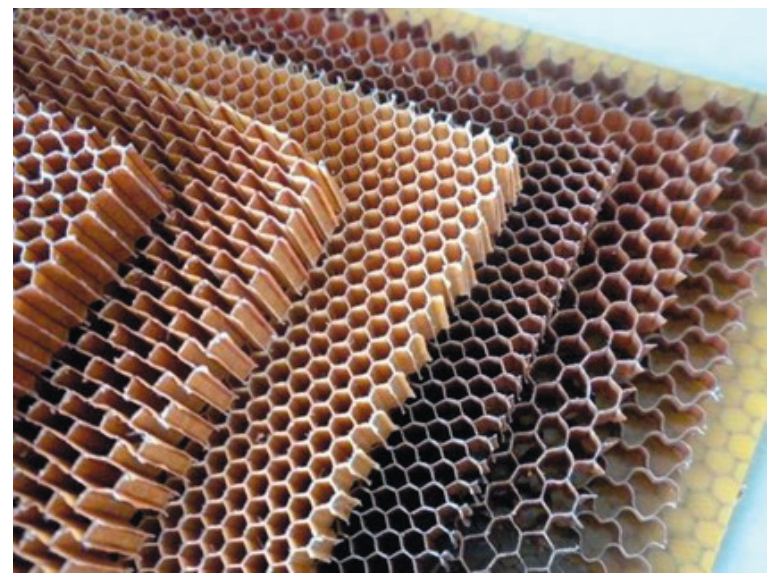

Fuente: (FIBRAPLUS, 2017) 


\section{Metodología.}

La metodología experimental empleada durante el desarrollo de esta investigación fue encaminada a caracterizar mediante ensayos mecánicos de resistencia a la tracción, dureza shore, resistencia al impacto, flexión y determinación de la densidad especifica los materiales compuestos de fibra de vidrio + resina poliéster + material ridigizante "CORES"(estructura tipo sándwich) y de fibra de vidrio + resina poliéster que serán utilizados en la fabricación del molde y de la carrocería de un vehículo supermilage, para las categorías prototipo y etanol de la competencia Shell eco-marathon, respectivamente. Una breve descripción de cada etapa se hace a continuación:

\subsection{Revisión Bibliográfica.}

Primera etapa de la investigación en donde se consultaron libros, revistas indexadas y no indexadas, sitio web y normas técnicas que permitió profundizar en los conocimientos de los materiales compuestos y la normatividad vigente para la realización de ensayos mecánicos.

\subsection{Adquisición de Material de Trabajo.}

Se obtuvieron dos materiales compuestos en placas de $50 \mathrm{~cm}$ x $50 \mathrm{~cm}$, el primero de ellos conformado por fibra de vidrio + resina poliéster de coloración blanca con espesor de $2,8 \mathrm{~mm}$ (figura 4) que será usado en la fabricación de la carrocería el vehículo supermilage y el segundo conformado por fibra de vidrio + resina poliéster + material ridigizante "CORES"(estructura tipo sándwich) de coloración roja con espesor de $8,6 \mathrm{~mm}$ (figura 5) que será usado en la fabricación del molde de la carrocería del vehículo. 
Figura 4. Material compuesto conformado por fibra de vidrio + resina poliéster
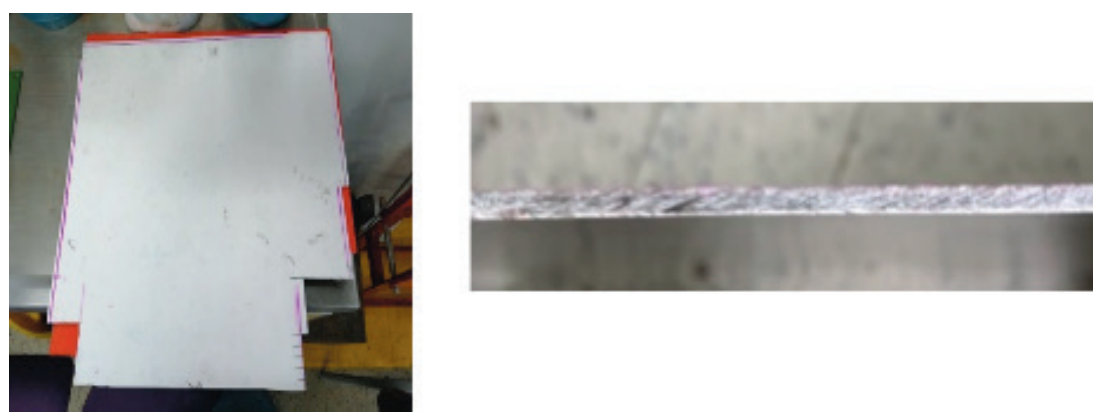

Fuente: los autores.

Figura 5. Material compuesto conformado por fibra de vidrio + resina poliéster + material ridigizante "CORES" (estructura tipo sándwich)
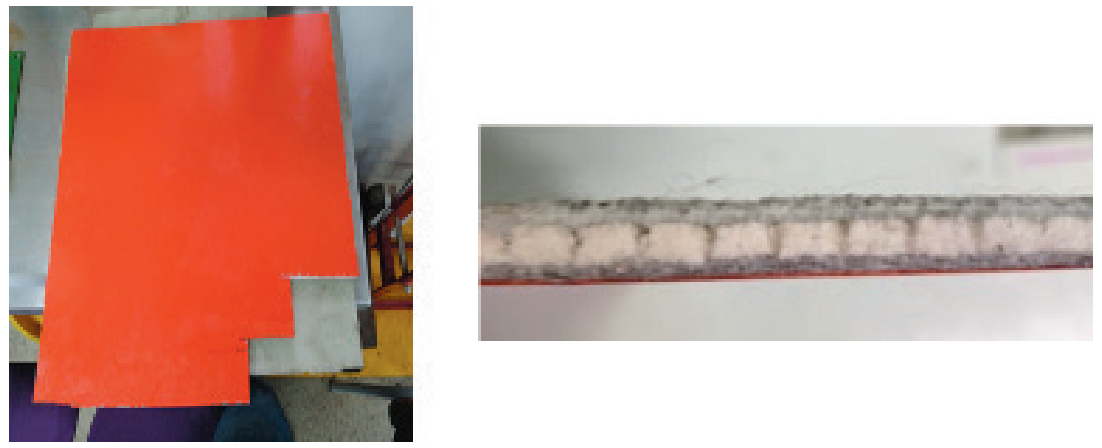

Fuente: los autores.

\subsection{Realización de ensayos mecánicos.}

Teniendo en cuenta las especificaciones dadas en la normatividad vigente para la realización de los ensayos mecánicos se diseñaron y maquinaron las probetas a ensayar de la siguiente manera: 


\subsubsection{Resistencia a la Flexión.}

Es la norma técnica ASTM D790 (American Society for Testing and Materials - ASTM International, 20017) la que define los equipos y sus parámetros de operación, además, de la geometría de las probetas a ensayar (figura 6) para obtener valores de resistencia a flexión.

Figura 6. Probetas para ensayo de flexión a) material compuesto para fabricación del molde y b) material compuesto para la fabricación de la carrocería
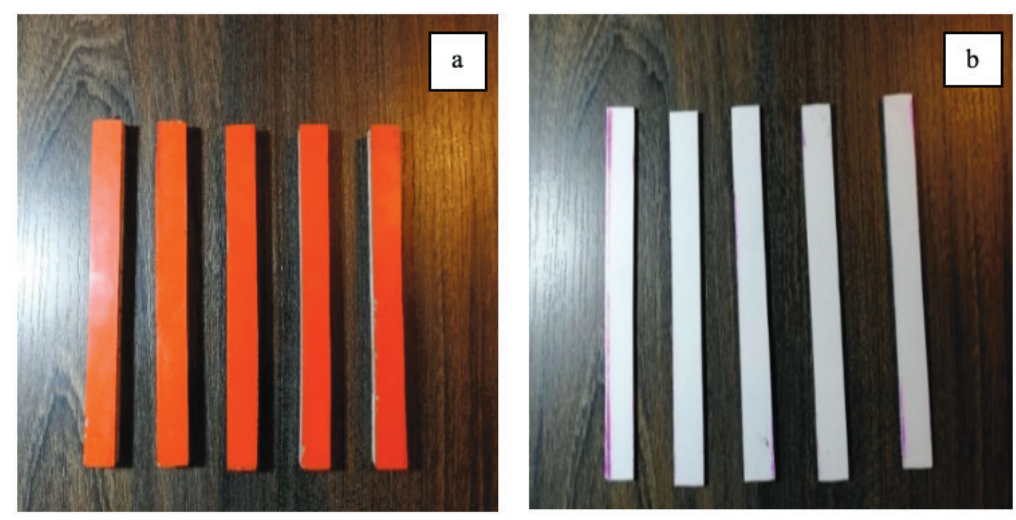

Fuente: los autores 
En la figura 7 muestra el montaje de la prueba de flexión.

Figura 7. Montaje del ensayo de flexión a) material compuesto para fabricación del molde y b) material compuesto para la fabricación de la carrocería
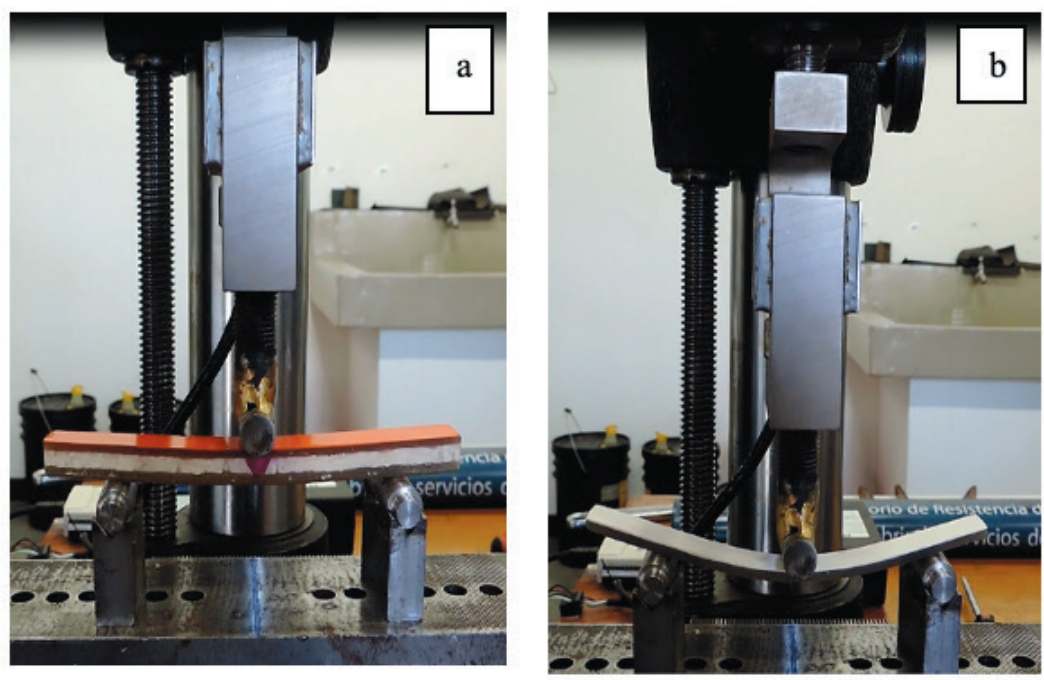

Fuente: los autores

\subsubsection{Resistencia a la Tracción.}

Bajo parámetros establecido en la norma técnica ASTM D3039/D3039M (American Society for Testing and Materials ASTM International, 2017) se manufacturaron las probetas que se sometieron a ensayo para obtener su resistencia a la tracción (figura 8). 
Figura 8. Probetas para ensayo de tracción a) material compuesto para fabricación del molde y b) material compuesto para la fabricación de la carrocería.
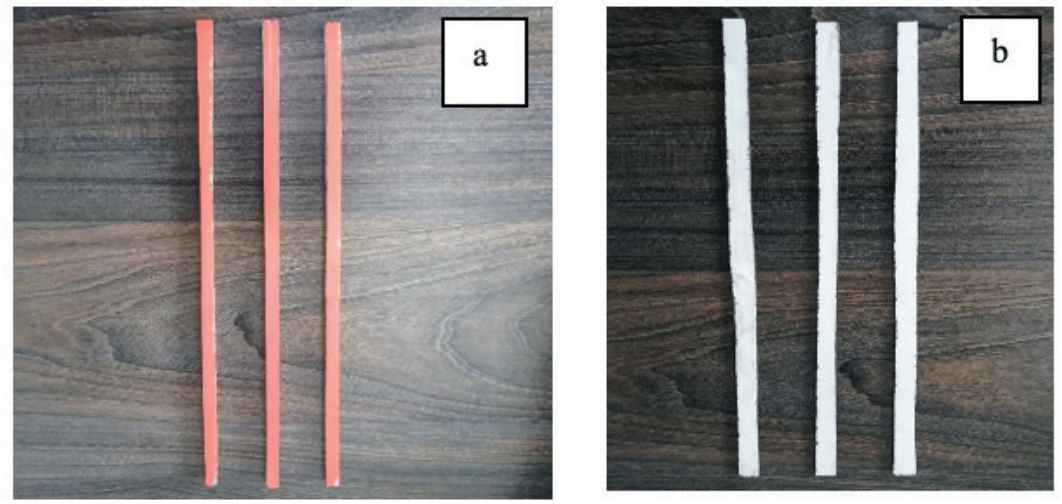

Fuente: los autores

En la figura 9, se muestra el montaje de las probetas en la máquina de ensayos universal para la realización del ensayo de tracción.

Figura 9. Montaje del ensayo de tracción a) material compuesto para fabricación del molde y b) material compuesto para la fabricación de la carrocería.
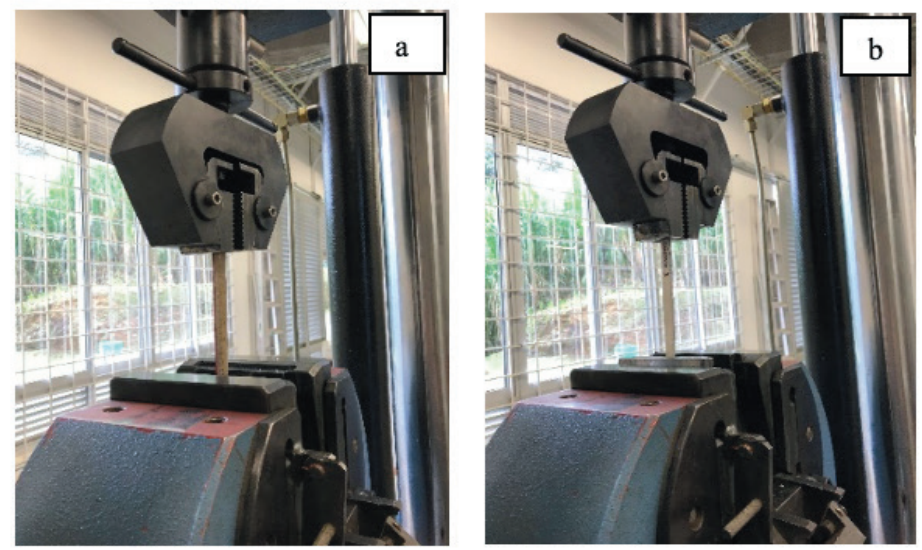

Fuente: los autores 


\subsubsection{Resistencia al impacto.}

En la norma técnica ASTM D256 (American Society for Test and Materials - ASTM International, 2018), se establecen los parámetros de ensayo para determinar la resistencia al impacto y la geometría de las probetas a ensayar de los materiales compuestos a ser usados en la fabricación del molde y de la carrocería de un vehículo supermilage (figura 10).

Figura 10. Probetas para ensayo de impacto a) material compuesto para fabricación del molde y b) material compuesto para la fabricación de la carrocería.
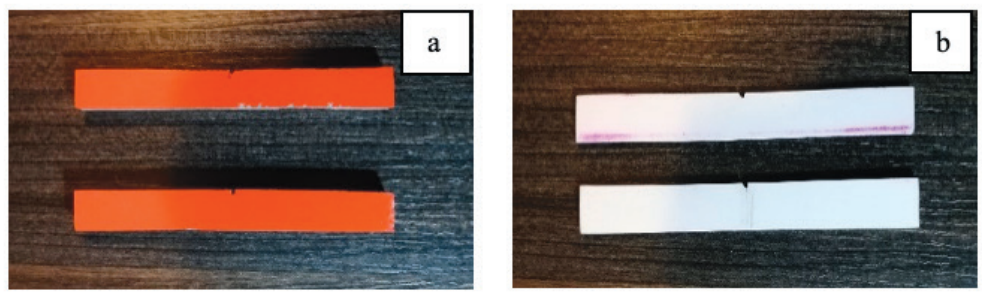

Fuente: los autores

En la figura 11, se aprecia el montaje de la prueba de impacto para los materiales compuestos estudiados.

Figura 11. Montaje para ensayo de impacto.

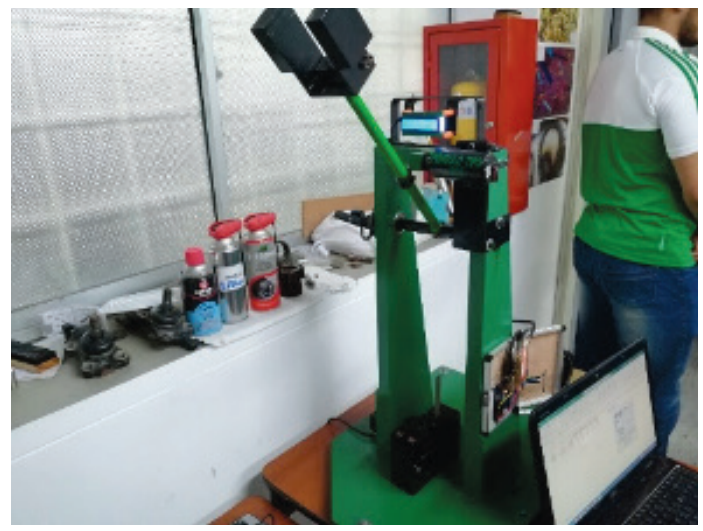

Fuente: los autores. 


\subsubsection{Dureza Shore.}

Los parámetros establecidos en la norma técnica ASTM D2240 (American Society for Testing and Materials - ASTM Intenational, 2015) permiten determinar los valores correspondientes a dureza shore escala A para los materiales compuestos a ser usados en la construcción del molde y la carrocería del vehículo supermilage. La dureza puede ser tomada en cualquier parte de la superficie de las láminas de los materiales compuestos. En la figura 12 se muestra la imagen del equipo utilizado.

Figura 12. Durómetro Shore.

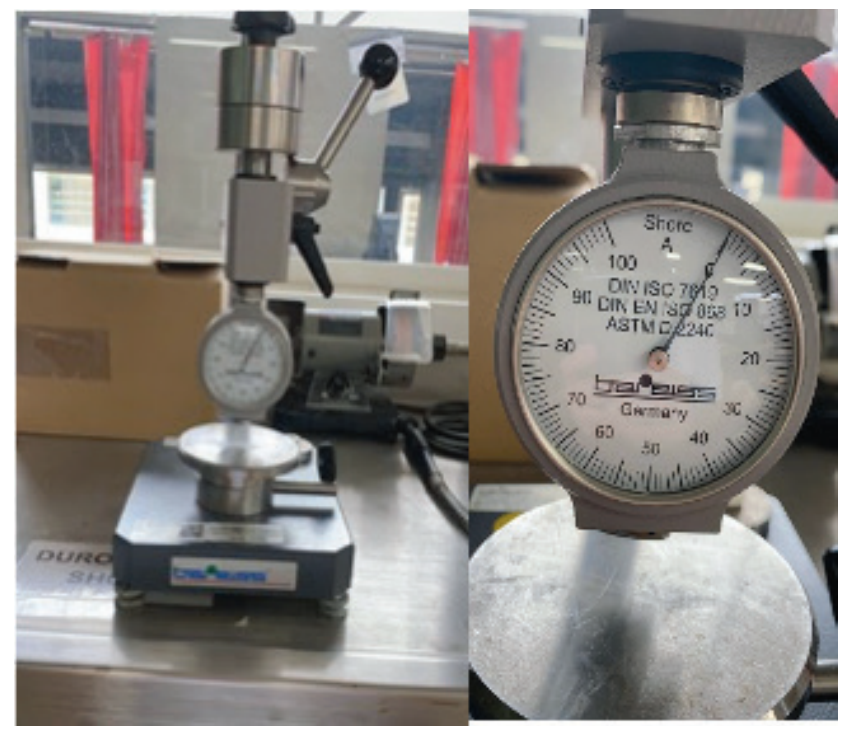

Fuente: los autores.

\subsubsection{Densidad específica.}

Ensayo realizado bajo procedimientos establecidos en la norma técnica ASTM D792 (American Society for Testing and Materials - ASTM International, 2020) que permiten determinar la densidad específica de cada uno de los materiales. Para esto se 
procedió a cortar probetas de $6.5 \mathrm{~cm} \times 7 \mathrm{~cm}$, fueron pesadas, en balanza analítica, y su volumen fue determinado (figura 13).

Figura 13. Probetas parara ensayo de densidad específica a) material compuesto para fabricación del molde y b) material compuesto para la fabricación de la carrocería.
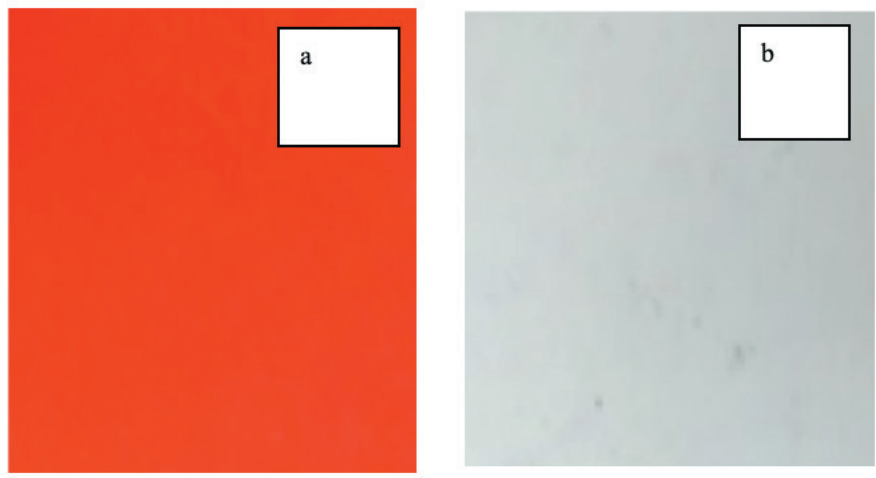

Fuente: los autores

\section{Resultados.}

\subsection{Ensayo de resistencia a la flexión.}

Para este ensayo se obtiene el resultado en el momento en que la probeta a ensayar, al estar soportada sobre dos apoyos, presenta rotura ante la aplicación de una carga puntual.

En la figura 14 se muestra la gráfica fuerza vs tiempo para el material compuesto a ser utilizado en la fabricación del molde. Se puede deducir de ella que este material soporta una fuerza máxima de 124,2073 Kg-f (equivalente a 1218,473 N) antes de presentarse su rotura. El momento máximo que experimenta la muestra en el momento de alcanzar la fuerza máxima de rotura equivale a 24674,087 N.mm y un esfuerzo máximo a flexión de $152,958 \mathrm{MPa}$. 
Figura 14. Gráfica fuerza vs tiempo para el material compuesto que será utilizado en la fabricación del molde.

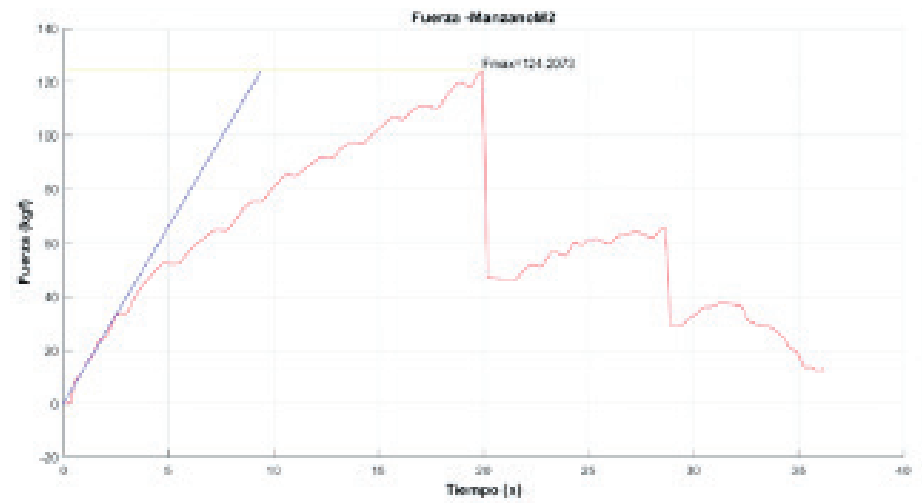

La figura 15, se muestra la gráfica fuerza vs tiempo para el material compuesto a ser utilizado en la fabricación de la carrocería. Se puede deducir de ella que este material soporta una fuerza máxima de 18,4341 Kg-f (equivalente a 180,838 N) antes de presentarse su rotura. El momento máximo que experimenta la muestra en el momento de alcanzar la fuerza máxima de rotura equivale a 3661,977 N.mm y un esfuerzo máximo a flexión de 205,762 MPa.

Figura 15. Gráfica fuerza vs tiempo para el material compuesto que será utilizado en la fabricación de la carrocería.

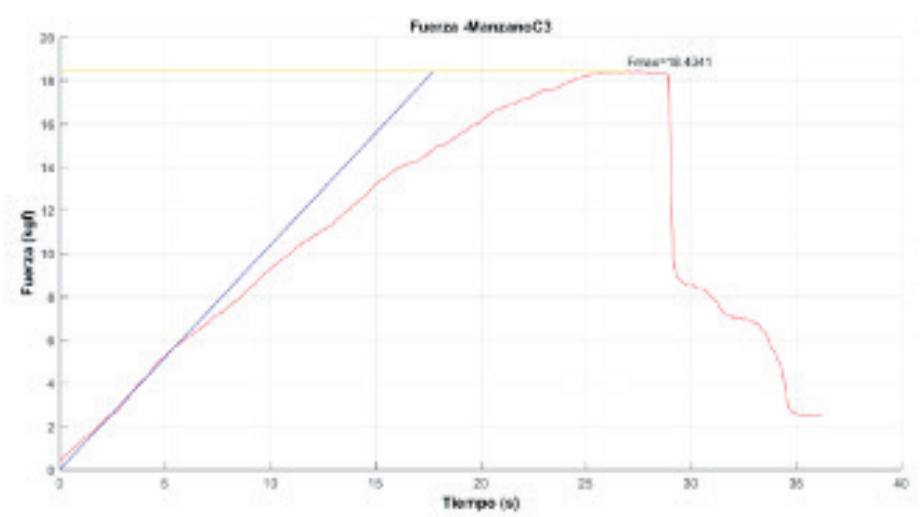




\subsection{Resistencia a la Tracción.}

En la figura 16 se muestra la curva esfuerzo vs deformación para el material compuesto que será usado para la fabricación del molde. De la gráfica se logró determinar el valor de la fuerza máxima soportada por el material (fuerza total) obteniéndose un valor de $4642,9 \mathrm{~N}$, al alcanzar este valor el alargamiento total o deformación que presentó el espécimen fue de un valor de $6,3176 \%$ de su longitud. La resistencia a la rotura o esfuerzo máximo presento un valor de $64,1 \mathrm{MPa}$ y fue alcanzado en un tiempo aproximado de 4,16 $\min (249,6 \mathrm{~s})$. El límite elástico obtenido fue de 55,4 MPa, después de sobrepasar este esfuerzo, el material inicio su deformación permanente hasta fallar por rotura obteniéndose un módulo de elasticidad de 4,6 MPa.

Figura 16. Gráfica esfuerzo vs deformación para el material compuesto que será utilizado en la fabricación del molde.

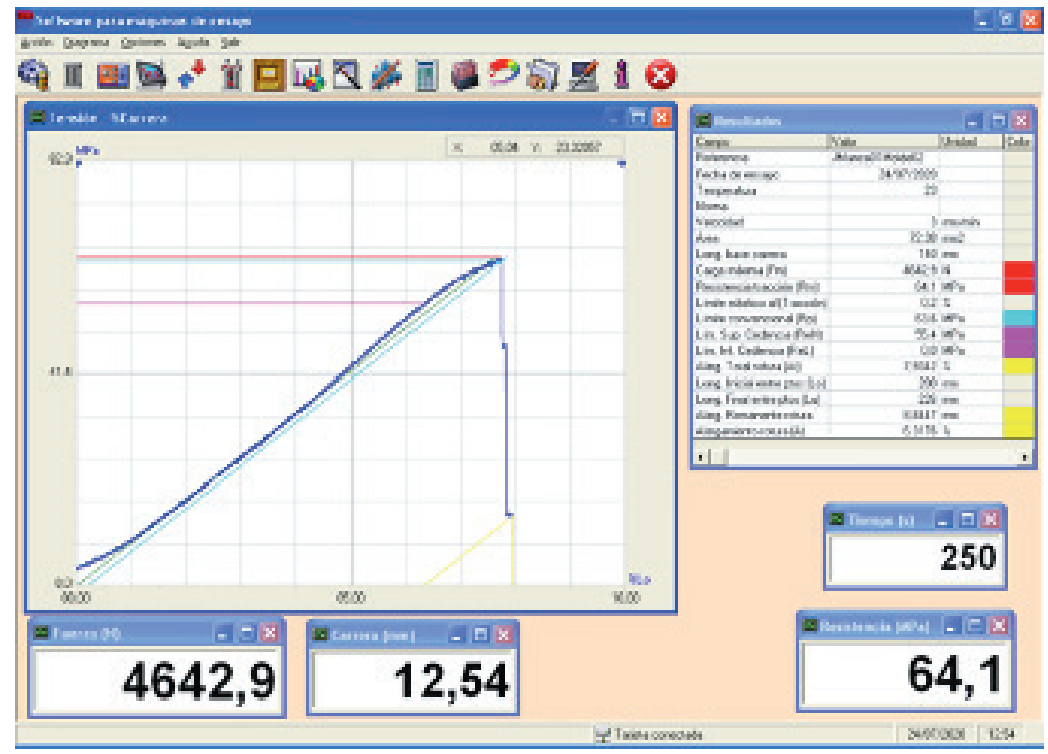

En la figura 17 se muestra la curva esfuerzo vs deformación para el material compuesto que será usado para la fabricación de la carrocería del vehículo supermilage. De la gráfica se determinó 
el valor de la fuerza máxima soportada por el material (fuerza total) obteniéndose un valor de $2792,0 \mathrm{~N}$, al alcanzar este valor el alargamiento total o deformación que presentó el espécimen fue de un valor de 4,784\% de su longitud. La resistencia a la rotura o esfuerzo máximo presento un valor de $86,6 \mathrm{MPa}$ y fue alcanzado en un tiempo aproximado de 2,28 min (136,8 s). El límite elástico obtenido fue de $81,3 \mathrm{MPa}$, después de sobrepasar este esfuerzo, el material inicio su deformación permanente hasta fallar por rotura obteniéndose un módulo de elasticidad de 6,5 MPa.

Figura 17. Gráfica esfuerzo vs deformación para el material compuesto que será utilizado en la fabricación de la carrocería.

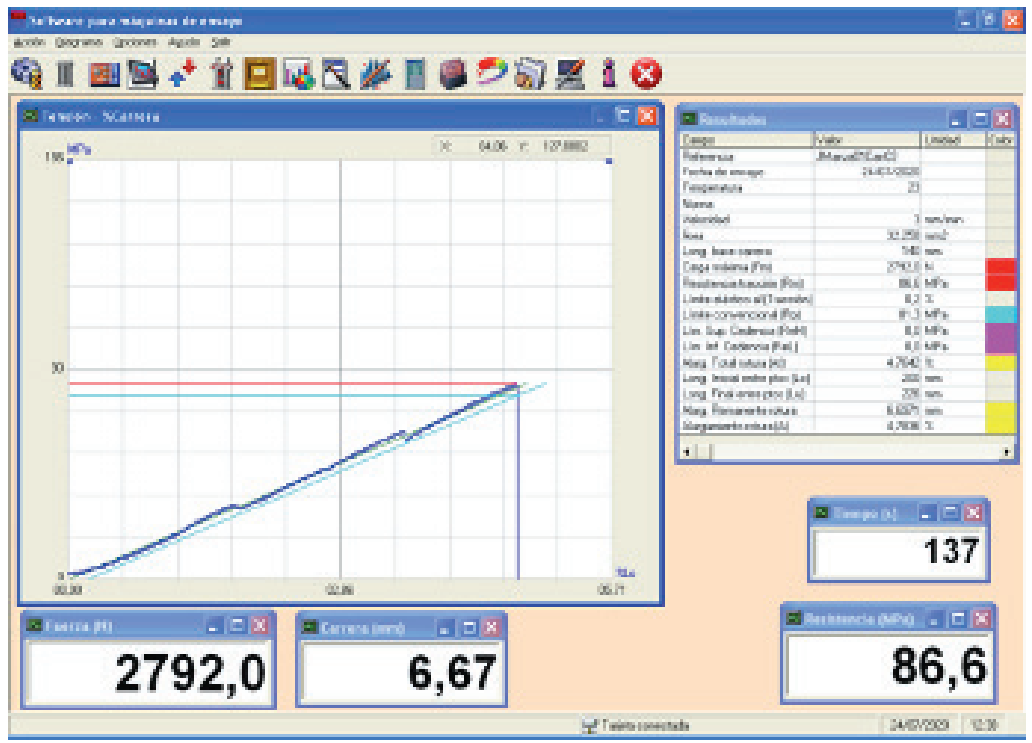

\subsection{Resistencia al impacto.}

En la figura 18, se muestra el resultado correspondiente a la energía absorbida por el material que se ha de utilizar para la fabricación del molde, se puede deducir que el material compuesto esta en capacidad de absorber aproximadamente el 95\% de la energía de impacto que el péndulo genera al caer sobre él, la energía generada por el péndulo fue de $10 \mathrm{~J}$. 
Figura 18. Gráfica de energía total absorbida para el material compuesto que será utilizado en la fabricación del molde.

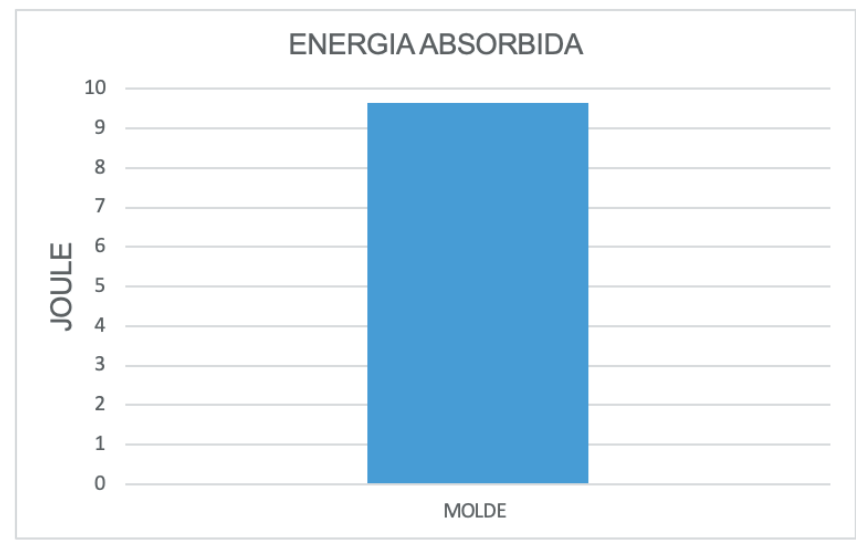

Los resultados correspondientes a la tenacidad de impacto mostrada por el material del molde se presentan en la figura 19, reportando un valor de resistencia al impacto de $97,1322 \mathrm{~kJ} / \mathrm{m} 2$.

Figura 19. Gráfica de resistencia al impacto para el material compuesto que será utilizado en la fabricación del molde.

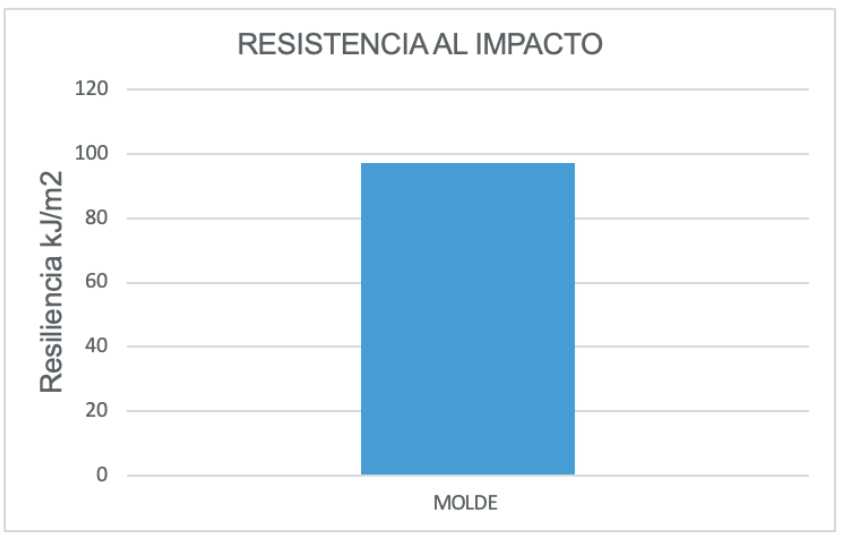

La figura 20, muestra el resultado correspondiente a la energía absorbida por el material compuesto ha ser utilizado para la fabricación de la carrocería del vehículo supermilage. Este compuesto logra absorber aproximadamente un 45\% de la energía 
de impacto proporcionada por el péndulo, se puede evidenciar que este tipo de material presenta alta fragilidad en el momento de resistir un impacto de mayor magnitud.

Figura 20. Gráfica de energía total absorbida para el material compuesto que será utilizado en la fabricación de la carrocería.

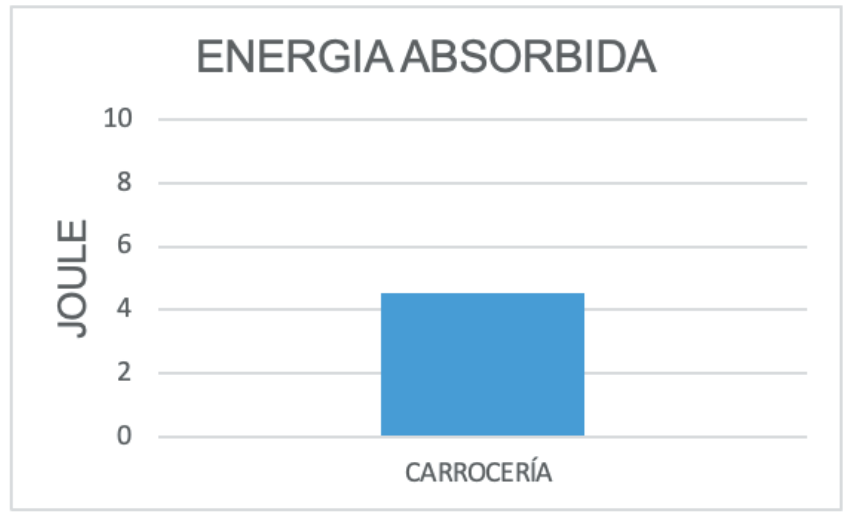

El resultado correspondiente a la tenacidad de impacto que presenta el material compuesto que ha de ser usado para la fabricación de la carrocería se presenta en la figura 21, se obtiene un valor de resistencia al impacto de 136,465 kJ/m2.

Figura 21. Gráfica de resistencia al impacto para el material compuesto que será utilizado en la fabricación de la carrocería.

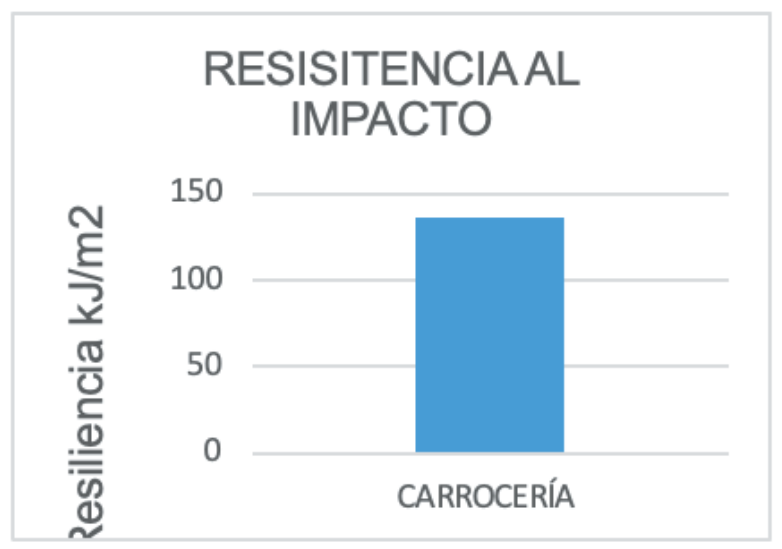




\subsection{Dureza Shore.}

Los resultados arrojados por el ensayo de dureza shore escala A, para los materiales compuestos que han de ser usados para la fabricación del molde y de la carrocería del vehículo supermilage, son mostrados en las tablas 1 y 2

Tabla 1. Resultados de dureza shore A para el material del molde.

\begin{tabular}{|l|l|}
\hline $\begin{array}{c}\text { DUREZA SHORE A - MATERIAL COMPUESTO PARA } \\
\text { EL MOLDE. }\end{array}$ \\
\hline TOMA. & DUREZA SHORE A. \\
\hline 1 & 94 \\
\hline 2 & 93 \\
\hline 3 & 94 \\
\hline 4 & 97 \\
\hline 5 & 97 \\
\hline PROMEDIO & $\mathbf{9 5}$ \\
\hline
\end{tabular}

Al obtener el promedio de las cinco (5) tomas de dureza realizadas, sobre el material que se usará para la fabricación del molde, se obtiene un valor promedio de 95 en escala shore A, este valor promedio de dureza muestra que este material compuesto presenta buenas propiedades de dureza en la escala seleccionada.

Tabla 2. Resultados de dureza shore A para el material de la carrocería.

\begin{tabular}{|l|l|}
\hline $\begin{array}{c}\text { DUREZA SHORE A - MATERIAL COMPUESTO PARA } \\
\text { EL MOLDE. }\end{array}$ \\
\hline TOMA. & DUREZA SHORE A. \\
\hline 1 & 92 \\
\hline 2 & 89 \\
\hline 3 & 86 \\
\hline 4 & 90 \\
\hline 5 & 88 \\
\hline PROMEDIO & $\mathbf{8 9}$ \\
\hline
\end{tabular}


El promedio de las cinco (5) tomas de dureza realizadas, sobre el material que se usará para la fabricación de la carrocería, mostraron un valor promedio de 89 en escala shore A, este valor promedio de dureza muestra que este material compuesto presenta buenas propiedades de dureza en la escala seleccionada.

\subsection{Densidad específica}

Los resultados obtenidos a partir del ensayo de densidad específica para los materiales compuestos que se han de utilizar en la fabricación del molde y la carrocería del vehículo supermilage se muestran en la tabla 3.

Tabla 3. Resultados de densidad específica para los materiales del molde y de la carrocería.

\begin{tabular}{|l|l|l|l|l|c|c|}
\hline \multirow{2}{*}{ MATERIAL. } & \multicolumn{3}{|c|}{ DIMENSIONES cm } & VOLUMEN & $\begin{array}{c}\text { PESO } \\
\text { gr. }\end{array}$ & $\begin{array}{c}\text { DENSIDAD } \\
\text { gr/cm }\end{array}$ \\
\cline { 2 - 4 } Espesor. $^{\mathbf{3}}$ & Profundidad. & Ancho. & $\mathbf{c m}^{\mathbf{2}}$ & $\mathbf{g}$. & \\
\hline Molde. & 0,86 & 7 & 6.5 & 39.13 & 0.035 & $8.944 \times 10^{-4}$ \\
\hline Carrocería. & 0,28 & 7 & 6.5 & 12.74 & 0.015 & $1.177 \times 10^{-3}$ \\
\hline
\end{tabular}

\section{Conclusiones.}

Se lograron caracterizar, mediante ensayos mecánicos de resistencia a la tracción, dureza shore, resistencia al impacto, flexión y determinación de la densidad especifica los materiales compuestos de fibra de vidrio + resina poliéster + material ridigizante "CORES"(estructura tipo sándwich) y de fibra de vidrio + resina poliéster que serán utilizados en la fabricación del molde y de la carrocería de un vehículo supermilage, para las categorías prototipo y etanol de la competencia Shell ecomarathon, respectivamente.

A partir de los resultados obtenidos de los ensayos de resistencia a flexión se logró determinar los valores de fuerza máxima antes del momento de rotura, momento máximo al alcanzar la fuerza máxima de rotura y el esfuerzo máximo a flexión para cada uno de los materiales compuestos que se han de utilizar 
en la construcción tanto del molde como de la carrocería del vehículo supermilage. Para el material del molde se identificaron valores de fuerza máxima de 124,2073 Kg-f (equivalente a $1218,473 \mathrm{~N}$ ), momento máximo que experimenta la muestra en el momento de alcanzar la fuerza máxima de rotura equivale a 24674,087 N.mm y un esfuerzo máximo a flexión de 152,958 $\mathrm{MPa}$, mientras que para el material compuesto a ser utilizado en la fabricación de la carrocería se determinó una fuerza máxima de $18,4341 \mathrm{Kg}$-f (equivalente a 180,838 N) antes de presentarse su rotura, el momento máximo que experimenta la muestra en el momento de alcanzar la fuerza máxima de rotura equivale a 3661,977 N.mm y un esfuerzo máximo a flexión de 205,762 MPa.

Los ensayos de resistencia a la tracción mostraron un valor de fuerza máxima soportada por el material del molde de 4642,9 $\mathrm{N}$, al alcanzar este valor el alargamiento total o deformación que presentó el espécimen fue de un valor de $6,3176 \%$ de su longitud, un valor de resistencia a la rotura de $64,1 \mathrm{MPa}$ que fue alcanzado en un tiempo aproximado de 4,16 min (249,6 s), un límite elástico de 55,4 MPa y un módulo de elasticidad de 4,6 MPa, por otra parte, el material de la carrocería mostro un valor de fuerza máxima de $2792,0 \mathrm{~N}$, al alcanzar este valor el alargamiento total de un valor de $4,784 \%$ de su longitud, la resistencia a la rotura de $86,6 \mathrm{MPa}$ y fue alcanzado en un tiempo aproximado de $2,28 \mathrm{~min}(136,8 \mathrm{~s})$ un límite elástico de $81,3 \mathrm{MPa}$ y un módulo de elasticidad de 6,5 $\mathrm{MPa}$.

Los ensayos de resistencia al impacto mostraron que el material del molde está en capacidad de absorber un 95\% de la energía de impacto que el péndulo genera al caer sobre él, mientras que el material de la carrocería solo está en capacidad de absorber el $45 \%$ de esta energía lo que demuestra que material rigidizante usado en el compuesto del molde cumple a cabalidad con su objetivo. Por otra parte, se determinó que el material del molde presento una resistencia al impacto de $97,1322 \mathrm{~kJ} / \mathrm{m} 2$ mientras que el material de la carrocería mostro un valor de 136,465 kJ/m2. 
De los ensayos de dureza shore en escala A reportaron valores de dureza promedio de 95 y 89 para los materiales compuestos del molde y de la carrocería respectivamente. Por otra parte, se obtuvieron valores de densidad especifica de $8.944 \times 10-4 \mathrm{gr} / \mathrm{cm} 3$ para el material el molde y de $1.177 \times 10-3$ para el material de la carrocería.

\section{Bibliografía}

American Society for Test and Materials - ASTM International. (2018). ASTM D256 Standard Test Methods for Determining the Izod Pendulum Impact Resistance of Plastics.

American Society for Testing and Materials - ASTM Intenational. (2015). ASTM D2240 Standar Test Method for Rubber Property - Durometer Hardness.

American Society for Testing and Materials - ASTM International. (20017). ASTM D790 "Standart Test Methods for Flexural Properties of Unreinforced and Reinforced Plastics and Electrical Insuating Materials.

American Society for Testing and Materials - ASTM International. (2017). ASTM D3039/D3039M "Standart Test Method for Tensile Propierties of Polymer Matrix Composite Materiales.

American Society for Testing and Materials - ASTM International. (2020). ASTM D792 Standard Test Methods for Density and Specific Granty (Relative Density) of Plastics by Displacement.

Askeland, D. (2016). Ciencia e Ingeniería de Materiales. México: Cengage Learning.

Barry Carter, C., \& Grant Norton, M. (2013). Cermic Material Sciencie and Engineering. New York: Springer. 
Callister, Jr., W. D. (2009). Introducción a la ciencia e ingeniería de los materiales. México: LIMUSA WILEY.

Chawla, K. K. (2012). COMPOSITE MATERIALS Science an Enginnering (Third ed.). New York: Springer.

da Costa, C. E., Velasco López, F., \& Torralba Castello, J. M. (2000). Materiales compuestos de matriz metálica. I parte. Tipos, propiedades, aplicaciones. Revista de Metalurgia, 179 $-192$.

FIBRAPLUS. (15 de Julio de 2017). http://fibraplus.com/ rigidizantes. Obtenido de http://fibraplus.com/rigidizantes: http://fibraplus.com/rigidizantes

Islas Mascareñas, J. A. (2013). Estudio de la aleación de aluminio reforzada con materiales compuestos para la reducción de peso en la industria automotriz. Universidad Autónoma de Nuevol León, Facultad de Ingeniería Mecánica y Eléctrica. Monterrey: Universidad Autónoma de Nuevo León.

Mazumdar, S. K. (2002). COMPOSITES MANUFACTURING Materials, Product and Process Engineering. New York: CRC Press LLC.

Paris, F. (2008). Introducción al análisis y diseño con materiales compuestos. Sevilla: Universidad de Sevilla, Escuela Técnica Superior de Ingenieros.

Ravve, A. (2013). Principles of polymer chemestry. New York: Springer.

Universidad Politécnica de Valencia. (24 de Marzo de 2020). https://www.upv.es/materiales/Fcm/Fcm15/pfcm15_9_2. html. Obtenido de https://www.upv.es/materiales/Fcm/ Fcm15/pfcm15_9_2.html: https://www.upv.es/materiales/ Fcm/Fcm15/pfcm15_9_2.html 


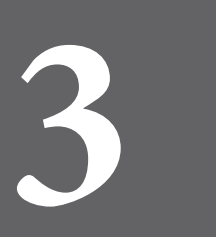

CAPÍTULO TRES 



\section{MÉTODO PARA EVALUAR LA INCORPORACIÓN DE FUENTES NO CONVENCIONALES DE ENERGÍA EN COLOMBIA}

\section{ASSESSMENT METHOD FOR THE INCLUSION OF NON- CONVENTIONAL ENERGY SOURCES IN COLOMBIA}

Juan Carlos Castillo Herrera, M.Sc David Andrés Serrato Tobón, M.Sc Juan Esteban Tibaquirá, Ph.D Alvaro Restrepo, Ph.D Harold Salazar, Ph.D Universidad Tecnológica de Pereira Email: juantiba@utp.edu.co 


\section{Resumen}

Las tecnologías que aprovechan fuentes no convencionales de energía en los países pertenecientes a la OECD han sido altamente promovidas con el propósito de producir energía más limpia y mejorar las condiciones de vida de las personas en áreas urbanas. Sin embargo, los países en vía de desarrollo requieren de un análisis extendido que permita evaluar la viabilidad de implementación de este tipo de iniciativas, identificando riesgos financieros y estableciendo reducción en las emisiones de gases de efecto invernadero. Particularmente, en los últimos años, Colombia ha promovido estrategias de políticas públicas para diversificar el abastecimiento energético y cumplir con la meta trazada en la COP 21 de reducir en un 20\% las emisiones de gases de efecto invernadero antes del 2030. Teniendo en cuenta lo anterior, en este estudio se desarrolló un método que emplea métodos de toma de decisión multicriterio (MCDM) para evaluar comparativamente tecnologías que aprovechan fuentes de energía no convencionales que aún no han sido implementadas en el país con aquellas que actualmente se encuentran en uso bajo criterios técnicos, económicos y ambientales. El método permite identificar la jerarquía de las alternativas, así como las condiciones técnicas y económicas que permiten que la alternativa propuesta sea competitiva en el mercado energético. En este sentido, mediante el método se evaluaron diferentes tecnologías que aprovechan la energía de los mares.

Palabras claves: Energía renovable, Energía de los mares, Matriz energética, Método de toma de decisiones multicriterio, Transición energética.

\section{Abstract}

Renewable energy technologies in OECD countries have been highly promoted for the purpose of producing cleaner energy and better life conditions for people in urban areas. However, 
developing countries require an extended analysis to assess the feasibility for their implementation, identifying financial risks and settling emissions reduction. In Colombia, in the last few years, there have been enhanced public policy strategies to enlarge energy supply alternatives and accomplishing the COP 21 limits of $20 \%$ GHG reduction before 2030. In this work, it was developed a methodology based on Multicriteria Decision Making Methods (MCDM) to assess comparatively new renewable energy technologies with renewable energy technologies currently used in the country based on technical, financial, and environmental criteria. The methodology allows to identify the best and the worst alternative from the output ranking, considering the numerical value of criteria placed on the decision matrix and the dominance index output. The methodology was used to assess comparatively ocean energy technologies in Colombia. It was identified that tidal range is the best alternative and ocean current the worst among the projects evaluated.

Keywords: Energy matrix, Energy transition, Multicriteria decision making methods, Ocean energy, Renewable energy.

\section{Introducción}

En este trabajo, se desarrolló un método resultado del proyecto de investigación titulado "Método para evaluar la incorporación de fuentes no convencionales de energía en Colombia y su evaluación en un caso base de estudio" ejecutado por el Grupo de Investigación en Gestión Energética - GENERGÉTICA de la Universidad Tecnológica de Pereira en alianza con la Unidad de Planeación Minero-Energética - UPME de Colombia. El método diseñado permite identificar la viabilidad de implementación de proyectos que aprovechan fuentes de energía renovable para la generación de potencia. Durante su ejecución se llevó a cabo una revisión de las fuentes de energía primarias empleadas en la matriz energética de los países de la OCDE, así como aquellas referenciadas en documentos o artículos científicos. A partir de lo anterior y 
realizando una comparación con la regulación colombiana, se identificaron aquellas que aún no han sido consideradas en la Ley 1715 de 2014. Adicionalmente, se determinaron las características y los aspectos técnicos de las tecnologías que aprovechan las FNCE no consideradas y aún no empleadas en el país. Además, se analizaron los sistemas para evaluar la madurez de las tecnologías y se estableció el más indicado para ser empleado en Colombia.

Por otro lado, se realizó una revisión de los métodos de toma de decisiones multicriterio (MCDM), los cuales permiten evaluar las tecnologías que aprovechan FNCE. Se establecieron los criterios requeridos para seleccionar el método que mejor se adapta a las características del país y se describieron las fases para la implementación del método seleccionado. Se presentaron los criterios de selección de las FNCE que fueron evaluadas mediante el método propuesto, las condiciones técnicas y económicas de las tecnologías que aprovechan la FNCE seleccionada como caso base de estudio, así como las estrategias para llevar a cabo el ajuste del método a las condiciones particulares del caso colombiano. Adicionalmente, se presentaron los principales indicadores de desempeño económico, energético, financiero y ambiental ampliamente difundidos en los estudios de viabilidad de implementación de tecnologías que aprovechan FNCE. Finalmente, se presenta la propuesta metodológica ajustada en la cual son consideradas las fases donde tienen lugar los procedimientos que permiten el ajuste del método.

Mediante el método propuesto, es posible comparar proyectos de generación de potencia considerando criterios técnicos, económicos, y ambientales, como la capacidad instalada, el factor de capacidad, los costos de inversión, el costo nivelado de energía y las emisiones de gases de efecto invernadero evitadas. El método fue aplicado para llevar a cabo la evaluación comparativa entre las tecnologías que aprovechan la energía de los mares y proyectos de energía solar fotovoltaica y eólica en Colombia para así establecer parámetros que permitan desarrollar estrategias de transición de 
la matriz energética. Considerando que esta clase de evaluación teórica comparativa entre la energía de los mares y otras fuentes no ha sido desarrollada aún en Colombia y, a diferencia de los métodos tradicionales mediante los cuales se llevan a cabo este tipo de análisis para una región, este método fue diseñado considerando la aplicación simultánea de tres métodos MCDM con el fin de validar los resultados, fueron integradas correlaciones que definen el valor de indicadores de desempeño técnico, financiero y ambiental para ajustar el valor de los criterios en la matriz de decisión y fue adicionado un algoritmo complementario al código principal de los métodos MCDM desarrollado en Python para así establecer condiciones mínimas de competitividad.

\section{Planteamiento del problema y justificación}

Globalmente, en la última década ha tenido lugar un continuo impulso y promoción de alternativas tecnológicas para la generación de electricidad más limpias, económicas y escalables a partir del aprovechamiento de fuentes de energía renovable, considerando que el crecimiento demográfico acelerado ha incrementado el uso de energía de fuentes de origen fósil con el consecuente deterioro de la calidad del aire [1]hydrogen fuel cell electric generator to provide power with zero noise and emissions for myriad ground based applications. The hydrogen fuel cell electric generator utilizes a novel, scalable apparatus that safely generates hydrogen $(\mathrm{H} 2$. Así, la cuestión recae en garantizar la calidad de vida de las personas, limitando el impacto negativo sobre el medio ambiente asociado a la explotación de fuentes de origen fósil, mediante la promoción de tecnologías maduras que aprovechan fuentes de energía renovable [2].

Con el propósito de mejorar sus programas de seguridad energética, los países de la OECD han estado explorando múltiples alternativas para la explotación sustentable de fuentes de energía renovable como la biomasa, la energía hídrica, solar, eólica, geotérmica, de corrientes oceánicas, mareas, olas, 
gradientes térmicos oceánicos, gradientes de salinidad, sísmica o vibracional, de residuos y el hidrógeno verde como vector energético [3]. En 2018, las tecnologías que aprovechan fuentes de energía renovable contribuyeron con una participación del 26 $\%$ en la generación de electricidad a nivel global [4]. De acuerdo con REN 21, las fuentes de energía renovable contribuyeron a un aumento de la oferta energética a una tasa del $4 \%$ anual entre el 2013 y el 2018, equivalente a 7,3 EJ aproximadamente. Entre estas, el $48 \%$ de las fuentes explotadas fueron la energía solar y eólica mediante tecnologías de celdas fotovoltaicas y turbinas eólicas, respectivamente [5].

Por otro lado, los países subdesarrollados presentan una alta dependencia de fuentes de origen fósil, por lo cual se requiere un análisis extendido con el fin de evaluar la viabilidad de implementación de tecnologías que aprovechan fuentes de energía renovable, en un mercado energético marcadamente fósil. Tal análisis puede llevarse a cabo mediante métodos de toma de decisiones multicriterio los cuales permiten identificar la mejor alternativa tecnológica entre un conjunto de posibilidades, establecer riesgos financieros, condiciones mínimas de competitividad y determinar el impacto ambiental asociado a la reducción efectiva de emisiones de gases de efecto invernadero. Particularmente, en Colombia el 68\% del consumo de energía eléctrica es suplido por hidroelectricidad, el 31\% mediante plantas de generación de potencia a gas y carbón incluyendo cogeneración, y el 1\% mediante plantas de generación de potencia que aprovechan fuentes de energía renovable como la solar y la eólica en la región norte del país.

Considerando las características y limitaciones actuales en Colombia, tales como, las altas tasas de crecimiento demográfico, los desafíos financieros y los compromisos ambientales adquiridos en la COP 21 en París, donde fue acordado el cumplimiento de una reducción del 20\% de las emisiones de gases de efecto invernadero antes del 2030, se requieren estrategias para el desarrollo de 
escenarios que permitan ampliar el número de alternativas con las cuales sea posible cubrir la demanda energética. En consecuencia, la Unidad de Planeación Minero-Energética (UPME) con el fin de apuntar al cumplimiento de este objetivo, elaboró un programa de promoción de tecnologías que aprovechan fuentes de energía renovable para así establecer las condiciones mediante las cuales será posible cubrir el $17 \%$ del consumo total de energía en Colombia al 2030 [6,7]. En este sentido, tecnologías como la solar fotovoltaica, las turbinas eólicas, y nuevas tecnologías que consideran el aprovechamiento de fuentes de energía no consideradas en la Ley 1715 de 2014 o aún no desarrolladas en Colombia, como la energía de los mares, la energía vibracional, y el hidrógeno verde, podrían abrir las posibilidades al cumplimiento de este objetivo.

\section{Objetivos}

\section{General}

Establecer el límite requerido para que una FNCE sea considerada una fuente convencional de energía en Colombia.

\section{Específicos}

1. Identificar las FNCE maduras y reconocidas por los países de la OCDE y economías en rápido crecimiento, y que no estén incluidas en la ley 1715 de 2014.

2. Establecer los métodos para evaluar técnica y económicamente la aplicabilidad de las FNCE identificadas y seleccionar el que mejor se adapte a las características de Colombia.

3. Aplicar el método seleccionado sobre una FNCE para establecer las condiciones técnicas y económicas asociadas a su implementación en Colombia. 
4. Definir los requisitos o condiciones mínimas para establecer si la FNCE puede ser competitiva en Colombia, a partir de un análisis de escenarios.

5. Establecer el límite requerido para que una FNCE sea considerada una fuente convencional de energía en Colombia.

\section{Referente teórico}

Las fuentes de energía globalmente son clasificadas según sean renovables o no renovables, el grado de disponibilidad y la forma de utilización. Aquellas fuentes de energía renovables son las que cuentan con un potencial inagotable, puesto que, provienen de la energía que llega a la tierra en consecuencia de la radiación del sol o la atracción gravitatoria de otros planetas. Según su disponibilidad, las fuentes de energía convencionales son aquellas que presentan una participación importante en los balances energéticos de los países industrializados (carbón, petróleo, gas natural, hidráulica y nuclear). Así, una fuente no convencional o nueva fuente de energía, es aquella que se encuentra en una etapa de desarrollo tecnológico en cuanto a su utilización generalizada y no cuenta con una participación importante en la cobertura energética de estos países, como es el caso de la energía solar, eólica, mareomotriz y biomasa [8]. Por último, según su utilización, son primarias y secundarias, donde las primarias son aquellas que se obtienen directamente de la naturaleza como los combustibles fósiles y las fuentes renovables, mientras que, las fuentes de energía secundaria, también llamados portadores de energía, se utilizan para almacenar y transportar energía [9].

Los países de la OCDE en su energía primaria empelan diversas fuentes de energía, en función de realizar una transición energética hacia fuentes menos contaminantes, lo cual ha permitido reducir la participación de los combustibles fósiles en países como Islandia, Nueva Zelanda, Noruega, entre otros. No obstante, la participación del petróleo, el carbón y el gas natural 
aún se encuentran predominante en la mayoría de los países, por lo tanto, se presenta una necesidad de descarbonización de sectores productivos en aras de reducir las emisiones contaminantes y de efecto invernadero. En la Tabla 1, se presenta la energía primaria de algunos países miembros de la OCDE.

Tabla 1. Energía primaria de algunos países miembros de la OCDE.

\begin{tabular}{lccccccc}
\hline Energía primaria [\%] & \multicolumn{7}{l}{} \\
\hline Países & Petróleo & Carbón & $\begin{array}{c}\text { Gas } \\
\text { natural }\end{array}$ & Hidro & $\begin{array}{c}\text { Geotérmica, } \\
\text { solar, eólica }\end{array}$ & $\begin{array}{l}\text { Biocombustibles } \\
\text { y residuos }\end{array}$ & Nuclear \\
\hline Islandia & 10 & 2 & - & 21 & 67 & - & - \\
Japón & 42 & 28 & 24 & - & 4 & 2 & 1 \\
Alemania & 32 & 22 & 24 & 1 & 3 & 10 & 6 \\
Noruega & 31 & 3 & 14 & 43 & 1 & 7 & - \\
Nueva Zelanda & 35 & 5 & 20 & - & 22 & 7 & - \\
Reino Unido & 35 & 6 & 39 & - & 3 & 7 & 10 \\
Estados Unidos & 36 & 13 & 31 & 1 & 2 & 5 & 8 \\
\hline
\end{tabular}

En Colombia, la Ley 1715 de 2014 define las fuentes no convencionales de energía como recursos disponibles a nivel mundial que son ambientalmente sostenibles, que no son empleados o sin utilizados de manera marginal y que no se comercializan ampliamente. Con estas características se consideran la energía nuclear o atómica y las FNCE renovable como la biomasa, la geotérmica, los pequeños aprovechamientos hidroeléctricos, la eólica, la geotérmica, la solar y la energía de los mares [10]. Actualmente, la UPME tiene la obligación de identificar y evaluar fuentes no convencionales de energía que no fueron mencionadas en la Ley para su posterior inclusión. Sin embargo, para ser incluidas estas deben ser un medio necesario para el desarrollo económico sostenible y para garantizar la seguridad del abastecimiento energético. Por lo tanto, es necesario que las tecnologías se encuentren maduras y empleadas o comercializadas en referentes internacionales. 
En este sentido, se realizó una revisión de diferentes fuentes empleadas en los países de la OCDE y economías en crecimiento, con el fin de identificar aquellas que aún no se encuentran mencionadas en la Ley 1715 de 2014, y que posiblemente puedan entrar en el proceso de evaluación [3]. Así, en la Figura 1 se identifican las fuentes de energía tanto renovables como no renovables que no son mencionadas en la Ley 1715 de 2014 y que son exploradas en diferentes países.

Figura 1. Fuentes de energía no mencionadas en la Ley 1715 de 2014.

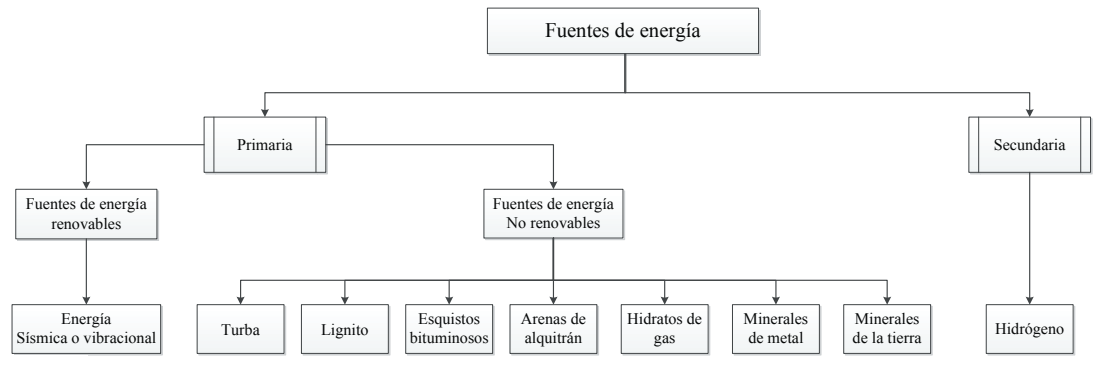

Adicionalmente, se identifica que, entre las fuentes de energía mencionadas en la Ley, que aún no se utilizan en Colombia, se encuentran los gradientes térmicos, los gradientes de salinidad, las mareas, los oleajes y las corrientes marinas, las cuales hacen parte de la energía de los mares. Así mismo, las energías geotérmica y nuclear son fuentes de energía que podrían ser implementadas, pero aún no se han desarrollado ampliamente en el país.

\section{Selección FNCE para el caso base de estudio}

Para la selección de una fuente no convencional de energía como caso base de estudio, se revisó que las fuentes no mencionadas en la Ley cumplan con las características exigidas. Para ello, se empleó los Technology readiness levels (TRL) desarrollado por la NASA para verificar la clasificación que presentan las tecnologías que aprovechan la FNCE y se tuvo en cuenta las direcciones y metas trazadas por las mesas de trabajo gubernamentales en el 
país. Con base en lo anterior, se identificó que las fuentes de energía primaria no renovable como el lignito y la turba son fases del ciclo de formación del carbón, los esquistos bituminosos, las arenas de alquitrán y los hidratos de gas son fuentes no convencionales de petróleo y de gas, y los minerales de metal y minerales de la tierra son fuentes mayormente usadas para la construcción tecnológica o para procesos de fisión nuclear [11-14]. Por lo tanto, al no ser fuentes ambientalmente sostenibles no hacen parte del objeto de la Ley en cuestión.

Por otro lado, las tecnologías que aprovechan el hidrógeno en celdas o pilas de combustible presentan niveles de madurez desde el TRL 5 en crecimiento hasta el TRL 9 madura, donde las aplicaciones de mayor nivel son vehículos livianos (automóviles, montacargas) o micro grupos electrógenos para edificaciones $[15,16]$. El hidrógeno es un portador energético o fuente secundaria, en consecuencia, no es conveniente emplearlo para realizar una comparación directa con fuentes de energía primaria, además existen mesas de trabajo en la UPME que estudian la implementación de sus tecnologías en Colombia, por lo tanto, no se considera en el presente estudio. Para la energía sísmica o vibracional, las tecnologías que aprovechan esta fuente aún se encuentran en un TRL 4 nivel de madurez emergente $[17,18]$, en este sentido, no es apta para la comparación con las FNCE maduras que se emplean en el país. Lo anterior, indica que las FNCE primaria no mencionadas en la Ley 1715 de 2014, aún se encuentran en procesos de demostración tecnológica a pequeña escala.

Respecto a las FNCE que no son empleadas aún en Colombia como la energía de los mares, la geotérmica, y la nuclear, se identificó que actualmente existen mesas de trabajo donde se discute la posibilidad de iniciar estudios orientados a evaluar la implementación de la energía geotérmica y la nuclear, no obstante, no se han identificado las mismas iniciativas asociadas a la inclusión e implementación de la energía de los mares. 
Teniendo en cuenta lo mencionado y considerando que la energía de los mares es una fuente de energía renovable con presencia de recursos en el país, se propuso esta fuente como caso base de estudio, con especial énfasis en la energía de las mareas, corrientes y olas, las cuales cuentan con tecnologías maduras o próximas a serlo $[19,20]$, tal como se presenta en la Figura 2.

Figura 2. Nivel de madurez tecnológica para la energía de los mares.

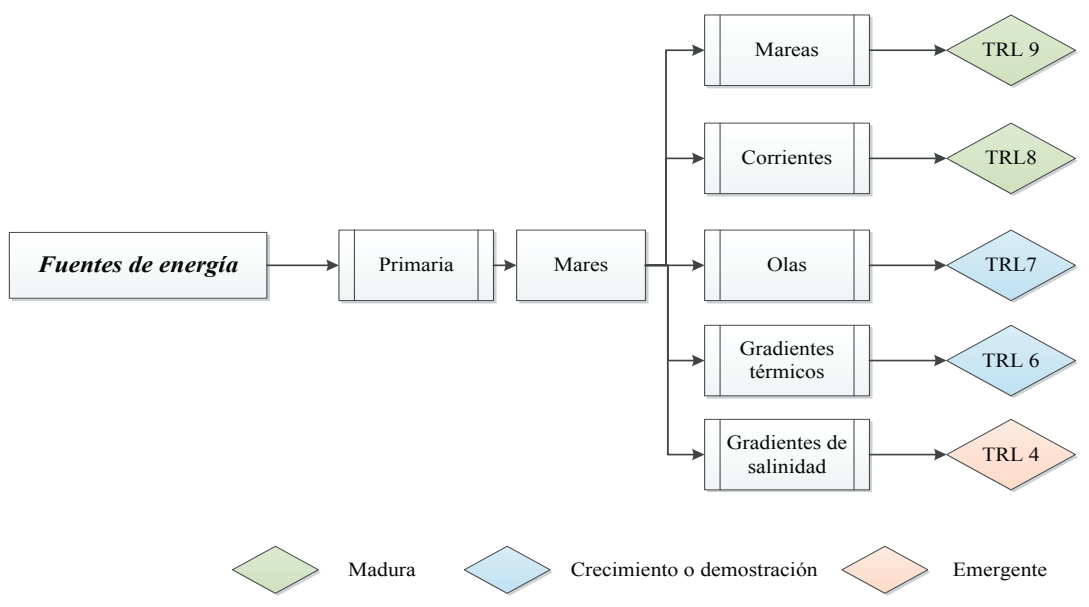

Características técnicas y tecnológicas de la energía de los mares

Corrientes marinas: existe poca confianza para estimar el CAPEX y el LCOE para la tecnología de las corrientes, debido a la escasa experiencia de los prototipos en operación y la confidencialidad de los resultados. Actualmente, se estima que el LCOE para los proyectos de corrientes de marea se encuentra en el rango de 191 USD/MWh a 400 USD/MWh [21]. Así mismo, se identifica que en función de las capacidades instaladas, el CAPEX podría estar entre 9300 USD/kW y 15800 USD/kW para proyectos con capacidades menores a $10 \mathrm{MW}$ (predemostración), entre $3800 \mathrm{USD} / \mathrm{kW}$ y $6500 \mathrm{USD} / \mathrm{kW}$ para proyectos de $10 \mathrm{MW}$ (demostración) y entre 3400 USD / kW y 5100 USD/kW para proyectos con capacidades mayores a $50 \mathrm{MW}$ (comerciales) [22] 
we present a new geospatial tool to determine the optimum sites for tidal stream energy exploitation based on this fundamental requirement of economic feasibility, and more specifically, on the LCOE (levelised cost of energy. Cabe mencionar que los proyectos implementados actualmente no superan los $10 \mathrm{MW}$ de capacidad instalada y que la mayoría que se encuentran en el Reino Unido.

Los proyectos de referencia para esta fuente son:

- MeyGen: 6 MW de capacidad instalada, un costo de inversión aproximado de $10625 \mathrm{USD} / \mathrm{kW}$ y turbinas hidrocinéticas tipo Andriz Hydro Hammerfest. Se encontró un LCOE de 743 USD/ MWh, 7366 tCO2/MWh no emitidas al año y un factor de capacidad del 26\%, resultado de simulación en RETScreen.

- Strangford Lough: 1,2 MW de capacidad instalada emplea Marine Current Turbines y un costo de inversión aproximado de 12357 USD/MW. Se identifica un LCOE de 633 USD/MWh, 1905 tCO2/MWh no emitidas al año y un factor de capacidad del 35\%, resultado de simulación en RETScreen.

Olas: Algunos proyectos tienen despliegues en Australia, Canadá, Irlanda, Portugal, España y Reino Unido. Para el año 2015, el LCOE de proyectos entre $2 \mathrm{MW}$ y $75 \mathrm{MW}$, se encontraban en el rango de $120 \mathrm{USD} / \mathrm{MWh}$ a los $470 \mathrm{USD} / \mathrm{MWh}$, respectivamente [23]. El CAPEX de los proyectos de la energía de las olas a la fecha se encuentra estimado entre $2700 \mathrm{USD} / \mathrm{kW}$ y $9100 \mathrm{USD} / \mathrm{kW}$ para capacidades instaladas de 2 MW y 75 MW, respectivamente.

Los proyectos de referencia para esta fuente son:

- Rompeolas de Mutriku: 16 turbinas de columna oscilante de agua (OWC), una capacidad instalada total de $296 \mathrm{~kW}$, un costo total de $€ 6,7$ millones (25600 USD/kW). S identifica un LCOE de $561 \mathrm{USD} / \mathrm{MWh}$ y $141 \mathrm{tCO} 2 / \mathrm{MWh}$ no emitidas al año, resultado de simulación en RETScreen. 
- Granja de Olas Okeanos: capacidad instalada de 2,25 MW, un costo total de USD 12,3 millones (5466 USD/kW). Se identifica un LCOE de 299 USD/MWh, y 3061 tCO2/MWh no emitidas al año, resultado de simulación en RETScreen

Mareas: La energía de las mareas es la más utilizada a nivel mundial con proyectos en Francia, Bélgica, Canadá, China y Reino Unido superando la capacidad de 100 MW, es más asequible con respecto a las demás fuentes de energía de los mares porque utiliza turbinas convencionales. El LCOE identificado en el 2015 para esta tecnología fue de 130 USD/MWh a 280 USD/MWh para proyectos con capacidad instalada de 90 MW [23]. En el 2019, el Department of Enegy of United States

(DOE) utilizó los datos mencionados anteriormente para realizar las proyecciones de las tecnologías de las mareas [24] through literature review, workshops, interviews, and national lab analyses, as well as a Request for Information process. Each market was assessed by a set of common analyses: opportunity summary; application description and power requirements; market description, power options, and geographic relevance; marine energy potential value proposition; and path forward including research and development needs and potential partners. The major finding is that there are more markets with potential than anticipated, both for Power at Sea (including ocean observation and navigation, underwater vehicle charging, marine aquaculture, marine algae, and seawater mining. Se espera que los costos a largo plazo disminuyan a medida que se gana experiencia con la implementación. El CAPEX de esta tecnología se encuentra entre 3300 USD/kW y 5600 USD/kW para capacidades instaladas de $3 \mathrm{MW}$ y $90 \mathrm{MW}$ respectivamente. Sin embargo, los costos pueden aumentar hasta $7921 \mathrm{USD} / \mathrm{kW}$ según World Energy Council $[23,25]$. 
Los proyectos de referencia para esta fuente son:

- Lago Sihwa: utiliza una tecnología de barraje con una capacidad instalada de $254 \mathrm{MW}$, un costo de inversión de USD 355 millones (1398 USD/kW). Se identifica un LCOE de 96 USD/MWh y 303284 tCO2/MWh no emitidas al año, resultado de simulación en RETScreen.

- Swansea Bay: utiliza turbinas de bulbo con las cuales se obtiene una capacidad instalada de $320 \mathrm{MW}$, tiene un costo de USD 1200 millones (3750 USD/kW). Se identifica un LCOE de 400 USD/ MWh y 259726 tCO2/MWh no emitidas al año

\section{Metodología}

La evaluación técnico-económica comparativa de las tecnologías que aprovechan las FNCE consideradas se realiza mediante la implementación de métodos de toma de decisiones multicriterio, ya que tienen la capacidad de determinar la jerarquía de las alternativas propuestas considerando criterios de naturaleza técnica, económica y ambiental. El método propuesto para llevar a cabo dicha evaluación se describe en la Figura 3. En esta se identifican tres fases: I) Mapeo del problema, II) Evaluación de desempeño, y III) Evaluación mediante método MCDM. En la fase del mapeo del problema se recolectan datos y se definen los evaluadores, que tendrán la responsabilidad de realizar la toma decisiones, el objetivo de la evaluación, las alternativas y los criterios, su atributo y su naturaleza con base en la cual se definen los casos de evaluación. En la Fase II, se lleva a cabo la evaluación del desempeño de las alternativas como estrategia para el ajuste del valor de los criterios. En esta fase se calcula la energía entregada a la red en función de la capacidad instalada y el factor de capacidad, la ganancia por la venta de energía, la deuda y el capital. Así mismo, se realiza la evaluación del desempeño financiero de las alternativas donde son calculados indicadores financieros como el valor presente neto, la razón costo beneficio, los ahorros anuales de ciclo de vida, el período de retorno de capital y el costo nivelado de energía. Finalmente, en esta fase, 
se evalúa el desempeño ambiental donde son calculadas las emisiones de GHG brutas anuales del caso base, las emisiones de GHG brutas anuales del caso y la reducción de emisiones de GHG brutas anuales. En última instancia, en la Fase III, se lleva a cabo la evaluación de las alternativas mediante el método MCDM, donde se define la matriz de decisión, se ajusta el valor de los pesos de los criterios mediante el método Analytic Hierarchy Process (AHP) y se realiza un análisis de sensibilidad posterior a la ejecución de los algoritmos mediante los cuales se obtiene la jerarquía de las alternativas por casos de evaluación.

Figura 3. Diagrama metodológico, evaluación de FNCE.

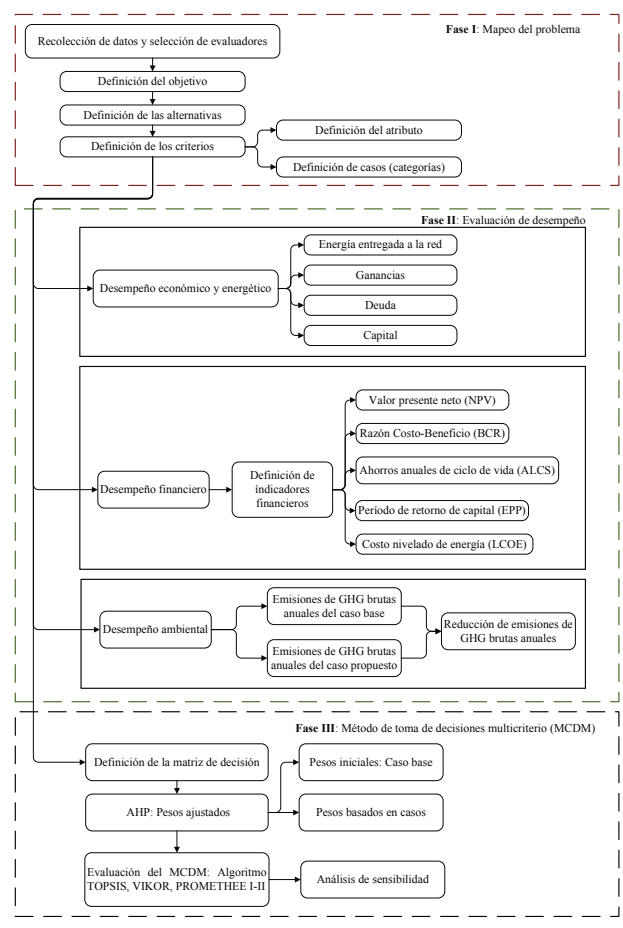

\section{Definición de alternativas y escenarios}

La evaluación de la viabilidad de implementación de nuevas tecnologías que aprovechan FNCE puede realizarse mediante 
la comparación técnico-económica con tecnologías que tienen características similares y que están siendo empleadas a nivel nacional. Para evaluar las tecnologías que aprovechan la energía de las mareas, corrientes y olas, se realiza la simulación de alternativas a desarrollar en Colombia con estas tecnologías, tomando como base la información de los proyectos realizados a nivel internacional y los referentes teóricos y se compara mediante el método MCDM con proyectos nacionales de energía solar y eólica, bajo los siguientes escenarios:

- Escenario 1: comparación energía solar, eólica y de las mareas.

- Escenario 2: comparación energía solar, eólica y de las corrientes.

- Escenario 3: comparación energía solar, eólica y de las olas.

Los escenarios se plantearon con el fin de obtener información detallada de cada una de las alternativas propuestas de la energía de los mares y obtener criterios para que la energía de los mares pueda eventualmente tenerse en cuenta en la matriz energética.

\section{Definición de los criterios}

Los criterios seleccionados para llevar a cabo la evaluación de las tecnologías que aprovechan FNCE se presentan en la Tabla 2, exceptuado la madurez tecnológica (TRL), ya que es identificada en la etapa preliminar correspondiente a la selección de la alternativa a evaluar por el método MCDM. La madurez tecnológica para las alternativas propuestas se selecciona con base en la literatura y referencias internacionales [19,20,26,27]. La capacidad instalada de energía de los mares se consideró con base en proyectos internacionales actualmente operativos. De igual forma, el CAPEX, se seleccionó con base en el valor más alto entre los proyectos identificados y las proyecciones teóricas de esta fuente con el fin de garantizar un análisis conservativo. Por otro lado, para la energía solar y eólica se empleó la información suministrada por los pares UPME. 
Tabla 2. Lista de criterios para la evaluación de FNCE en Colombia.

\begin{tabular}{cccccc}
\hline Criterio & Símbolo & Nombre & Naturaleza & Atributo & Unidad \\
\hline $\mathrm{C} 1$ & $\mathrm{CI}$ & Capacidad instalada & \multirow{2}{*}{ Técnico } & Positivo & $\mathrm{MW}$ \\
$\mathrm{C} 2$ & $\mathrm{FC}$ & Factor de capacidad & & Positivo & $\%$ \\
\hline $\mathrm{C} 3$ & $\mathrm{CAPEX}$ & Costos de inversión & \multirow{2}{*}{ Económico } & Negativo & $\$ / \mathrm{MW}$ \\
$\mathrm{C} 4$ & $\mathrm{LCOE}$ & $\mathrm{LCOE}$ & & Negativo & $\$ / \mathrm{kWh}$ \\
\hline $\mathrm{C} 5$ & $\mathrm{CO}_{2} \mathrm{e}$ & Emisiones de $\mathrm{CO}_{2}$ no emitidas & Ambiental & Positivo & $\mathrm{tCO}_{2} /$ año \\
\hline
\end{tabular}

Para llevar a cabo el ajuste del método al caso colombiano se consideran tres procedimientos. Se realiza un ajuste al valor de los criterios para cada alternativa, principalmente al valor del factor de capacidad (FC), el costo nivelado de energía (LCOE) y las emisiones evitadas ya que estos exhiben una relación de dependencia entre sí y con la energía entregada a la red. El ajuste se realiza mediante un análisis del desempeño económico, energético, financiero y ambiental de las alternativas. Paralelamente, se realiza un ajuste de los pesos de los criterios mediante el método AHP considerando la comparación por pares entre criterios y el juicio de expertos UPME. En última instancia, se incorpora una nueva función al algoritmo que define el método, la cual permite obtener los valores de los criterios indicados para que la alternativa objeto de evaluación logre alcanzar una posición especificada por el evaluador.

\section{Ajuste del peso de los criterios}

Para ajustar el peso de los criterios descritos en la Tabla 1 se emplea el método AHP cuya metodología se describe en el Anexo A. Este método consiste en la comparación por pares de los criterios, la cual se llevó a cabo mediante una encuesta dirigida a 5 expertos técnicos en energías renovables, generación de energía eléctrica y áreas afines pertenecientes a la Unidad de Planeación Minero-Energética (UPME). Las matrices de comparación de 
criterios y los pesos individuales de cada encuestado se presentan en el Anexo B. Después de revisar y ajustar inconsistencias presentadas en las respuestas, se obtuvo el valor del peso de los criterios como el valor promedio de la preferencia indicada por los expertos técnicos, como se muestra en la Figura 4.

Figura 4. Peso promedio de los criterios.

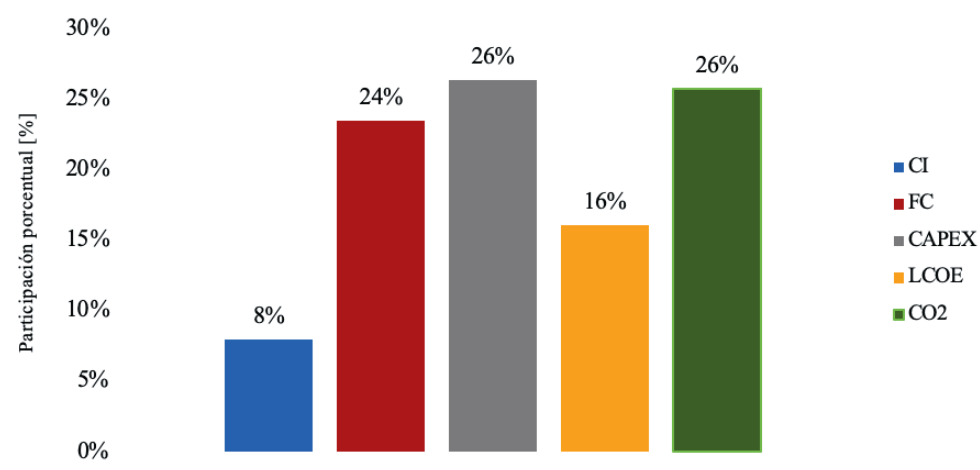

Ajuste del valor de los criterios con base en análisis de viabilidad

Los mercados de energía que involucran el uso de tecnologías que aprovechan fuentes de energía renovable no se encuentran usualmente balanceados. En consecuencia, los precios de la energía ofrecida a partir de estas fuentes pueden incrementarse por encima del costo total durante cortos períodos de tiempo cuando la oferta no se expande a una tasa lo suficientemente alta para igualar a la demanda. En contraste, para períodos de sobre oferta, las pérdidas pueden ocasionar una caída del precio de la energía por debajo de los costos de producción. Por las razones expuestas, se hace necesario realizar un análisis del desempeño financiero de la tecnología de generación de potencia como medio para evaluar viabilidad y competitividad en los mercados energéticos actuales [28,29] respectively, for the South-West region of Algeria. This study considers the atlas development of wind characteristics analysis. Hourly mean wind data recorded during the years 2003 to 2008 by ONM "Office National de la 
Météorologie" (the Algerian Meteorological Office.

Con el propósito de ajustar el método al caso colombiano, fueron considerados los indicadores calculados para cada proyecto en el análisis del desempeño económico, energético, financiero $\mathrm{y}$ ambiental. Estos indicadores permitieron garantizar un valor ajustado del LCOE y de la reducción de emisiones de GHG brutas anuales, los cuales son dos de los criterios utilizados directamente en el método propuesto basado en el método MCDM. En el análisis de la viabilidad de implementación de los proyectos fue considerado una razón de deuda del $70 \%$, un interés a la deuda del $7 \%$, una vida útil 25 años, un período de pago de la deuda de 15 años, una tasa de descuento del $9 \%$ y una tasa de escalamiento de la energía entregada a la red del $2 \%$. Por otro lado, las emisiones de GHG brutas anuales del caso base y las emisiones de GHG brutas anuales del caso propuesto fueron calculadas considerando un factor de emisión de 0,548 $\mathrm{tCO}_{2} / \mathrm{MWh}$ y $0,000 \mathrm{tCO}_{2} / \mathrm{MWh}$, respectivamente. El caso base fue elaborado considerando la generación de potencia de una planta térmica a gas con una eficiencia del 38\% y asumiendo unas pérdidas de transmisión y distribución del $5 \%$.

\section{Ajuste del valor de los criterios}

El tercer ajuste realizado consta de la incorporación de una segunda etapa del método descrito, la cual permite calcular el valor del criterio o los criterios deseados para que la alternativa objeto de evaluación logre alcanzar una posición especificada. A continuación, se describen algunas fases relevantes del proceso:

- Definir información relacionada al criterio o criterios a modificar: se debe especificar tanto el nombre del criterio como los límites entre los cuales se desea modificar el valor.

- Mejorar el valor de los criterios: indica un aumento o disminución porcentual en el valor de dicho criterio, ya sea de atributo positivo o negativo, respectivamente. 
- Recalcular el valor de los otros criterios dependientes: antes de continuar el proceso iterativo, es necesario recalcular el valor de los criterios que presentan dependencia ante otros, es decir, aquellos que presentan un - 1 en la fila de la matriz de dependencia de criterios, presente en la Tabla 3.

- A modo de ejemplo, la interpretación de la matriz de dependencia de criterios es el siguiente: la modificación del valor de CI varía (1) los valores de LCOE y CO2e, mientras que, el valor del LCOE es modificado (-1) por un cambio en el valor de CI, FC o CAPEX.

Tabla 3. Matriz de dependencia de criterios.

\begin{tabular}{cccccc}
\hline & CI & FC & CAPEX & LCOE & CO2E \\
\hline CI & - & 0 & 0 & 1 & 1 \\
FC & 0 & - & 0 & 1 & 1 \\
CAPEX & 0 & 0 & - & 1 & 0 \\
LCOE & -1 & -1 & -1 & - & 0 \\
CO2E & -1 & -1 & 0 & 0 & - \\
\hline
\end{tabular}

\section{Resultados}

Con el objetivo de analizar comparativamente los aspectos técnicos, económicos y ambientales de las alternativas consideradas se hace uso del método de toma de decisiones multicriterio. Previamente a la implementación del método MCDM, en la Tabla 4 se indica el peso de los criterios para cada uno de los casos considerados. Estos casos dependen de la naturaleza de los criterios empleados para la evaluación. 
Tabla 4. Matriz de decisión.

\begin{tabular}{|c|c|c|c|c|c|}
\hline Caso & CI [MW] & $\begin{array}{l}\text { CAPEX } \\
\text { [\$/MW] }\end{array}$ & $\begin{array}{c}\text { LCOE } \\
{[\$ / k W h]}\end{array}$ & $\begin{array}{c}\mathrm{CO}_{2} \text { evitadas } \\
\left.\text { [tCO } \mathrm{CO}_{2} / \mathrm{año}\right]\end{array}$ & FC [\%] \\
\hline Base (Encuesta) & $8 \%$ & $26 \%$ & $16 \%$ & $26 \%$ & $24 \%$ \\
\hline Homogéneo & $20 \%$ & $20 \%$ & $20 \%$ & $20 \%$ & $20 \%$ \\
\hline Técnico & $20 \%$ & $7 \%$ & $7 \%$ & $6 \%$ & $60 \%$ \\
\hline Económico & $7 \%$ & $50 \%$ & $30 \%$ & $6 \%$ & $7 \%$ \\
\hline Ambiental & $5 \%$ & $5 \%$ & $5 \%$ & $80 \%$ & $5 \%$ \\
\hline
\end{tabular}

Los resultados obtenidos para el análisis comparativo de los escenarios 1, 2 y 3, se muestran en la Tabla 5, Tabla 6, Tabla 7 respectivamente.

Tabla 5. Jerarquía obtenida del escenario 1.

\begin{tabular}{ccccc}
\hline Base & Homogéneo & Técnico & Económico & Ambiental \\
\hline Solar & Solar & Eólica & Solar & Solar \\
Eólica & Eólica & Corrientes & Eólica & Eólica \\
Corrientes & Corrientes & Solar & Corrientes & Corrientes \\
\hline
\end{tabular}

Tabla 6. Jerarquía obtenida del escenario 2.

\begin{tabular}{ccccc}
\hline Base & Homogéneo & Técnico & Económico & Ambiental \\
\hline Eólica & Eólica & Eólica & Solar & Mareas \\
Solar & Mareas & Mareas & Eólica & Solar \\
Mareas & Solar & Solar & Mareas & Eólica \\
\hline
\end{tabular}

Tabla 7. Jerarquía obtenida del escenario 3.

\begin{tabular}{ccccc}
\hline Base & Homogéneo & Técnico & Económico & Ambiental \\
\hline Solar & Solar & Eólica & Solar & Solar \\
Eólica & Eólica & Solar & Eólica & Eólica \\
Olas & Olas & Olas & Olas & Olas \\
\hline
\end{tabular}

En el caso base, la alternativa de las corrientes es la opción menos deseada para su desarrollo, esto se cumple para el resto de los casos analizados, exceptuando aquel donde priman los aspectos técnicos, donde logra superar a la alternativa solar. Por otra parte, la alternativa de las mareas presenta competitividad 
con las demás alternativas consideradas en la comparación. Sin embargo, los aspectos económicos no la favorecen haciendo que sea la opción menos preferible para el caso económico y el caso base. Finalmente, la alternativa de las olas no destaca en ninguno de los casos considerados, siendo jerarquizada como la peor alternativa en todos ellos.

Condiciones mínimas de competitividad de la energía de los mares en Colombia

Una vez realizada la evaluación mediante el método MCDM y haber identificado la posición inicial de la alternativa objeto de evaluación, es posible determinar los valores requeridos para cada criterio de tal manera que dicha tecnología presente competitividad respecto a las FNCE empleadas en Colombia. En este sentido, se propone modificar el valor del costo de inversión (CAPEX) para cada una de las alternativas evaluadas en su respectivo escenario, de tal manera que resulte preferible sobre una de las dos alternativas propuestas para la comparación, es decir, que ocupe la segunda posición en la jerarquía. Esto último, con el objetivo de establecer valores considerados mínimos bajo estas condiciones.

La alternativa objeto de evaluación logra alcanzar la segunda posición en la jerarquía del caso base para los tres escenarios propuestos, por lo tanto, los valores modificados del costo de inversión (CAPEX) y del costo nivelado de energía (LCOE) para las alternativas de las corrientes, mareas y olas se indican en la Figura 5, Figura 6 y Figura 7, respectivamente. 
Figura 5. Criterios modificados, alternativa de las corrientes.
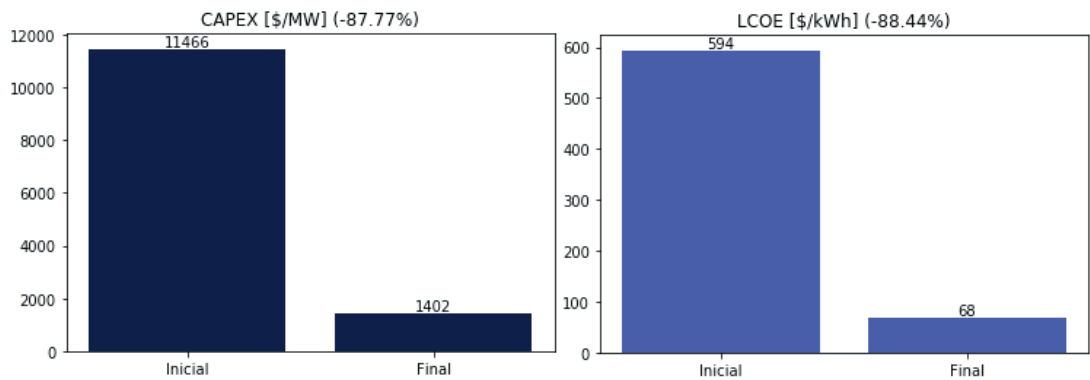

Figura 6. Criterios modificados, alternativa de las mareas.
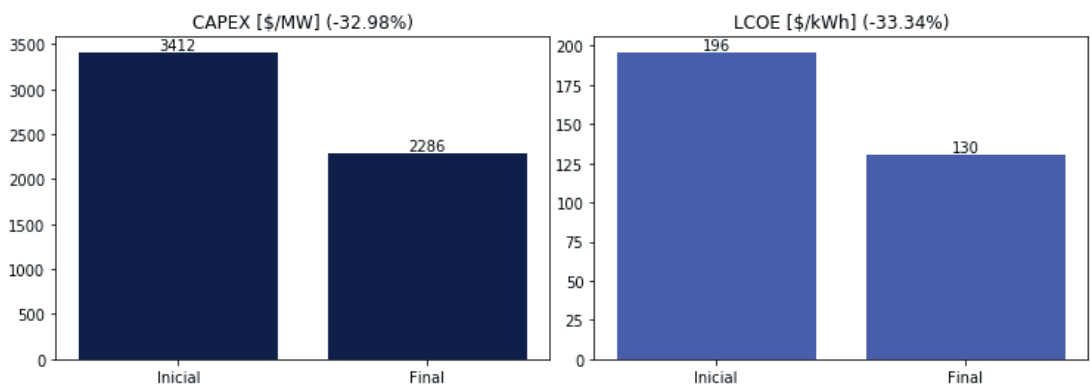

Figura 7. Criterios modificados, alternativa de las olas.
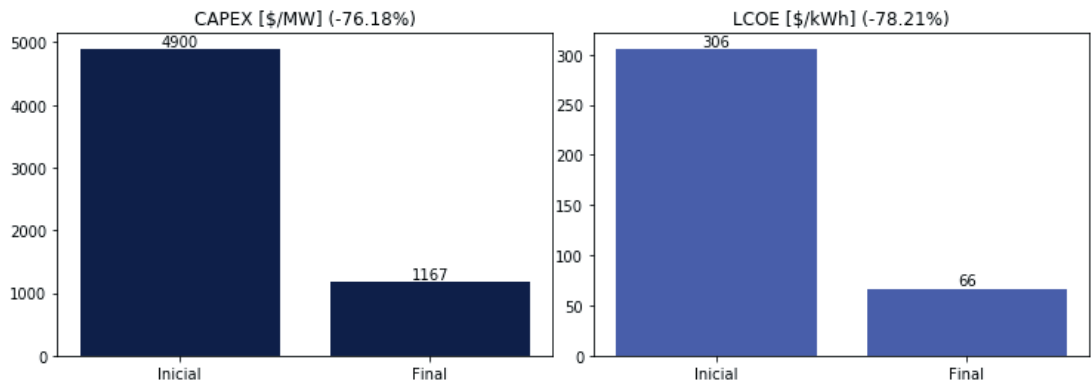

Posteriormente, considerando proyecciones relacionadas a la disminución del costo de inversión y costo nivelado de cada una de estas alternativas de energía de los mares, será posible determinar si los resultados obtenidos presentan viabilidad a futuro. El procedimiento permite obtener una aproximación de 
las condiciones económicas mínimas y necesarias para garantizar la competitividad de las tecnologías que aprovechan la energía de los mares.

\section{Conclusiones}

La mayoría de las fuentes no convencionales de energía empleadas en las matrices energéticas de los países de la OCDE, ya se encuentran mencionadas en la Ley 1715 de 2014. Sin embargo, la energía sísmica o vibracional como fuente primaria de energía y el hidrógeno como portador energético o fuente secundaria aún no se encuentran mencionados. Adicionalmente, se identifica que entre las fuentes mencionadas en la Ley la energía de los mares, nuclear y geotérmica aún no son empleadas en Colombia.

Se identificaron métodos para la evaluación de la madurez tecnológica, donde la mayoría, a excepción del TRL, entregan resultados cualitativos, emplean métricas no estandarizadas y no son utilizados ampliamente. Por lo tanto, se seleccionó el método TRL para la evaluación de la madurez de las tecnologías que aprovechan las diferentes FNCE, agregando que este método, es empleado por diferentes entidades y organismos internacionales.

Se realizó la revisión del funcionamiento y las tecnologías que aprovechan las fuentes no convencionales de energía no mencionadas en la Ley 1715 de 2014. Donde, se identificó que, para la energía sísmica o vibracional las tecnologías que aprovechan este recurso son los piezoeléctricos y electromagnéticos, los cuales, se encuentran en una etapa emergente con un TRL 4. Para el caso del hidrógeno las tecnologías según su aplicación se encuentran categorizadas entre TRL 5 y TRL 9, sin embargo, al ser un portador de energía la comparación con FNCE primaria no es conveniente.

Se realizó una revisión bibliográfica identificando los diferentes métodos de toma de decisiones multicriterio y validando su implementación como alternativa para la evaluación de FNCE. 
Considerando las aplicaciones dadas a los métodos de toma de decisiones multicriterio en la evaluación de fuentes de energía renovable, se construyó una propuesta metodológica basada en estos métodos con el fin de evaluar FNCE en Colombia.

Se definió la lista de criterios a ser considerados en la evaluación de FNCE en Colombia. Estos son: madurez tecnológica, capacidad instalada, disponibilidad de recursos, costo de inversión, costo nivelado de energía y emisiones evitadas.

Se considera la evaluación de las alternativas mediante la implementación simultánea del método VIKOR, TOPSIS, PROMETHEE I y II. Mediante esta estrategia es posible validar la solución y obtener respuestas complementarias considerando que se tienen de estos, la jerarquía de las alternativas y el conjunto de matrices que permiten el análisis de dominancia por alternativa.

Se seleccionó la fuente de energía de los mares como caso base de estudio, específicamente la energía de las corrientes, olas y mareas.

Se identificaron los criterios de selección de la energía de los mares y demás características técnicas y económicas que permiten su evaluación mediante el método de toma de decisiones multicriterio. Debido a la importancia de la madurez tecnológica (TRL) se implementó como un criterio preliminar para la selección de las alternativas del caso base de estudio.

Se ajustó el peso de los criterios mediante el método AHP y una encuesta dirigida a cinco expertos de las UPME con el objetivo de obtener valores representativos al caso colombiano.

Se ajustó el valor de los criterios con base en el desempeño económico energético, financiero y ambiental de las alternativas, teniendo en cuenta indicadores ampliamente utilizados para la evaluación de tecnologías que aprovechan FNCE. 
Se adicionó una función al algoritmo base con el propósito de poder alterar la posición de una alternativa en la jerarquía inicial, modificando de manera iterativa los valores de los criterios en la matriz de decisión.

Se propusieron escenarios para la comparación de las alternativas de los mares en el método MCDM. Así, mediante la aplicación del método, se logró identificar que para mejorar la competitividad de algunas tecnologías que aprovechan la energía de los mares, es necesario que algunos de los criterios se amplifiquen o reduzcan ostensiblemente.

\section{Bibliografía}

[1] Stern AG. A new sustainable hydrogen clean energy paradigm. Int J Hydrogen Energy 2018;43:4244-55. https:// doi.org/10.1016/j.ijhydene.2017.12.180.

[2] Mitsos A, Asprion N, Floudas CA, Bortz M, Baldea M, Bonvin $\mathrm{D}$, et al. Challenges in process optimization for new feedstocks and energy sources. Comput Chem Eng 2018;113:209-21. https://doi.org/10.1016/j.compchemeng.2018.03.013.

[3] OECD - Better policies for better lives. Data - Organisation for Economic Co-operation and Development n.d. https:// www.oecd.org/fossil-fuels/data/ (accessed April 6, 2020).

[4] REN 21 - RENEWABLES NOW. Global Overview n.d. https://www.ren21.net/gsr-2019/chapters/chapter_01/ chapter_01/\#fig_4 (accessed July 18, 2019).

[5] REN 21 - RENEWABLES NOW. Renewables 2020 - Global Status Report n.d. https://www.ren21.net/gsr-2020/chapters/ chapter_01/chapter_01/(accessed September 1, 2020). 
[6] Unidad de Planeación Minero Energética - UPME. Plan Energetico Nacional Colombia: Ideario Energético 2050 2015:184.

[7] Gómez-Navarro T, Ribó-Pérez D. Assessing the obstacles to the participation of renewable energy sources in the electricity market of Colombia. Renew Sustain Energy Rev 2018;90:131-41. https://doi.org/10.1016/j.rser.2018.03.015.

[8] Foro Nuclear - Foro de la Industria Nuclear Española. Energía y fuentes de energía n.d. https://www.foronuclear.org/es/ energia-nuclear/faqas-sobre-energia/capitulo-1/115488icomo-se-clasifican-las-fuentes-de-energia (accessed March 5, 2020).

[9] U.S. Energy Information Administration (EIA). Sources of energy 2019. https://www.eia.gov/energyexplained/what-isenergy/sources-of-energy.php (accessed May 4, 2020).

[10] República de Colombia - Gobierno Nacional. LEY No 1715 del 13 de mayo de 2014. TAPPI J 2014;13. https://doi. org/10.32964/tj13.5.

[11] Seredin V V, Dai S, Sun Y, Yu I. Applied Geochemistry Coal deposits as promising sources of rare metals for alternative power and energy-efficient technologies. Appl Geochemistry 2013;31:1-11. https://doi.org/10.1016/j. apgeochem.2013.01.009.

[12] Zhao S, Sun Y, Lü X, Li Q. Energy consumption and product release characteristics evaluation of oil shale non-isothermal pyrolysis based on TG-DSC. J Pet Sci Eng 2020;187:106812. https://doi.org/10.1016/j.petrol.2019.106812.

[13] Wang K, Vredenburg H, Wang T, Feng L. Financial return and energy return on investment analysis of oil sands, shale oil and shale gas operations. J Clean Prod 2019;223:826-36. https://doi.org/10.1016/j.jclepro.2019.03.039. 
[14] Chong ZR, Yang SHB, Babu P, Linga P, Li X Sen. Review of natural gas hydrates as an energy resource: Prospects and challenges. Appl Energy 2016;162:1633-52. https://doi. org/10.1016/j.apenergy.2014.12.061.

[15] International Energy Agency (IEA). The Future of Hydrogen - Analysis - IEA n.d. https://www.iea.org/reports/the-futureof-hydrogen (accessed April 4, 2020).

[16] Roland Berger - Global Consulting. Fuel Cells and Hydrogen Applications for Regions and Cities. Consolidated Technology Introduction Dossiers 2017;1:108-23.

[17] Gholikhani M, Roshani H, Dessouky S, Papagiannakis AT. A critical review of roadway energy harvesting technologies. Appl Energy 2020;261:114388. https://doi.org/10.1016/j. apenergy.2019.114388.

[18] Yang Z, Zhou S, Zu J, Inman D. High-Performance Piezoelectric Energy Harvesters and Their Applications. Joule 2018;2:642-97. https://doi.org/10.1016/j.joule.2018.03.011.

[19] Wang J, Liu Y, Chen L, Tang J. Using the technology readiness levels to support technology management in the special funds for marine renewable energy. Ocean 2016 - Shanghai 2014. https://doi.org/10.1109/OCEANSAP.2016.7485608.

[20] International Renewable Energy Agency - IRENA. Ocean Energy:Techmology Readiness, Patents, Deployment Status and Outlook. Int Renew Energy Agency IRENA 2014:76. https://doi.org/10.1007/978-3-540-77932-2.

[21] Lande-Sudall D, Stallard T, Stansby P. Co-located deployment of offshore wind turbines with tidal stream turbine arrays for improved cost of electricity generation. Renew Sustain Energy Rev 2019;104:492-503. https://doi.org/10.1016/j. rser.2019.01.035. 
[22] Vazquez A, Iglesias G. LCOE (levelised cost of energy) mapping: A new geospatial tool for tidal stream energy. Energy 2015;91:192-201. https://doi.org/10.1016/j. energy.2015.08.012.

[23] Ocean Energy Sistems - OES, Energy Technology Network iea. Cost of Energy Technologies. Cocme 2015:48.

[24] U.S. Department of Energy - Energy Efficiency and Renewable Energy. Powering the Blue Economy: Exploring Opportunities for Marine Renewable Energy in Maritime Markets 2019.

[25] World Energy Council. World Energy Perspective - Cost of Energy Technologies 2013:48. https://doi.org/ISBN: 9780 946121304.

[26] Watson S, Moro A, Reis V, Baniotopoulos C, Barth S, Bartoli $\mathrm{G}$, et al. Future emerging technologies in the wind power sector: A European perspective. Renew Sustain Energy Rev 2019;113:109270. https://doi.org/10.1016/j.rser.2019.109270.

[27] Gokarakonda S, Hennicke P, Moore C, Thomas S. Relevant technologies for the energy transition in Germany, with potential relevance for Japan: a preparatory study in the framework of the GJETC project 2018:57.

[28] International Renewable Energy Agency. Renewable Power Generation Costs 2018. 2018.

[29] Himri Y, Merzouk M, Kasbadji Merzouk N, Himri S. Potential and economic feasibility of wind energy in south West region of Algeria. Sustain Energy Technol Assessments 2020;38:100643. https://doi.org/10.1016/j.seta.2020.100643. 
Vicerrectoría de Investigaciones, Innovación y Extensión

Colección Trabajos de Investigación 